\title{
THE DENDROCLIMATIC SIGNAL IN WHITE SPRUCE (PICEA GLAUCA) RING-WIDTHS, CENTRAL NORTHWEST TERRITORIES
}

By

Philippe E. Muise, B.A. (Hons.)

A thesis submitted to the Faculty of Graduate and Postdoctoral Affairs in partial fulfillment of the requirements for the degree of

Master of Science

in

Physical Geography

Carleton University

Ottawa, Canada

(C) 2013 Philippe E. Muise 


\begin{abstract}
White spruce samples were collected at 10 sites along a latitudinal gradient in the central Northwest Territories near treeline. Extending to 1643 , the chronologies represent the oldest tree ring-width records in the region. Composite chronologies were developed: COMP1 is composed of five sites situated in the northern part of the sampling area; COMP2 is composed of the three southernmost sites. Growth patterns of COMP1 and COMP2 are highly synchronous until the 1930s. After the 1930s, COMP1 exhibits increasing growth, while COMP2 exhibits decreasing growth. COMP1 is positively correlated with summer temperatures and precipitation. COMP2 is inversely correlated with summer temperatures and May precipitation. Rising temperatures may have caused landscape scale patterns of moisture stress at COMP2 sites and improved growing conditions at COMP1 sites. The earlier onset of the growing season is hypothesized to have shifted the limiting factor for growth of COMP1 from July to June precipitation at $\sim 1977$.
\end{abstract}




\section{Acknowledgements}

This thesis would not have been possible without the help and support of my advisor, committee members, colleagues, friends, and family. I want to thank my advisor Dr. Michael Pisaric for his help and encouragement. I would also like to thank Drs. R. Timothy Patterson, Elyn Humphreys, and Dan Smith for their support and suggestions.

It was a great pleasure to work in the Carleton University Paleoecological Laboratory (CUPL) and I am indebted to many of my fellow graduate students who helped me on this study. My lab mates have been informative, open-minded, and always willing to give a helping hand. I am especially grateful to Dr. Trevor Porter and Colin Mustaphi who provided much needed support. I would also like to thank Stephanie Delaney and undergraduate assistants Sonam Drakto and Kerry Robillard for their help in processing my samples and making my journey much more enjoyable. My field work would not have been possible without the help of Dr. Pisaric, Stefan Goodman, and Hendrik Falck.

On a personal note, many thanks to my friends Jackson Reggie, Sarah Hobbs, Darren Pacione, Jesse van den Berg, and Thomas MacTavish, to name a few. To Alexandra Guiry, your love, encouragement, and support has been a blessing and I can't thank you enough. Valerie and Fred, I am so happy to be your brother, and becoming an uncle to Miriam has been a wonderful experience. Miriam's 'joi de vivre' is contagious and her smile undoubtedly helped me through the long days of thesis writing. Mom and dad, thank you for your support over the years. 


\section{Table of Contents}

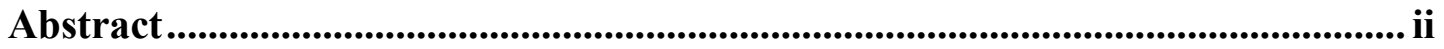

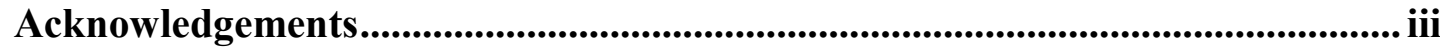

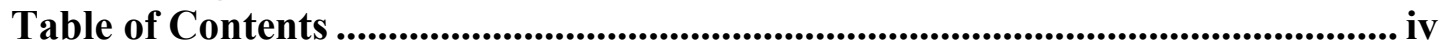

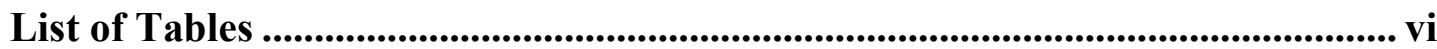

List of Figures .......................................................................................................... vii

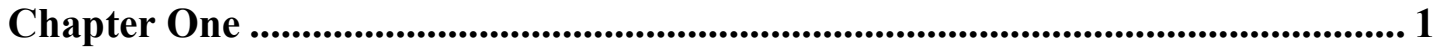

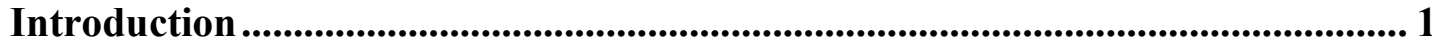

1.1 Introduction and Theoretical Context .................................................. 1

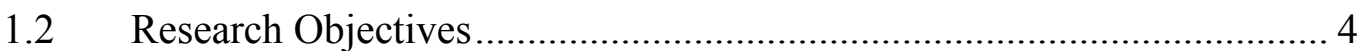

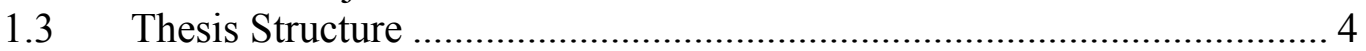

Chapter Two

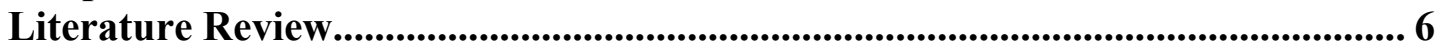

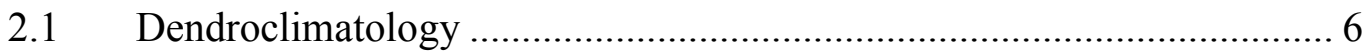

2.2 White Spruce.............................................................................. 10

2.3 Review of relevant dendroclimatological studies in northern Canada ... 12

2.3.1 Regional temperature studies............................................... 12

2.3.2 Regional precipitation studies..................................................... 16

$2.4 \quad$ The 'Divergence Problem' ................................................................... 18

2.4.1 Defining the divergence problem ............................................... 18

2.4.2 Extent of the divergence problem ............................................. 19

2.4.2.1 North America............................................................... 19

2.4.2.2 Eurasia ...................................................................... 24

2.4.3 Northern Hemisphere reconstructions and the divergence problem 25

2.4.4 Causes of the divergence problem ............................................... 26

2.4.5 Implications of the divergence problem ...................................... 31

2.5 Dynamics of the treeline response to a warming climate ...................... 31

Chapter Three ........................................................................................................... 34

Study Area and Methods ......................................................................................... 34

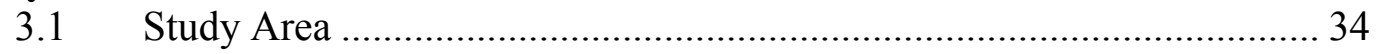

3.1.1 Environment of the Study Area .................................................. 34

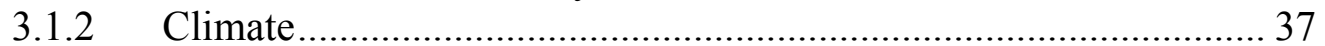

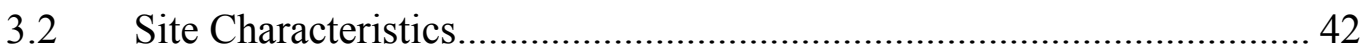

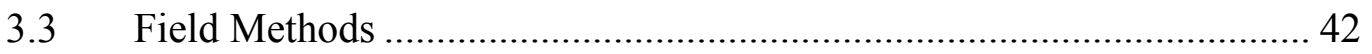

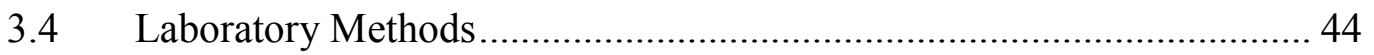

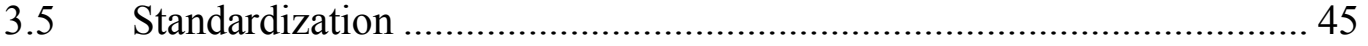

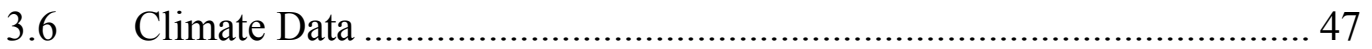

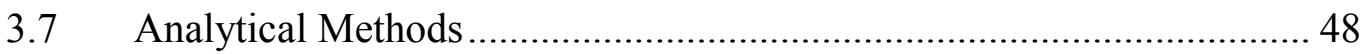

3.7.1 Mean Sensitivity Statistic ......................................................... 48

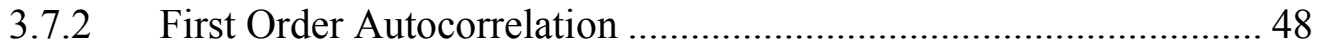

3.7.3 Expressed Population Signal ....................................................... 49

3.7.4 Correlation Analysis ............................................................ 50

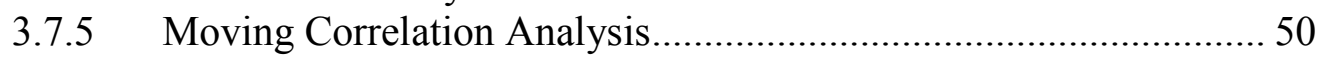

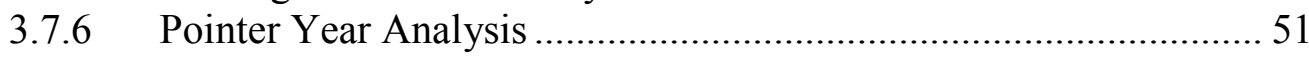

3.7.7 Principal Component Analysis .................................................. 51 
Chapter Four .......................................................................................................... 53

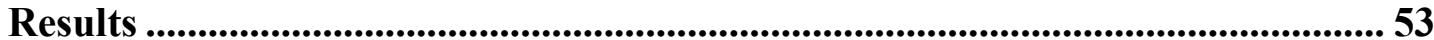

4.1 Assessment of Descriptive Chronology Statistics ................................... 53

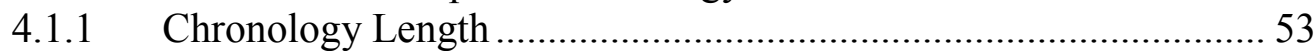

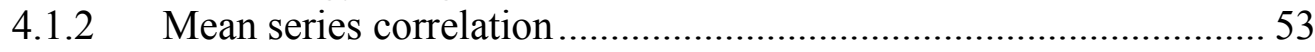

4.1.3 Mean Ring-Width Measurements .................................................... 57

4.1.4 Standard Deviation and Coefficient of Variation ..............................5 57

4.1.5 Mean Sensitivity Statistic ……………………............................ 58

4.1.6 First Order Autocorrelation ......................................................... 58

4.2 Results from chronology building …………........................................ 58

4.3 Assessment of chronology signal strength: EPS..................................... 59

4.4 Signal strength analysis of the chronology network ................................5 59

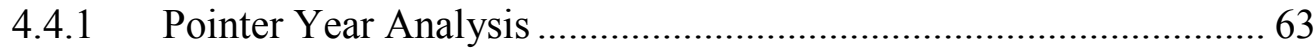

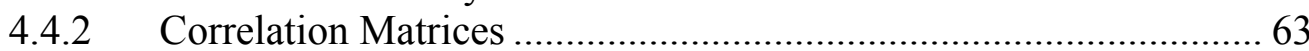

4.4.3 Principal Component Analysis (PCA) .............................................. 66

4.4.4 Final chronology assessment and development of the composite

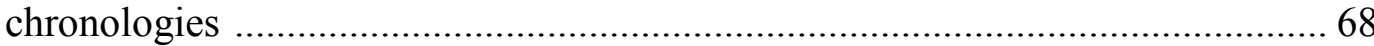

4.5 Climate-Growth Relationships............................................................ 72

4.5.1 Full Period Correlation Analysis .................................................... 72

4.5.1.1 Precipitation and Temperature ............................................ 73

4.5.1.2 Palmer Drought Severity Index (PDSI) ................................ 78

4.5.2 Split Period and Moving Correlation Analysis.................................. 78

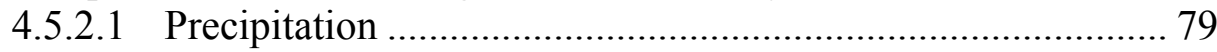

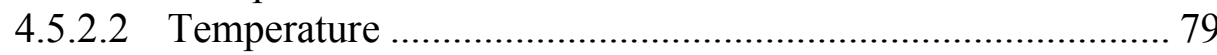

4.5.3 Medium-Frequency Relationships ................................................ 80

Chapter Five ............................................................................................................... 87

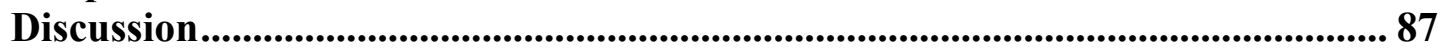

5.1 Soil moisture availability and COMP1 radial growth............................. 87

5.2 Shift in the climate-growth relationship ............................................... 88

5.3 Comparison with temperature reconstructions and other regional tree-

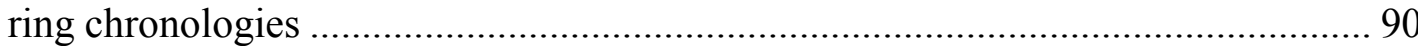

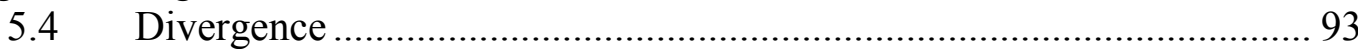

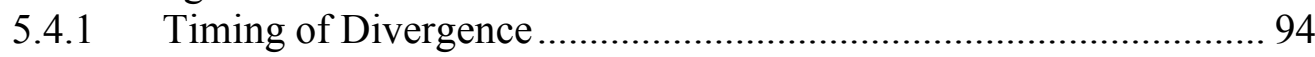

5.4.2 Possible Causes................................................................................. 95

5.4.3 Interior Boreal vs. Treeline Forest Cover ......................................... 96

5.5 Potential for Reconstruction ............................................................... 98

Chapter Six .................................................................................................................99

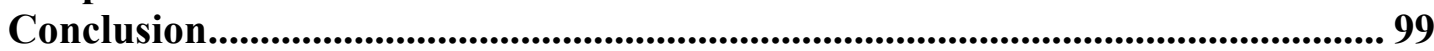

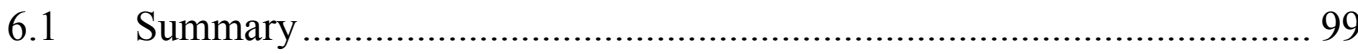

6.2 Recommendations for Future Research ................................................. 101

References .................................................................................................................. 103 


\section{List of Tables}

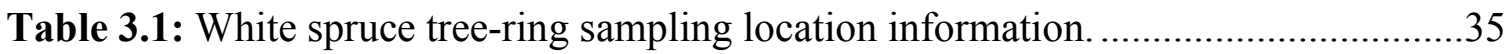

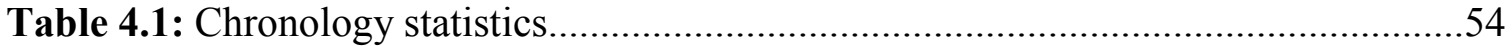

Table 4.2: EPS $<0.85$ cutoff years for each chronology ...........................................60

Table 4.3: Narrow and wide pointer years found in $70 \%$ or more of the chronologies (given a chronology depth greater than 3 series).

Table 4.4: Correlation matrix of the ten sites for the period 1804-2009. Bolded values are statistically significant at $\mathrm{p} \leq 0.05$. The mean correlation between all sites is $r=0.574$.

Table 4.5: Correlation matrix of the ten sites for the period 1901-2009. Bolded values are statistically significant at $\mathrm{p} \leq 0.05$. The mean correlation between all sites is $r=0.319$.

Table 4.6: Principal component analysis summary table. The first two components were found to be statistically significant $(\mathrm{p} \leq 0.05)$ following parallel analysis...69

Table 4.7: Loadings of the site chronologies on the first four principal components. Statistically significant correlations $(\mathrm{p} \leq 0.05)$ are bolded.

Table 4.8: Pearson product moment correlation values of the site, principal component, and composite chronologies with (a) total monthly precipitation, and, (b) mean monthly temperatures from instrumental data from the Yellowknife, NT climate station (1943-2009; Environment Canada, 2012). PDSI correlations with the nearest grid point are presented in (c) (1901-1990). All values are significant at $\mathrm{p} \leq 0.05$. Bold values are positively related. $p$ signifies previous year.

Table 4.9: Pearson product moment correlation values of the site, principal component, and composite chronologies with (a) area CRUTEM3 total monthly precipitation data (1901-2004), and with (b) CRUTEM4 mean monthly temperatures (1914-2009). All values are significant at $p \leq 0.05$. Bold values are positively related. $p$ signifies previous year. 


\section{List of Figures}

Figure 2.1: Drawing of cell structures along a stem of a conifer. Earlywood is composed of thin-walled tracheids and latewood is composed of thick-walled tracheids. False rings form when growth during a part of the growing season slows before returning to the production of the early season. (Reproduced from Fritts, 1976).

Figure 2.2: Distribution of white spruce in Canada. Map developed by the Canadian Forest Service (1999) using distribution data from (Little, 1971). Map retrieved from http://tidcf.nrcan.gc.ca/.

Figure 2.3: Location of the study area and relevant tree-ring chronologies from the NT and YT. The coordinates of the chronologies were retrieved from the International Tree-Ring Databank (http://www.ncdc.noaa.gov/paleo/treering.html)....

Figure 2.4: Example of divergence in trend between summer temperatures and tree growth from the dendroclimatological perspective (Briffa et al., 1998a).

Figure 2.5: Example of sub-population divergence in trend (Pisaric et al., 2007, p. 3). Pisaric et al. (2007) developed a 'positive responder' and a 'negative responder' regional chronology by separating individual tree series based on their $20^{\text {th }}$ century linear growth trends. They are plotted in a) with Northern Hemisphere summer (June-September) temperature anomalies (1856-2003). b) The number of chronologies contained in each 'responder' chronology in any given year is plotted.

Figure 3.1: Location of the ten white spruce sampling sites and Yellowknife, NT climate station.

Figure 3.2: Mean monthly precipitation (grey bars) with minimum (short dashed line), mean (solid line), and maximum (long dashed line) monthly temperatures for the Yellowknife, NT climate station 1971-2000 (Environment Canada, 2012)....39

Figure 3.3: Winter (Dec-Feb), spring (Mar-May), summer (Jun-Aug), and fall (SepNov) mean seasonal temperatures (grey lines) and linear trendlines (black lines) for the Yellowknife, NT climate station (1943-2009; Environment Canada, 2012).

Figure 3.4: Winter (Dec-Feb), spring (Mar-May), summer (Jun-Aug), and fall (SepNov) total seasonal precipitation (grey lines) and linear trendlines (black lines) for the Yellowknife, NT climate station (1943-2009; Environment Canada, 2012).

Figure 4.1: Signal-free standardized chronologies (black) plotted with sample depth (grey dashes). Sample depth refers to the number of radii used to develop the site chronology for that year. EPS $<0.85$ cutoff years are presented with a vertical dashed line.

Figure 4.2: EPS plots for the signal free detrended chronologies. The black line is the EPS value for the chronology and the dashed blue line is the 0.85 EPS threshold

Figure 4.3: Negative pointer years (a) and wide pointer years (b) that occur in more than $50 \%$ of the chronologies for that year. The dashed line shows the sample depth, which is the number of chronologies at that particular time. 
Figure 4.4: The first four principal component chronologies (grey line) plotted with a smoothing spline (black line). The common variance explained by each chronology is included in the title for each plot. The period of analysis for the PCA is 1901-2009.

Figure 4.5: a) COMP1 (black) and COMP2 (grey) chronologies. The COMP1 chronology was computed by taking the average of the YEL2, YEL3, YEL6, YEL7, and DRY1 chronologies. The COMP2 chronology was computed by taking the average of the YEL4, YEL5, and YEL8 chronologies. The COMP1 chronology extends from 1643 to 2009 and the COMP2 chronology extends from 1744 to 2009. a) Radii sample depth of the COMP1 (black) and COMP2 (grey) chronologies.

Figure 4.6: June (a), July (b), and June-July (c) total precipitation plotted with the COMP1 chronology. Pearson product moment correlation values for split periods (1943-1976, 1977-2009) are presented and separated by the dashed vertical line.

Figure 4.7: The COMP2 chronology is plotted with inverted previous-year mean May-August gridded temperatures. Pearson product moment correlation values for split periods (1914-1960, 1961-2009) are presented and separated by the dashed vertical line.

Figure 4.8: Moving correlation analysis between Yellowknife Station total monthly precipitation and the COMP1 chronology using a 32-year moving window, for the period 1943-2009. Total monthly precipitation is plotted on the y-axis. Previous-year May precipitation is at the bottom of the axis and current-year August precipitation is at the top. The $\mathrm{x}$-axis indicates the last year of the 32year moving interval.

Figure 4.9: Moving correlation analysis between Yellowknife Station total monthly precipitation and the COMP2 chronology using a 32-year moving window, for the period 1943-2009. Total monthly precipitation is plotted on the y-axis. Previous-year May precipitation is at the bottom of the axis and current-year August precipitation is at the top. The $\mathrm{x}$-axis indicates the last year of the 32year moving interval.

Figure 4.10: Evolutionary moving correlation analysis between CRUTEM4 mean monthly temperature and the COMP1 chronology starting with a 32-year interval, for the period 1914-2009. Mean monthly temperature is plotted on the $y$-axis. Previous-year May mean temperature is at the bottom of the axis and current-year August mean temperature is at the top. The start year of each interval is 1914, and for each iteration the end year is incremented by one and is represented on the $\mathrm{x}$-axis.

Figure 4.11: Evolutionary moving correlation analysis between CRUTEM4 mean monthly temperature and the COMP2 chronology starting with a 32-year interval, for the period 1914-2009. Mean monthly temperature is plotted on the y-axis. Previous-year May mean temperature is at the bottom of the axis and current-year August mean temperature is at the top. The Start start year of each interval is 1914, and for each iteration the End end year is incremented by one and are is represented on the $\mathrm{x}$-axis. 
Figure 4.12: 11-year running average composite chronology plotted with 11-year running average of June, July, and June -July precipitation. Climate data used is from Yellowknife Station (1943-2009; Environment Canada, 2012).

Figure 4.13: 11 -year running average COMP2 chronology and 11-year running average inverted mean May-August temperatures. Climate data used is from the CRUTEM4 dataset (1914-2009; Jones et al., 2012).

Figure 5.1: a) COMP1 and reconstructed Northern Hemisphere annual temperature anomalies from the 1961-1990 mean (1643-2000; $\mathrm{r}=0.743, \mathrm{p} \leq 0.0001$; D'Arrigo et al., 2006); b) COMP1 and reconstructed June-July mean temperatures from northwestern Canada (1643-1990; $\mathrm{r}=0.302, \mathrm{p} \leq 0.0001$; Szeicz and MacDonald, 1995); c) COMP1 and Coppermine River, NT tree-ring chronology (1643-2000; $r=0.685, \mathrm{p} \leq 0.0001$; D'Arrigo et al., 2009). The three chronologies were retrieved from http://www.ncdc.noaa.gov/dataaccess/paleoclimatology-data/datasets. . 



\section{Chapter One}

\section{Introduction}

\subsection{Introduction and Theoretical Context}

Over the past 150 years, global temperatures have risen significantly. The Intergovernmental Panel on Climate Change (IPCC, 2007) estimates that global average temperature increased by $0.74{ }^{\circ} \mathrm{C}$ in the last 100 years. This observed warming has disproportionally affected Arctic environments, which are currently experiencing rapid and widespread changes (Briffa et al., 2004; IPCC, 2007; D’Arrigo et al., 2009). Instrumental climate records indicate that, over the past 100 years, average temperatures in Arctic regions have increased by twice the global rate (IPCC, 2007). Northern forested regions are especially sensitive to global climate change due to several positive feedbacks, including changes in surface albedo, atmospheric stability, and cloud dynamics (Overpeck, 1997; Jones and Mann, 2004).

The estimates, however, of recent warming are limited because instrumental records are often geographically sparse and of relatively short duration (typically under 100 years in length). These records only capture a small portion of spatial and temporal climatic variability; therefore, they are often inadequate for a proper understanding of climate. Because of this instrumental data information gap, other indicators of climate are needed to reconstruct past climates. Consequently, 'proxy data' is often necessary to advance our understanding of natural climatic variability.

Proxy records are an indirect measure of climate variability deciphered from biological and geological sources, and provide most of the information used to understand medium and long term changes to regional and global climatic patterns (IPCC, 2007). These different proxies include, but are not limited to: borehole 
temperature records (Prensky, 1992), corals (Felis and Pätzold, 2004), pollen assemblages (Wright, 1967), lake sediments (Cohen, 2003), ocean sediments (Wright, 2000), ice cores (Bradley, 1999), and the focus of this study, tree-rings (Fritts, 1976).

As environmental conditions important to the proxy data sources change through time, the growth or composition of the proxy is affected and changes as well. If the manner in which environmental variability influences the proxy is well understood, researchers can determine how climatic and environmental conditions have changed over time. The large spatial distribution of proxy records has enabled paleoclimatologists to develop a globally distributed set of records that range on time scales from dozens to millions of years.

Tree-ring records are an invaluable resource for interpreting both the nature of human-induced climate change compared to natural variability, and also for understanding the response of forests to changes in climate (D'Arrigo et al., 2009). Treerings are one of the most widely used proxy data sources in climate reconstructions largely because they provide high resolution climate information due to their annual nature (Fritts, 1976). In addition, the study of tree-rings through time is perhaps the most rigorous paleoenvironmental method due to the statistical calibration and verification of tree-ring based reconstructions and the unmatched replication employed in tree-ring studies (Hughes, 2002). Unfortunately, the incomplete distribution of tree-ring records in the circumpolar north has limited the understanding of large, regional, and local scale temperature and precipitation patterns over the past several hundred years (e.g. Briffa, 2000; D'Arrigo et al., 2005; Cook et al., 2007; IPCC, 2007). 
At the northern boreal treeline, tree growth is closely related to summer temperature (Fritts, 1976). Numerous dendrochronological studies, especially those using white spruce (Picea glauca) at the North American latitudinal treeline, have successfully reconstructed summer climate variability during the past several centuries to millennia (e.g. Szeicz and MacDonald, 1995; D’Arrigo et al., 2009, Anchukaitis et al., 2013). However, a number of recent studies have shown that rapid warming during the $20^{\text {th }}$ century has caused the previously temperature sensitive white spruce trees to become decoupled from summer temperatures. Trees that previously tracked summer temperature variability are now recording declining trends in growth under theoretically more optimal growing conditions (e.g. Jacoby and D’Arrigo, 1995; Briffa et al., 1998a; Wilmking et al., 2004, 2005; Pisaric et al., 2007; D’Arrigo et al., 2008; Porter and Pisaric, 2011). This phenomenon is known as the 'divergence problem' (D’Arrigo et al., 2008).

While the divergence problem has been observed at sites across the northern boreal treeline, much of the north has continued to experience increasing productivity in response to recent warming trends (Myneni et al., 1997; D’Arrigo et al., 2005; Xu et al., 2013). Satellite imagery indicates increasing productivity near and beyond the foresttundra boundary, but declining productivity in warmer regions south of this ecotone (Bunn and Goetz, 2006; Beck and Goetz, 2011; Beck et al., 2011; Berner et al., 2011). Furthermore, recent dendroclimatological studies in Alaska have noted that trees growing near the boundary of latitudinal and altitudinal treeline have been more likely to respond positively to rising temperatures; whereas, trees growing further away from treeline have been more likely to respond negatively to rising temperatures (Lloyd and Bunn, 2007; Williams et al., 2011). 


\subsection{Research Objectives}

The purpose of this thesis is to assess the climatic and environmental factors that influence the radial growth of white spruce across a latitudinal transect in the central Northwest Territories (NT). Tree ring-width chronologies were developed from ten sites near latitudinal treeline in the central NT collected in the Fall of 2010 and Winter of 2011. The following research objectives were proposed:

1. Develop ring-width chronologies measured from samples of white spruce in the central NT.

2. Identify the climate variables to which white spruce in central NT respond.

3. Evaluate the temporal stability of climate-growth relationships.

4. Assess if these chronologies show evidence of divergence in trend during the $20^{\text {th }}$ century.

5. Determine if white spruce growing at sites closer to treeline are responding differently to climate than white spruce growing at sites further away from treeline.

\subsection{Thesis Structure}

This thesis is divided into six chapters. Chapter One has presented a brief introduction to the topic. Chapter Two presents the theoretical context of dendroclimatology, describes white spruce, provides an overview of relevant dendroclimatological studies, summarizes the 'divergence problem', and explores the observed changes to treeline and tundra vegetation under a warming climate. Chapter Three describes the study area and outlines the field, laboratory, and analytical methods utilized. Chapter Four investigates the response of white spruce to climate. Chapter Five 
discusses the climate-growth relationships and how they are situated in the research literature. Finally, Chapter Six summarizes the research results and offers suggestions for future research. 


\section{Chapter Two \\ Literature Review}

\subsection{Dendroclimatology}

Dendroclimatology is a subfield of dendrochronology and is concerned with the study of relationships between annual tree growth and climate (Fritts, 1976). To properly understand how climatic conditions affect tree growth it is important to understand how trees grow. There are two types of tree growth: primary and secondary (Kramer and Kozlowski, 1960). Primary growth is the vertical growth of a tree. It occurs at the apical meristem (terminal bud) with the formation of new cells that increase the height and length of stem and roots (Fritts, 1976). Secondary growth is the result of cell formation that increases the width of stems and branches at the vascular cambium (Fritts, 1976). It is this secondary, radial growth that is important for dendroclimatological purposes.

In middle to high latitude temperate regions, a tree adds biomass to its trunk every year which results in the formation of a ring reflecting that year's tree growth (Kramer and Kozlowski, 1960). Tree-ring formation takes place between the bark and the woody tissue in the region known as the vascular cambium. The vascular cambium is a thin layer of cells that produce phloem on the outside and xylem on the inside (Fig. 2.1; Fritts, 1976). Phloem distributes food-bearing sap developed in leaves and needles down to various parts of the tree. The phloem is composed of still living tissue and xylem is composed primarily of dead cells. Xylem, commonly referred to as sapwood, is the principal strengthening and conducting tissue of stem, roots, and branches (Fritts, 1976). At the start of the growing season the vascular cambium produces numerous cells that have large lumen with thin walls that form earlywood. Towards the end of the growing season growth slows down. The cells manufactured at this time of year are always 
flattened and have a more compact lumen with relatively thick walls. They form latewood that appears as a darker band on the tree cross section (Kramer and Kozlowski, 1960). The production of earlywood and latewood results in a tree ring representing one year of growth. In temperate climates, there is no growth during winter months because the cambium is completely inactive (Kramer and Kozlowski, 1960).

The annual radial growth of a tree is the net result of complex and interrelated biochemical processes. Radial growth varies diurnally, seasonally, annually, and with height along the tree stem (Speer, 2010). Annual radial growth also varies throughout the lifetime of the tree because younger trees have been shown to grow faster than older trees (Fritts, 1976; Szeicz and MacDonald, 1994). Trees interact directly with the microenvironment of leaf and root surfaces; therefore, radial growth may be affected by characteristics of the microclimate such as sunshine, precipitation, temperature, wind speed, and humidity (Cook, 1990). There are additional non-climatic factors that may influence radial growth (e.g. competition, defoliators, and soil nutrient characteristics; Cook, 1990). This relationship between microclimate conditions and larger scale climatic parameters enables dendroclimatologists to extract a measure of the overall influence of climate on annual radial growth (Fritts, 1976).

Dendroclimatology strives to separate the larger scale climatic influence (i.e. the 'climate signal') from 'noise' (Fritts, 1976). To interpret a climate signal in tree-rings, the climate variable in question needs to be the limiting factor for growth. Climate is often the limiting factor at the limits of a tree species' geographic extent (Fritts, 1976). The two most common climate limitations are moisture and temperature stress (Speer, 2010). Radial growth in semi-arid environments is frequently limited by the availability of water 


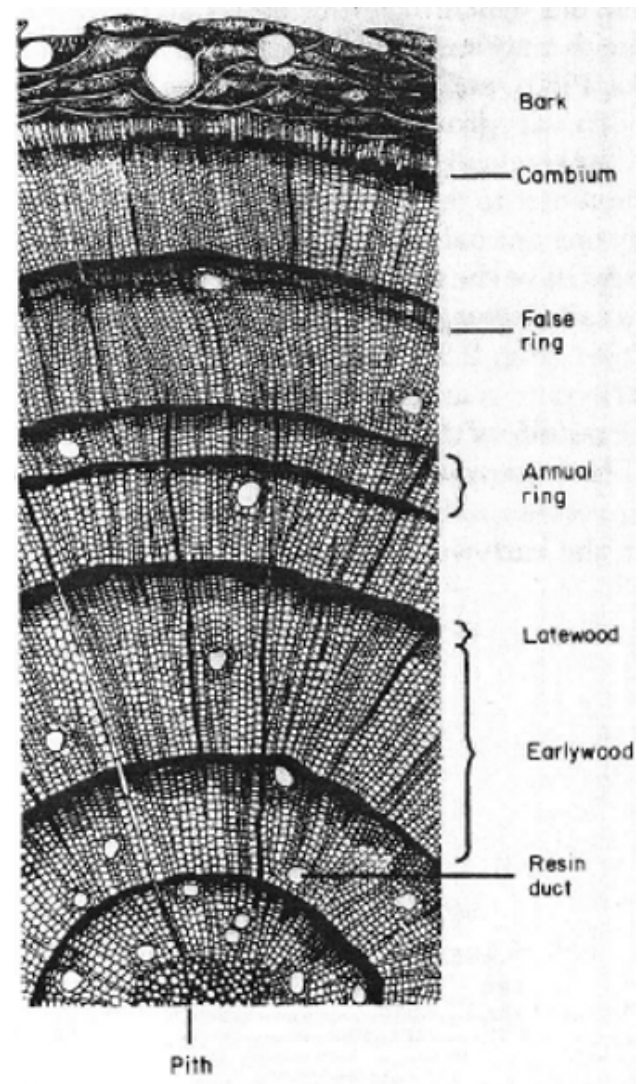

Figure 2.1 Drawing of cell structures along a stem of a conifer. Earlywood is composed of thin-walled tracheids and latewood is composed of thick-walled tracheids. False rings form when growth during a part of the growing season slows before returning to the production of the early season. (Reproduced from Fritts, 1976). 
and in these regions dendroclimatological studies analyze moisture stress (Fritts, 1976). Radial growth at elevational or latitudinal treeline is typically limited by temperature. In these regions, dendroclimatological studies analyze temperature limitations (e.g. Luckman and Wilson, 2005).

To better understand climatic variability, dendroclimatology relies on several assumptions (Speer, 2010). The fundamental assumption is the principle of uniformitarianism, which states that physical and biological processes that link present day environmental processes with present day tree growth have been in operation in the past (Fritts, 1976). It is also assumed that the relationship between climate as a limiting factor and the biological response is linear. Furthermore, all environmental factors that affect radial growth can be decomposed and expressed as a linear mathematical expression, where ring-width ( $R$ in any one year $t$ is a function of an aggregate of factors (Cook, 1990):

$$
R_{t}=A_{t}+C_{t}+\delta D 1_{t}+\delta D 2_{t}+E_{t}
$$

Equation 2.1

Where:

- $A$ is the age related growth trend due to normal physiological aging processes.

- $C$ is the climate that occurred during that year.

- D1 is the occurrence of disturbance factors within the forest stand.

- D2 is the occurrence of disturbance factors from outside the forest stand.

- $E$ is the cumulative of the factors that affect growth not accounted for by these other processes.

(The Greek letter (in front of D1 and D2 indicates either an 'O' for absence or ' 1 ' for presence of the disturbance signal)

To maximize the desired climate signal $(C)$, the other factors $(A, D 1, D 2$, and $E)$ need to be minimized. It should also be mentioned that tree-rings contain information about the current growth year as well as the months and years preceding it (Fritts, 1976). Climatic conditions during the previous year can affect current-year radial growth by 
preconditioning physiological processes within the tree. As a result tree-ring growth records, especially those sensitive to temperature, are often strongly autocorrelated (Luckman, 2007).

\subsection{White Spruce}

White spruce has a transcontinental ecological amplitude (Schweingruber, 1993). In eastern Canada, the northern extent of white spruce is at or near the latitudinal treeline from Newfoundland and Labrador west across to Hudson's Bay (Fig. 2.2). In western Canada, it forms the latitudinal treeline from Hudson's Bay to Alaska. The southern range extends from southern Maine west to southern British Columbia (MacDonald and Gajewski, 1992). White spruce thrives at high latitudes and elevations because it can grow in extreme climates and soils, such as the cold-coastal and cold semi-arid climates of northern Canada (Schweingruber, 1993). As a shallow rooting species, white spruce can prosper in areas with thin soils and continuous and discontinuous permafrost (MacDonald and Gajewski, 1992). Their ability to survive in such stressed climatic and edaphic conditions make them more likely to have temperature, and occasionally precipitation, as a limiting factor for growth (Fritts, 1976). In northern regions, they can also live for over 500 years (Szeicz and MacDonald, 1994). The ability to grow in highly stressed climatic conditions, coupled with their broad spatial distribution, and longevity make white spruce quite useful for dendroclimatological purposes.

White spruce has been studied extensively across North America's northern regions (e.g. Szeicz and MacDonald, 1994; Barber et al., 2000; Lloyd and Fastie, 2002; D'Arrigo et al., 2009; Porter and Pisaric, 2011). Unfortunately for the context of dendroclimatic research, white spruce stands are also prone to spruce budworm 


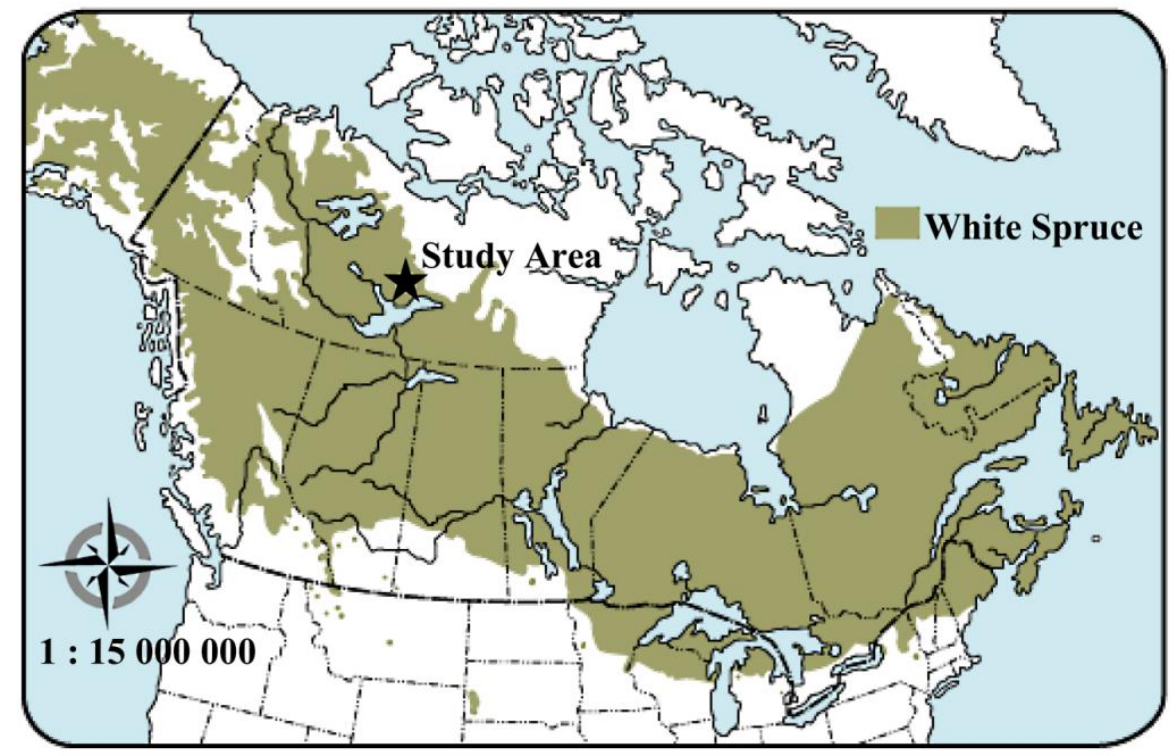

Figure 2.2 Distribution of white spruce in Canada. Map developed by the Canadian Forest Service (1999) using distribution data from (Little, 1971). Map retrieved from http://tidef.nrcan.gc.ca/. 
infestation and large-scale fires in the central NT (Ecosystem Classification Group, 2008). These disturbances can confound the climate signal contained in stands of white spruce impacted by these types of disturbances. Careful site selection is required to identify evidence of such disturbances so that large-scale climate signals are enhanced and localized disturbance factors are minimized.

\subsection{Review of relevant dendroclimatological studies in northern Canada}

Numerous dendroclimatological studies have been undertaken near central NT (Fig. 2.3; e.g. Schweingruber et al., 1993; Szeicz and MacDonald, 1995; Pisaric et al., 2009; D'Arrigo et al., 2009). Studies from the area have successfully reconstructed summer temperatures (e.g. D’Arrigo et al., 2009), summer precipitation (e.g. Pisaric et al., 2009), as well as combinations of both temperature and precipitation (e.g. Szeicz and MacDonald, 1995). Dendroclimatological studies in the central NT indicate that large, regional-scale climate patterns and synoptic level climate change are the primary drivers of the area's tree growth (e.g. Schweingruber et al., 1993; Szeicz and MacDonald, 1995; Szeicz, 1996; Pisaric et al., 2009; D'Arrigo et al., 2009). Unfortunately, compared to the extent of American and European dendroclimatological records, the area has relatively short and sparsely distributed dendroclimatological studies (Briffa et al., 2002a). This section reviews relevant dendroclimatological research undertaken near the study area.

\subsubsection{Regional temperature studies}

In one of the earliest studies to use proxy records in the central NT, Schweingruber et al. (1993) developed ring-width and density tree-ring series for up to 200 years at 69 sites across the northern North American conifer zone. When this study 


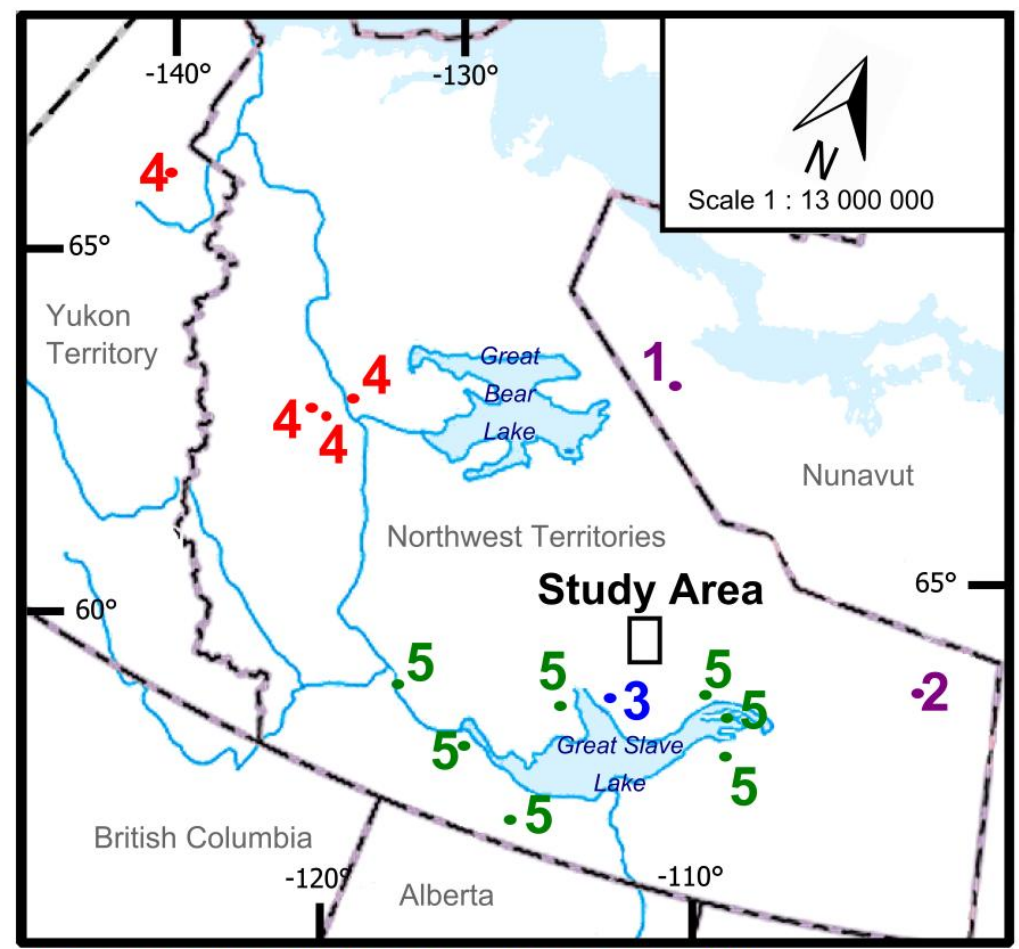

1. Coppermine River, NU. Picea glauca (D’arrigo et al., 2009).

2. Thelon South, NT. Picea glauca (D'Arrigo et al., 2009).

3. Yellowknife Region, NT. Pinus banksiana (Pisaric et al., 2009)

4. Northwestern NT and Northern YT. Picea glauca (Szeicz and MacDonald, 1995).

5. Great Slave Lake Region. Picea glauca (Schweingruber et al., 1993).

Figure 2.3: Location of the study area and relevant tree-ring chronologies from the NT and YT. The coordinates of the chronologies were retrieved from the International Tree-Ring Databank (http://www.ncdc.noaa.gov/paleo/treering.html). 
was published in 1993, it filled in many dendrochronological spatial gaps across Canada particularly in northern Quebec, Yukon Territory (YT), and NT. Of the 69 sites, 15 chronologies (including 9 white spruce chronologies) were developed in the region of Great Slave Lake. The study is comprehensive, and includes a time series for numerous growth parameters including: earlywood width, latewood width, total ring-width, mean earlywood density, mean latewood density, minimum and maximum ring density.

Tree growth in the Great Slave Lake region is likely being controlled by regional and, possibly, hemispheric level climatic change (Schweingruber et al., 1993). Spruce in the central NT may not be as sensitive to changes in temperature and precipitation as trees growing in other boreal forest environments. For example, the Great Slave Lake ring-width related variables are poorly correlated with temperature records, and no anomalous $20^{\text {th }}$ century growth was recorded in tree-rings during a period of significant regional warming. The lack of a low-frequency signal in the Great Slave Lake chronology led Schweingruber et al. (1993) to propose that their work is more suited to infer decadal scale variability in the region. Great Slave Lake trees had three periods of growth suppression (1810-1825, 1910-1920, and 1940-1950) possibly as a result of relatively colder and drier conditions (Schweingruber et al., 1993).

Szeicz and MacDonald (1995) reconstructed temperatures west of central NT. Studying tree growth at five white spruce stands at the alpine treeline in NT and YT, Szeicz and MacDonald (1995) developed an age dependent and a standard model to reconstruct two chronologies of June-July temperatures extending back to 1638 . This study supports the findings of Schweingruber et al. (1993), indicating that northern tree growth is influenced by large-scale climate patterns. Additionally, the chronologies have 
short and long term trends similar to other high latitude reconstructions ( $c f$. D'Arrigo et al., 1999; Briffa et al., 2002b; Briffa et al., 2004). The reconstruction indicates that relatively cool periods occurred around 1700 and the first half of the $19^{\text {th }}$ century. Since 1850 , temperatures have been rising with late- $20^{\text {th }}$ century temperatures being warmer than any period over the last 350 years (Szeicz and MacDonald, 1995). Of note, there is a relatively warm period from 1750 to 1800 , during the Little Ice Age, which indicates that the period was not uniformly cold as previously believed (Mann, 2002).

The only tree-ring study undertaken along the treeline between the Mackenzie Delta, NT and Hudson Bay further supports evidence that regional to continental scale climate patterns drive tree growth along the continental arctic treeline (D'Arrigo et al., 2009). D'Arrigo et al. (2009) developed white spruce ring-width and density chronologies from the Coppermine and Thelon Rivers, NT/Nunavut border that are each highly correlated with Northern Hemisphere reconstructions (cf. D'Arrigo et al., 1999; Briffa et al., 2004). The chronologies indicate that the area was relatively cold during the mid- $13^{\text {th }}$ century before warming to above average conditions during the $16^{\text {th }}$ century. Furthermore, tree growth was slowed during the parts of the Maunder Minimum around 1700 (Mann, 2002), and was particularly slow for the early part of the $19^{\text {th }}$ century, before increasing from the mid- $19^{\text {th }}$ century until the mid- $20^{\text {th }}$ century when the chronologies begin to differ in trend. The Coppermine River chronologies continue to track temperatures, although, less significantly than earlier periods. Whereas, from the mid- $20^{\text {th }}$ century, a period of rising temperatures, the Thelon River ring-width chronology exhibits decreasing radial growth. This loss of temperature sensitivity in radial growth has been observed in numerous dendroclimatological studies along the northern boreal 
forest treeline (Briffa et al., 1998a; D'Arrigo et al., 2008), and is known as 'the divergence problem' which is discussed in further detail in Section 2.4.

Of note, temperatures have been successfully reconstructed across northern environments of North America. Notably, at arctic and alpine treeline sites in Alaska (e.g. Lloyd and Fastie, 2002; Barber et al., 2004; Wilmking et al., 2004), YT (e.g. Youngblut and Luckman, 2008), British Columbia (e.g. Wilson and Luckman, 2003; Flower, 2008), northern Alberta (e.g. Larsen, 1996), and Churchill, Manitoba (e.g. Jacoby and Ulan, 1982; Scott et al.; 1987, Tardif et al., 2008).

\subsubsection{Regional precipitation studies}

Northern treeline dendroclimatological studies sometimes reveal a mixed climate signal with temperature and precipitation (Fritts, 1976; Szeicz and MacDonald, 1996; Gajewski and Atkinson, 2003). Szeicz and MacDonald (1996) developed a 930-year white spruce chronology from the Campbell Dolomite Upland, NT. Statistical analysis using Inuvik climate data indicated that $69 \%$ of the variation in ring-widths could be explained by monthly precipitation and temperature. High precipitation between February and May was positively related with tree growth, and previous-year temperatures were negatively related. The combined effects of precipitation and temperature inhibited the development of a climate reconstruction; however, Szeicz and MacDonald (1996) provide a qualitative assessment of past moisture stress. Tree growth was suppressed, hence moisture stress occurred, for the periods 1125-1170, 1260-1300, 1395-1405, 1585-1610, 1700-1710, and 1820-1855. Rapid growth, indicating times of greater moisture availability, was recorded for the periods $1185-1205,1215-1260,1510-1560$, 1725-1740, 1770-1780, and 1925-1940. 
Important information about precipitation patterns in the Great Slave Lake area was developed by Pisaric et al. (2009) who constructed twelve jack pine (Pinus banksiana) tree-ring chronologies from sites near Yellowknife, NT. The study extended the June precipitation record for the area by more than 260 years, and determined that the mid-20 $0^{\text {th }}$ century $(1927-1976)$ was the driest period since 1680 . Relatively dry periods were reconstructed for $1698-1735,1776-1796,1842-1865$, and 1879-1893. The periods with above-average reconstructed June precipitation include 1756-1775, 1822-1841, 1894-1926, and 1976-2005. Pisaric et al. (2009) concluded that large-scale atmospheric patterns influenced by sea-surface temperatures in the Pacific basin may have controlled precipitation patterns in the Yellowknife region at decadal time scales over the past three centuries or more. Comparably, a multi-proxy study of laminated lake sediments and white spruce tree-rings near Mirror Lake in southwest NT observed a similar decadal summer climate signal (Tomkins et al., 2008).

South of central NT in northern Alberta, water levels in Lake Athabasca were reconstructed for the period 1801-1999 (Meko, 2006). Studying white spruce growing in the Peace-Athabasca delta region, Meko (2006) determined that water levels in Lake Athabasca were low during the 1880-1890s, 1910s, 1940s, and early 1980s. Periods of high lake levels were reconstructed for approximately 1850, 1930s, and 1960s. However, these periods of low/high precipitation and soil moisture availability need to be interpreted with caution due to uncertainty in distinguishing the water-level signal from precipitation, and other correlated hydrological variables (Meko, 2006). In another study of Lake Athabasca, Stockton and Fritts (1973) determined that naturally low water levels were recorded in the 1860s and 1940s. 


\subsection{The 'Divergence Problem'}

A number of recent tree-ring studies have addressed the 'divergence problem' in high latitude northern forests (e.g. Jacoby and D'Arrigo, 1995; Briffa et al., 1998a; Vaganov et al., 1999; Barber et al., 2000; Wilson and Luckman, 2003; Wilmking et al., 2004, 2005; Luckman and Wilson, 2005; Pisaric et al., 2007; D'Arrigo et al., 2008; Youngblut and Luckman, 2008; Porter and Pisaric, 2011). From the late $19^{\text {th }}$ century to the mid- $20^{\text {th }}$ century, tree-ring records closely match instrumental summer temperatures. However, in the second half of the $20^{\text {th }}$ century high latitude tree growth has slowed during a period of increasing temperatures. This divergence is widely noted by researchers, but there is controversy regarding the definition, timing, spatial extent, cause, and its implication for future dendroclimatological work (Esper and Frank, 2009).

\subsubsection{Defining the divergence problem}

In their comprehensive review, D'Arrigo et al. (2008) define the divergence problem as "the tendency for tree growth at some previously temperature-limited northern sites to demonstrate a weakening in mean temperature response in recent decades, with the divergence being expressed as a loss in climate sensitivity and/or a divergence in trend" (p. 290). Divergence has been addressed from two perspectives in dendrochronological studies: from a dendroclimatological and a dendroecological perspective (Büntgen et al., 2008a). The dendroclimatological perspective expresses divergence as a weakening relationship between tree-ring based temperature reconstructions and instrumental climate data during the $20^{\text {th }}$ century (Fig. 2.4; e.g. Briffa et al., 1998a; Wilson et al., 2007). These studies typically indicate that temperatures have continued to control tree growth inter-annually, but that the long term warming trend is 
not captured in tree-rings (Esper and Frank, 2009). Studies from the dendroecological perspective have reported a 'growth divergence' between sub-populations of trees located at elevational and altitudinal treeline sites in the $20^{\text {th }}$ century (Fig. 2.5; e.g. Wilmking et al., 2005; Pisaric et al., 2007). These sub-populations were synchronous up until the early to mid- $20^{\text {th }}$ century when they begin to diverge. Sub-populations exhibiting increased growth during the $20^{\text {th }}$ century have been termed 'positive responders', while those with decreasing growth trends in the $20^{\text {th }}$ century are known as 'negative responders' (Pisaric et al., 2007).

\subsubsection{Extent of the divergence problem}

The weakening relationship of radial growth to temperatures at altitudinal and latitudinal treeline is primarily present in boreal forests of northwestern North America and Eurasia. This sub-section provides an overview of key studies related to the divergence problem throughout the Northern Hemisphere. It should be noted, however, that divergence has not been reported in all dendroclimatological studies of northern boreal forest trees (e.g. D'Arrigo et al., 2001; Wilson and Luckman, 2003; Davi et al., 2003; Büntgen et al., 2005, 2006, 2008b Anchukaitis et al., 2013).

\subsubsection{North America}

Divergence has been observed in Alaska (Jacoby and D'Arrigo, 1995; Barber et al., 2000; Jacoby et al., 2000; Lloyd and Fastie, 2002; Davi et al., 2003; Wilmking et al., 2004, 2005; Driscoll et al., 2005; McGuire et al., 2010; Andreu-Hayles et al., 2011; Juday and Alix, 2012; Ohse et al., 2012), YT (D’Arrigo et al., 2004; Porter and Pisaric, 2011), NT/Nunavut (Pisaric et al., 2007; D'Arrigo et al., 2009), and further south in the Canadian Rockies (Youngblut and Luckman, 2012). 


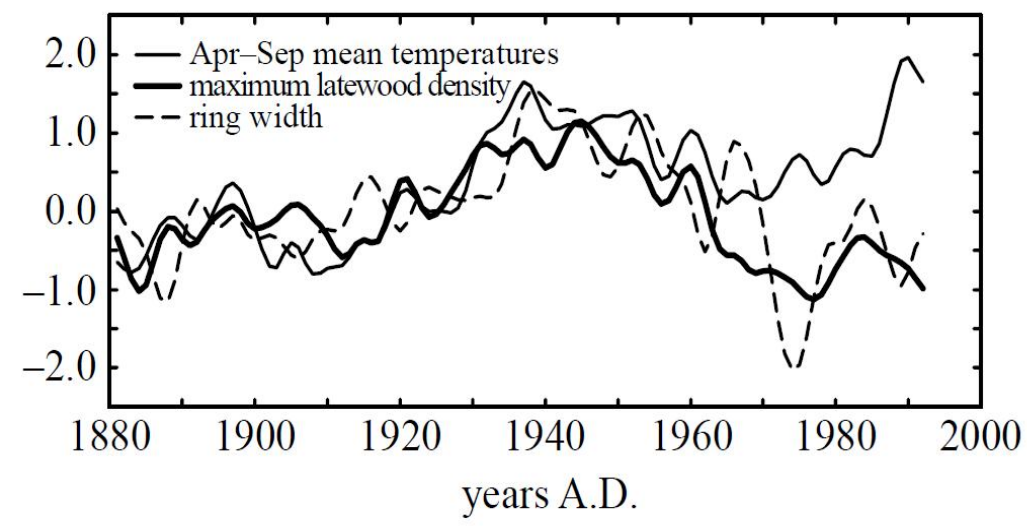

Figure 2.4 Example of divergence in trend between summer temperatures and tree growth from the dendroclimatological perspective (Briffa et al., 1998a).

a)

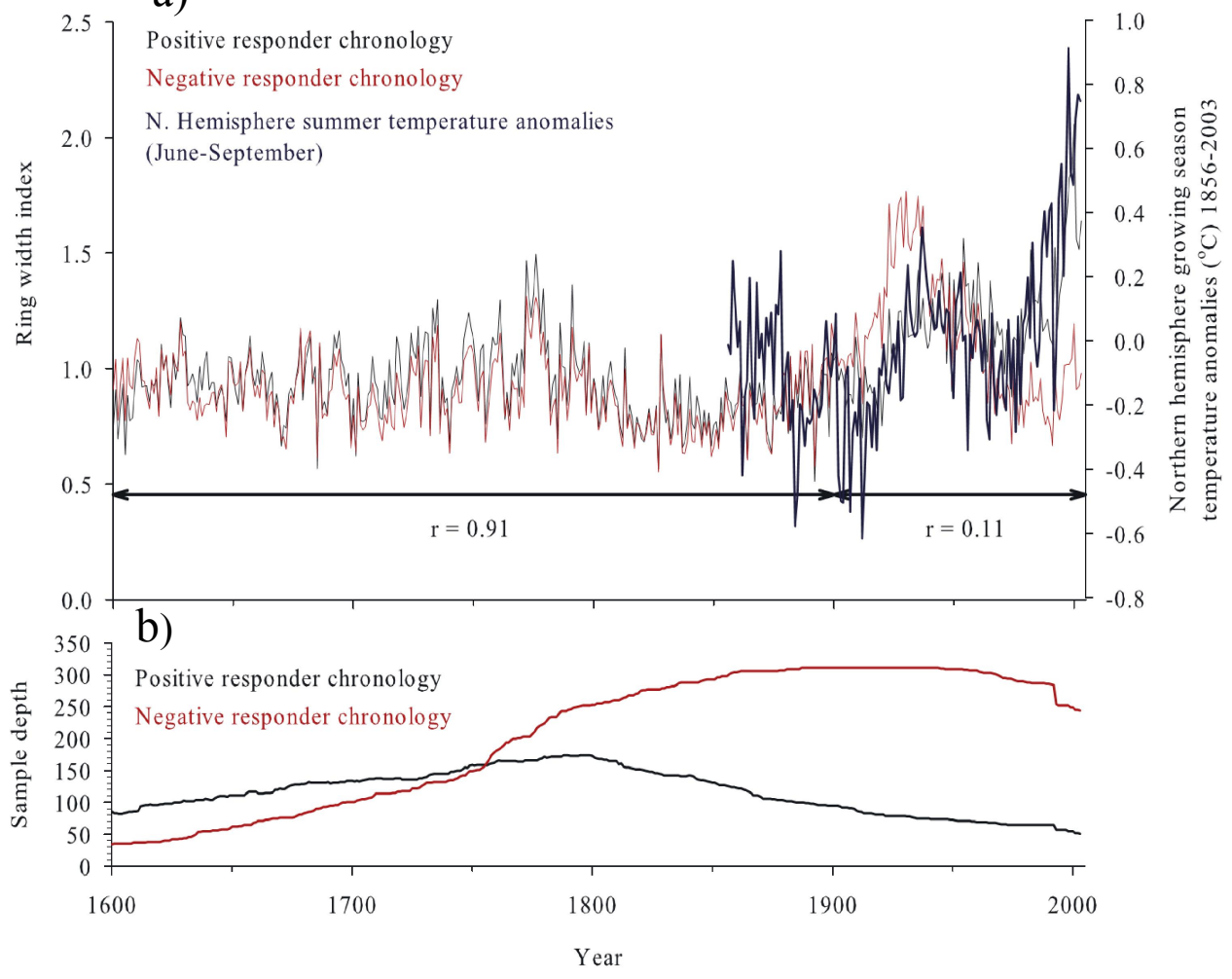

Figure 2.5 Example of sub-population divergence in trend (Pisaric et al., 2007, p. 3). Pisaric et al. (2007) developed a 'positive responder' and a 'negative responder' regional chronology by separating individual tree series based on their $20^{\text {th }}$ century linear growth trends. They are plotted in a) with Northern Hemisphere summer (June-September) temperature anomalies (1856-2003). b) The number of chronologies contained in each 'responder' chronology in any given year is plotted. 
Studying white spruce growing at treeline sites from interior and northern Alaska, Jacoby and D'Arrigo (1995) first identified the divergence problem. Jacoby and D'Arrigo (1995) developed ring-width chronologies that showed their greatest growth rates occurring during the 1930s and 1940s, a period of anomalous warmth. However, as annual temperatures continued to rise, tree growth did not track warming temperatures after the 1970s. Jacoby and D'Arrigo (1995) speculated that decreasing tree growth may be related to moisture stress caused by recent warming. D'Arrigo et al. (2008) updated these chronologies and added them to a large-scale Alaska-wide network of white spruce chronologies. Kalman-filter analysis of the chronology with gridded June-July temperature and July-August precipitation data revealed increased weakening in temperature-growth relationships and strengthening of precipitation-growth relationships during the second half of the $20^{\text {th }}$ century.

Another Alaskan study noted the weakening relationship between temperature and radial growth. Barber et al. (2000) developed ring-width, latewood density and carbon isotope records from 20 closed-canopy and productive upland white spruce stands. Since 1970, increased warmth and stable precipitation resulted in diminished tree growth. Because this period is thought to be unprecedentedly warm and dry, Barber et al. (2000) infer that drought stress negatively affected tree growth. Lloyd and Fastie (2002) sampled white spruce at eight sites near treeline in Alaska, providing additional evidence of divergence. From 1900-1950, tree growth increased at almost all sites, whereas declines occurred at all but one of the sites after 1950. Warmer temperatures were associated with decreased tree growth in all but the wettest regions (Lloyd and Fastie, 
2002). Additionally, white spruce growing in a forest-tundra transition zone in northeastern Alaska exhibited similar divergence (Andreu-Hayles et al., 2011).

Divergence appears to be more pronounced in ring-width chronologies than maximum density chronologies (Jacoby and D'Arrigo, 1995; D'Arrigo et al., 2009; Andreu-Hayles et al., 2011). Andreu-Hayles et al. (2011) developed a ring-width chronology that exhibited significant divergence after 1950; however, the relationship of their maximum latewood density chronology with July-August temperatures is stable throughout the $20^{\text {th }}$ century. Similarly, two density chronologies developed by D'Arrigo et al. (2009) diverge slightly from temperatures after 1980, but the ring-width chronologies exhibit a pronounced loss of sensitivity to summer temperatures with one chronology even exhibiting a negative trend in growth.

Divergence is also present within site chronology sub-populations (Wilmking et al., 2004, 2005; Driscoll et al., 2005; Pisaric et al., 2007). Wilmking et al. (2004) developed 13 white spruce ring-width chronologies in northern Alaska. July temperatures were negatively correlated with $40 \%$ of the trees, spring temperatures were positively correlated with $36 \%$ of the trees, and $24 \%$ of the trees showed no significant relationship to climate (Wilmking et al., 2004). These three different climate-growth responses were present at all sites, but there was no apparent pattern in sub-population proportion among the sites. Wilmking et al (2004) proposed that the weakened sensitivity of white spruce with late- $20^{\text {th }}$ century warming reported is likely caused by contrasting positive and negative signals within a site chronology that are being averaged.

Pisaric et al. (2007) used a similar methodology studying white spruce ring-width chronologies from nine sites within the Mackenzie Delta, NT. Individual cores from all 
sites were separated into 'positive responders' and 'negative responders' with regards to the direction of response to recent temperature trends. Negative responders totaled $75 \%$ of the samples and were negatively correlated with recent temperatures. Positive responders accounted for the remaining $25 \%$ and exhibited greater tree growth with rising temperatures. Because negative and positive responders were synchronous until the 1930 s, the study provides additional evidence that divergence is limited to the $20^{\text {th }}$ century. They also note that the sub-population divergence occurs earlier in the Mackenzie Delta than reported in previous studies (e.g. Jacoby and D’Arrigo, 1995), possibly due to the more northern location of the study (Pisaric et al., 2007).

In the northern YT, diverging trends have also been observed at the site level (Porter and Pisaric, 2011). White spruce chronologies were developed for 23 sites near treeline in Old Crow Flats, YT. The site chronologies correlate with each other from the $16^{\text {th }}$ century until the $1930 \mathrm{~s}$; whereupon, tree-ring chronologies from different sites respond in two distinct and opposite ways. After the 1930s, 11 site chronologies exhibit decreasing radial growth (Group 1), while 11 site chronologies exhibit greater radial growth (Group 2). Climate-growth analysis over the instrumental period (1930-2007) revealed that Group 1 chronologies were negatively related with previous-year July temperatures. Group 2 sites exhibited positive relationships with current-year June temperatures. Porter and Pisaric (2011) proposed that site level divergence observed throughout northwest North America implies a large-scale forcing (Porter and Pisaric, 2011). However, some sites with diverging trends are only separated by a few kilometres, suggesting site-level factors must also play an important role in determining the response to $20^{\text {th }}$ century warming (Porter and Pisaric, 2011). 


\subsubsection{Eurasia}

The divergence problem is present at sites across the northern boreal forests of Eurasia (Vaganov et al., 1999; Jacoby et al., 2000). Vaganov et al. (1999) analyzed climate-growth responses of ring-width and maximum latewood density chronologies from 6 sites in the forest-tundra zone of the Siberian Arctic treeline. Ring-widths were correlated with pentads (5 days of climate data) fixed from the initiation of cambial activity because temperatures largely determine tree growth during a very short period at the start of the growing season (Vaganov et al., 1999). As hypothesized, higher temperatures during the early pentads of the growing season led to greater ring-widths and this association does not weaken in the later parts of the $20^{\text {th }}$ century. However, relationships of chronologies with more traditional monthly climate data exhibit a weakening of the temperature-growth relationship. Vaganov et al. (1999) proposed that reduced sensitivity to summer temperatures occurred because increased winter precipitation over the course of the $20^{\text {th }}$ century led to a delay in snowmelt that impeded cambial initiation. Since the 1960 s, the growing season is occurring less during the period of maximum growth sensitivity to temperature leading to smaller ring-widths and a weakened statistical relationship between growth and temperatures (Vaganov et al., 1999).

North Siberian dahurian larch (Larix gmelini) exhibited divergence at four sites on the Taymyr Peninsula, which is the northernmost location of conifers in the world (Jacoby et al., 2000). Summer (May-September) temperatures for the past four centuries were successfully reconstructed, but the calibration and verification models were truncated in 1970 because the chronologies exhibited a weakened temperature response. 
The reconstruction showed coherence with other high latitude summer temperature reconstructions up until 1970, indicating that divergence is a recent phenomenon.

\subsubsection{Northern Hemisphere reconstructions and the divergence problem}

The widespread extent of the divergence problem has been noted in several northern hemispheric studies (e.g. Briffa et al., 1998a; Wilmking et al., 2005; Lloyd and Bunn, 2007). Climate-growth relationships of over 300 ring-width and maximum latewood density chronologies from North America, Northern Europe, and Siberia reveal a positively related association with summer temperatures in the $20^{\text {th }}$ century that weakened after 1960 (Briffa et al., 1998a). Briffa et al. (1998a) compared correlations between instrumental temperatures and tree growth for the periods 1881-1960 and 18811990. Including the years 1961-1980 in correlation analyses significantly decreased the positive relationship between temperature and tree growth. Another study analyzed eight previously published site chronologies to determine if there were positive and negative responder sub-populations present across the circumpolar north. Wilmking et al. (2005) developed positive and negative responder chronologies for each site and noted a divergence in trend beginning between the 1950s and 1970s at all but one site in Labrador. The negative responders were negatively or only weakly positively correlated to recent warming, likely due to moisture stress, whereas the positive responders still responded as expected to warmer temperatures.

Lloyd and Bunn (2007) performed climate-growth analysis for chronologies developed from ten different species at 232 sites across the circumpolar boreal forest. Thirty-year moving correlations from 1902-2002 demonstrated inverse relationships with temperatures in all species across the chronology network. The five most susceptible 
species were Norway spruce (Picea abies), white spruce, black spruce (Picea mariana), Siberian spruce (Picea obovata) and jack pine. After 1942, the frequency of negatively responding chronologies increased, while the frequency of positively related sites decreased.

The divergence problem is not confined to northern environments and has been noted in studies at lower latitudes from Europe (Carrer and Urbinati, 2006; Büntgen et al., 2006), Asia (Zhang and Wilmking, 2010), and North America (Anchukaitis et al., 2006). Unfortunately, because of a lack of tree-ring records from the lower mid-latitudes, tropics and southern hemisphere the global extent of divergence is not yet known (D'Arrigo et al., 2008).

\subsubsection{Causes of the divergence problem}

Causes of the divergence problem are not yet understood and are difficult to determine because so many co-varying environmental factors affect tree growth (D'Arrigo et al., 2008). At the individual tree to regional scale, possible causes include: temperature-induced drought stress (e.g. Jacoby and D'Arrigo 1995; Barber et al., 2000; Lloyd and Fastie 2002; Pisaric et al., 2007; McGuire et al., 2010; Porter and Pisaric, 2011), nonlinear thresholds or time-dependent responses to recent warming (e.g. D'Arrigo et al., 2004; Wilmking et al., 2004), delayed snowmelt and related changes in seasonality (Vaganov et al., 1999), differential climate-growth relationships inferred for maximum, minimum and mean temperatures (Wilson and Luckman, 2008), and insect infestation (Youngblut and Luckman, 2012). At the global scale, falling stratospheric ozone concentrations (Briffa et al., 2004) and 'global dimming' (D'Arrigo et al., 2008) 
may play a role. Additionally, dendrochronological methodologies may cause 'endeffect' issues (D'Arrigo et al., 2008) and induce biases (Esper et al., 2005).

The most widely proposed cause of divergence is temperature-induced drought stress. Barber et al., (2000) proposed that increasing temperatures and the resultant lengthening of the growing season can lead to a lack of soil moisture that inhibits tree growth. Barber et al. (2000) concluded that drought stress is likely occurring across the forest-tundra transition zone throughout Northern Hemisphere boreal forests and recent studies have supported this claim (e.g. Lloyd and Bunn, 2007). In another study of white spruce, Lloyd and Fastie (2002) determined that $20^{\text {th }}$ century growth declines were more prevalent in warmer and drier sites implying drought stress. Additionally, Porter and Pisaric (2011) proposed drought stress is a likely cause of divergence because inverse relationships between tree growth and temperatures have been linked to regional changes in moisture (Lloyd and Bunn, 2007). Drought stress has also been proposed to cause divergence of sub-populations. Wilmking et al. (2004) proposed that inter-tree competition for soil moisture can lead to divergence because negative responder trees were more prominent at higher-density upland sites. Sub-population divergence may be due to microsite factors (e.g. slope, aspect, depth to permafrost) that cause some trees to be more drought-stressed than others (Wilmking et al., 2005).

D'Arrigo et al. (2004) proposed that tree growth declines occur once temperatures rise above a tree's optimum growing temperature threshold. Surpassing the threshold leads to a net photosynthetic rate decline, while the respiration rate increases. Updating the D'Arrigo (2004) study, D'Arrigo et al. (2008) developed a nonlinear model to compute optimal average temperatures of $12.4{ }^{\circ} \mathrm{C}$ for July and $10.0{ }^{\circ} \mathrm{C}$ for August for 
white spruce tree growth. These findings led D'Arrigo et al. (2008) to propose that because both of these optimal temperatures were consistently exceeded since the 1960s divergence resulted. Additionally, Wilmking et al. (2004) demonstrated similar optimal temperatures for Alaskan white spruce growth; July air temperatures exceeding $11-12{ }^{\circ} \mathrm{C}$ after 1950 resulted in decreased tree growth. The temperature threshold theory has also been proposed for conifers growing in the Italian Alps (Carrer and Urbinati, 2006; Rossi et al., 2007) and is further discussed by Loehle (2007).

Nonlinear growth responses to increased winter precipitation since the 1960 s were proposed as a cause of divergence in Siberian conifers (Vaganov et al., 1999). Increasing winter precipitation has led to deeper snowpacks that delay snowmelt and tree growth. Snowmelt regulates the seasonal thawing of the upper layer of soil, indirectly controlling the commencement of cambial activity. The supposition is that delayed snowmelt shortens the optimal growing season and results in decreased tree growth (Vaganov et al., 1999). Youngblut and Luckman (2012) propose that snowpack and snowmelt may have caused divergence of trees growing at altitudinal treeline on sites along the southeastern portion of the Canadian Cordillera. In this region, declining winter precipitation has resulted in earlier snowmelt and less soil moisture availability during the period of peak cambial activity. Youngblut and Luckman (2012) report that those changes have resulted in reduced radial growth (Youngblut and Luckman, 2012).

Moreover, divergence may be occurring because some researchers do not include maximum and minimum monthly temperatures in their climate-growth analyses. After detecting divergence between their ring-width and maximum density chronologies with mean temperatures over the $20^{\text {th }}$ century, Wilson and Luckman (2003) hypothesized that 
temperature-limited trees would be more strongly influenced by summer daytime temperatures than nighttime temperatures and developed the first reconstruction of maximum summer temperatures in North America. Importantly, their reconstruction showed no loss of sensitivity or divergence in the recent period. Therefore, in regions where there is a marked difference in trend between nighttime and daytime temperatures, mean temperatures may cause calibration problems in reconstruction development (D'Arrigo et al., 2008). Furthermore, Youngblut and Luckman (2008) developed a tree ring-width based reconstruction model that showed no signs of divergence in the late$20^{\text {th }}$ century. In fact, correlation analysis between their ring-width chronologies and JuneJuly maximum temperatures indicated that temperature sensitivity was stronger during the last 25 years.

In an attempt to develop a global driver of divergence, Briffa et al. (2004) observed that stratospheric ozone concentrations have fallen in the $20^{\text {th }}$ century over most of the land above $40^{\circ} \mathrm{N}$. Briffa et al. (2004) propose that the decrease in stratospheric ozone has possibly resulted in an increase of ultra-violet radiation (UV-B) reaching the earth's surface (Briffa et al., 2004). Because UV-B potentially has a negative effect on the photosynthetic process, an increase in UV-B reaching northern trees may negatively affect tree growth (D'Arrigo et al., 2008). Briffa et al. (2004) correlated ozone data with instrumental temperatures that were highly correlated with maximum latewood density chronologies, and found marginally significant correlations for some northern regions and qualitatively similar trends.

Another potential global scale cause of divergence is global dimming which is defined as "a measured decline in solar radiation reaching the ground, which has been 
observed since the beginning of routine measurements over approximately the past half century" (D'Arrigo et al., 2008, p. 300). Global dimming is occurring due to a combination of more cloud water and aerosols in the atmosphere, reducing incoming solar radiation and effectively reducing the wavelengths critical to photosynthesis and plant growth (Stanhill and Cohen, 2001). The estimated decrease of incoming solar radiation over the $1961-1990$ period is $4-6 \%$ (Stanhill and Cohen, 2001). In the arctic, the reduction of solar radiation reaching the ground is thought to be $3.7 \%$ per decade. If this is true, it could explain why northern trees, particularly trees with short growing seasons, have shown divergence (D'Arrigo et al., 2008).

Methodological choices may also lead to observed divergence (Melvin and Briffa, 2008, Esper and Frank, 2009). In order to remove the age-related trend in a ring-width series, chronologies are usually standardized (Fritts, 1976). Standard detrending methods, such as negative exponential curves and negatively sloped regression lines, do not preserve low-frequency variation for periods longer than the length of a chronology (Melvin and Briffa, 2008). Furthermore, standard detrending may extract some of the low-frequency climate-forcing signal leading to a distortion, or divergence, in the detrended series (Esper and Frank, 2009). This is known as 'trend distortion' and is most common at the end of chronologies (i.e. the late $20^{\text {th }}$ century). Melvin and Briffa (2008) provide a comprehensive discussion of the issue of detrending. More methodological reasons for possible divergence include: biased reconstructions resulting from the choice of calibration technique and interval used (Esper et al., 2005), the time-series smoothing practice performed (Mann, 2004), and differing climate responses of younger vs. older samples (Szeicz and MacDonald, 1994, 1995, 1996). 


\subsubsection{Implications of the divergence problem}

The divergence problem has serious implications for dendroclimatic studies and reconstructions because it may challenge the fundamental principle of uniformitarianism (D’Arrigo et al., 2008). Loehle (2007) developed a mathematical model to show that if trees show a nonlinear growth response, then resulting reconstructions will potentially leave out any historical temperatures higher than those in the calibration period. If trees show nonlinear growth response, the mean and range of reconstructed values compared to actual temperatures would be reduced making it more difficult to make a statement about how recent warming compares to historical periods (Loehle, 2007). However, the divergence problem appears to be confined to the $20^{\text {th }}$ century. Cook et al. (2004) reconstructed Northern Hemisphere land temperatures over the past 1000 years and concluded that divergence is limited and is contained to the recent period. Additionally, multi-proxy studies have only noted a divergence in trend in trees over the recent period indicating that divergence may not have occurred in the past. Nonetheless, the divergence problem makes it more difficult to determine if recent warming is unprecedented (D’Arrigo et al., 2008), and some dendroclimatological reconstructions do not include recent decades in their calibrations, decreasing the opportunities for independent verification (Jacoby et al., 2000; Cook et al., 2004).

\subsection{Dynamics of the treeline response to a warming climate}

While diverging growth trends are apparent in tree-ring chronologies across the northern boreal forest treeline, satellite imagery indicates that regions near and beyond the forest-tundra boundary experienced greater vegetation productivity in response to recent warming (e.g., Bunn and Goetz, 2006; Beck and Goetz, 2011; Beck et al., 2011; 
Berner et al., 2011; Xu et al., 2013). At the same time, these studies observed declining vegetation productivity in warmer regions within forest interiors. A 22-year record (1982-2003) of advanced very high resolution radar satellite observations of high-latitude Northern Hemisphere environments found differing responses to warming temperatures between vegetation types (Bunn and Goetz, 2006). Treeline shrubs and tundra vegetation exhibited increased productivity, while forests of all types exhibited decreased productivity, particularly denser, closed-canopy forested regions (Bunn and Goetz, 2006; Beck and Goetz, 2011). Similar results were found in a study using different satellite indices of productivity. Beck and Goetz (2011) observed that since 1982 tundra vegetation and tundra-margin forests showed consistent growth increases with increasing temperatures. In contrast, interior boreal forested areas showed consistent productivity declines as a result of drought-induced stress.

The differing responses to warming between warmer, closed-canopy forests and colder, more open-canopy forests are also found in tree-ring data (Williams et al., 2011). Lloyd and Bunn (2007) noted that trees growing near the northern boundary of their ecological amplitude showed greater sensitivity to summer temperatures than more southern growing trees. Furthermore, Williams et al. (2011) analyzed 59 white spruce ring-width chronologies from a range of ecological settings in Alaska, noting a positive response to warmer temperatures at colder treeline sites compared to negative responses at warmer closed-canopy sites. In a multi-species tree-ring and satellite index study of the Siberian forest-tundra zone, Lloyd et al. (2011) observed that positive responses to temperature were strongest in northern trees and weakest in southern trees growing in closed-canopy forested regions. The radial growth response to warming has tracked 
normalized difference vegetation indices leading Lloyd et al. (2011) to postulate that the positive radial growth response to rising temperatures indicates increased vegetation productivity at a landscape-scale. 


\section{Chapter Three \\ Study Area and Methods}

\subsection{Study Area}

\subsubsection{Environment of the Study Area}

White spruce trees were sampled for dendroclimatological analysis along a latitudinal gradient centered on Gordon Lake $\left(63^{\circ} 00^{\prime} \mathrm{N} 113^{\circ} 10^{\prime} \mathrm{W}\right.$; Table 3.1$)$ in 2010 2011 (Fig. 3.1). The study area ranges over two ecoregions of the Taiga Shield: the Great Slave Upland Low Subarctic Ecoregion (GSU LS), and the Great Slave Upland High Boreal Ecoregion (GSU HB; Ecosystem Classification Group, 2008). Nine of the 10 sites are situated in the GSU LS ecoregion which is underlain by widespread permafrost with peat plateaus and low-growing white and black spruce forests with lichen and shrub understories. The GSU LS has three common types of white/black spruce stands: (i) widely interspersed white and black spruce trees growing on outcrops; (ii) densely populated white and black spruce woodlands found on till veneers; and, (iii) white spruce woodlands growing on moderately drained outwash. Jack pine stands are also found growing in the southern portion of the GSU LS. Exposed sedimentary bedrock is prominent throughout the region, which has a topographic makeup ranging from "gently rolling hills and hummocky terrain to rugged local hill systems" (Ecosystem Classification Group, 2008, p. 52). The soils in the area are primarily well-drained brunisols above stony, non-calcareous sandy loam overlying loamy sand till. Organic deposits are also found interspersed sporadically in the region.

The northern boundary of the GSU LS is approximately at treeline in the zone of transition from boreal woodland to forest tundra and finally to tundra. The position of treeline is largely controlled by climate, with treeline highly correlated with the 
Table 3.1 White spruce tree-ring sampling location information.

\begin{tabular}{cccccc}
\hline Site Name & Latitude $\left(^{\circ}\right) \mathbf{N}$ & Longitude $\left(^{\circ}\right) \mathbf{W}$ & $\begin{array}{c}\text { Elevation } \\
(\mathbf{m} \text { a.s.l.) }\end{array}$ & $\begin{array}{c}\text { Number of } \\
\text { series }\end{array}$ & $\begin{array}{c}\text { Duration } \\
\text { (years CE) }\end{array}$ \\
\hline YEL1 & $63^{\circ} 15^{\prime} 42.94^{\prime \prime}$ & $112^{\circ} 38^{\prime} 13.17^{\prime \prime}$ & 428 & 54 & $1804-2009$ \\
YEL2 & $63^{\circ} 10^{\prime} 26.21^{\prime \prime}$ & $113^{\circ} 07^{\prime} 41.56^{\prime \prime}$ & 300 & 56 & $1643-2009$ \\
YEL3 & $63^{\circ} 14^{\prime} 04.30^{\prime \prime}$ & $112^{\circ} 51^{\prime} 15.02^{\prime \prime}$ & 367 & 28 & $1651-2009$ \\
YEL4 & $62^{\circ} 56^{\prime} 49.40^{\prime \prime}$ & $113^{\circ} 15^{\prime} 50.30^{\prime \prime}$ & 294 & 60 & $1744-2009$ \\
YEL5 & $62^{\circ} 59^{\prime} 40.57^{\prime \prime}$ & $113^{\circ} 14^{\prime} 53.12^{\prime \prime}$ & 294 & 44 & $1773-2009$ \\
YEL6 & $63^{\circ} 02^{\prime} 40.00^{\prime \prime}$ & $113^{\circ} 10^{\prime} 44.70^{\prime \prime}$ & 300 & 68 & $1694-2009$ \\
YEL7 & $63^{\circ} 07^{\prime} 49.91^{\prime \prime}$ & $113^{\circ} 08^{\prime} 57.13^{\prime \prime}$ & 297 & 58 & $1678-2009$ \\
YEL8 & $62^{\circ} 42^{\prime} 17.02^{\prime \prime}$ & $113^{\circ} 50^{\prime} 37.81^{\prime \prime}$ & 268 & 44 & $1748-2009$ \\
BLK1 & $63^{\circ} 24^{\prime} 48.03^{\prime \prime}$ & $112^{\circ} 44^{\prime} 08.04^{\prime \prime}$ & 392 & 21 & $1804-2009$ \\
DRY1 & $63^{\circ} 22^{\prime} 06.34^{\prime \prime}$ & $112^{\circ} 35^{\prime} 07.51^{\prime \prime}$ & 401 & 24 & $1795-2009$ \\
\hline
\end{tabular}




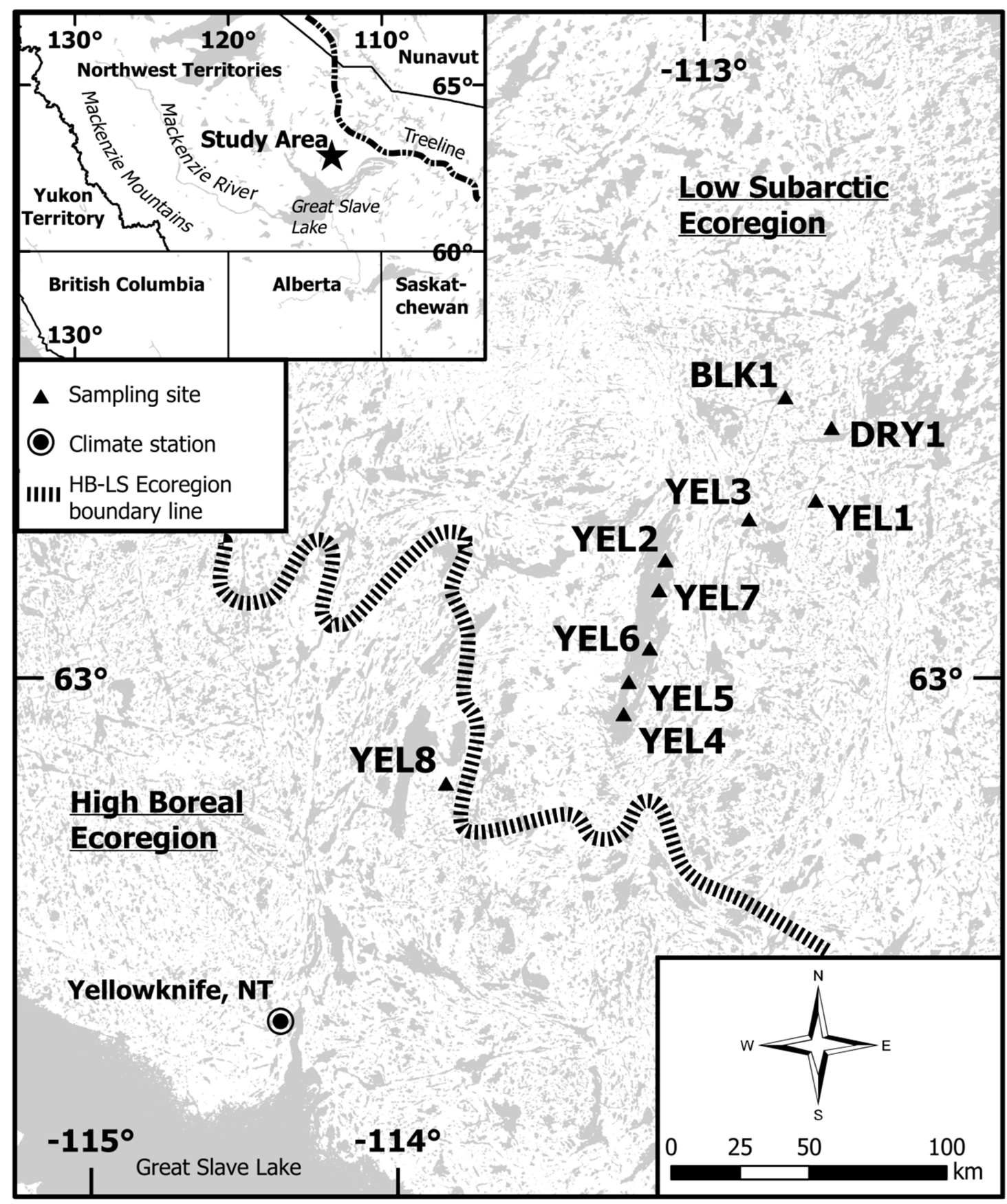

Figure 3.1 Location of the ten white spruce sampling sites and Yellowknife, NT climate station. 
$10{ }^{\circ} \mathrm{C}$ isotherm of the warmest month (Payette et al., 1989). It also corresponds roughly with the summer position of the arctic front, separating dry, cold arctic air masses and warm, moist southern air masses (Bryson, 1966).

Further south, the GSU HB Ecoregion has a warmer climate and is less varied in topography (Ecosystem Classification Group, 2008). The GSU HB is underlain by discontinuous permafrost with rock outcrops covered in many areas by a thin veneer of till. Ground vegetation in the HB ecoregion is dominated by lichens and moss, and the area has forests that are open subarctic woodlands dominated by black spruce, white spruce, tamarack (Larix laricina) white birch (Betula papyrifera), and jack pine. The geological makeup of the GSU HB is Precambrian sedimentary rock as well as fractured and dissected granite. Glacial Lake McConnell left many features such as wave-washed tills, variable-textured glaciolacustrine sediments and glaciofluvial material as thin, discontinuous deposits between rock outcrops and in fractures. Brunisolic soils are found on glacial deposits between bedrock exposures and in fractures. Organic cryosols are found with peat plateaus and organic soils and gleysols are found in wet depressions with shore fens and floating fens.

\subsubsection{Climate}

The nearest meteorological station is Yellowknife Airport and is located $100 \mathrm{~km}$

southwest of the study area with an instrumental record that extends back to 1942 (Environment Canada, 2012). The study area is characterised by short, cool summers and long, cold winters (Fig. 3.2) with a mean annual temperature of $-4.3{ }^{\circ} \mathrm{C}$, mean January temperature of $-26.5{ }^{\circ} \mathrm{C}$, and mean July temperature of $16.8{ }^{\circ} \mathrm{C}$ (1971-2000; Environment Canada, 2012). The area has experienced significant warming since the 
1940s (Fig. 3.3). The greatest warming occurred during the winter months (DecemberFebruary) where mean winter temperatures rose from an average of $-26.0^{\circ} \mathrm{C}$ for $1943-$ 1976 to an average of $-23.3{ }^{\circ} \mathrm{C}$ for $1977-2009$. Moreover, mean temperatures in the spring (March-May), summer (June-August), and fall (September-November) have also increased by $1.4{ }^{\circ} \mathrm{C}, 0.5^{\circ} \mathrm{C}$, and $0.5^{\circ} \mathrm{C}$, respectively (mean temperature for $1943-1976$ vs. mean temperature for 1977-2009). Notably, increasing summer temperatures occurred for both of the months of June and July where mean temperatures were $0.7{ }^{\circ} \mathrm{C}$ warmer for 1977-2009 than for 1943-1976, while August mean temperatures did not change.

The mean annual precipitation at Yellowknife, NT is $364 \mathrm{~mm}(1971-2000)$, with half of the precipitation falling as rain and the other half as snow (Environment Canada, 2012). Late winter and spring months are characterized by relatively dry conditions with all months between February and May experiencing an average of $25 \mathrm{~mm}$ of precipitation or less. The late summer and fall months are relatively wet; months spanning JulyNovember each experience $>40 \mathrm{~mm}$ of precipitation. The summer (June-August) and fall seasons (September-November) have much greater year-to-year variability in precipitation than winter and spring (March-May) seasons (Fig. 3.4). Precipitation at Yellowknife, NT has increased since 1943, with mean annual precipitation increasing from $322.6 \mathrm{~mm}$ for $1943-1976$ to $376.5 \mathrm{~mm}$ for the 1977-2009 period. June and July precipitation increased markedly: mean June precipitation was $10.5 \mathrm{~mm}$ greater for the later period and July precipitation increased by $5.6 \mathrm{~mm}$. 


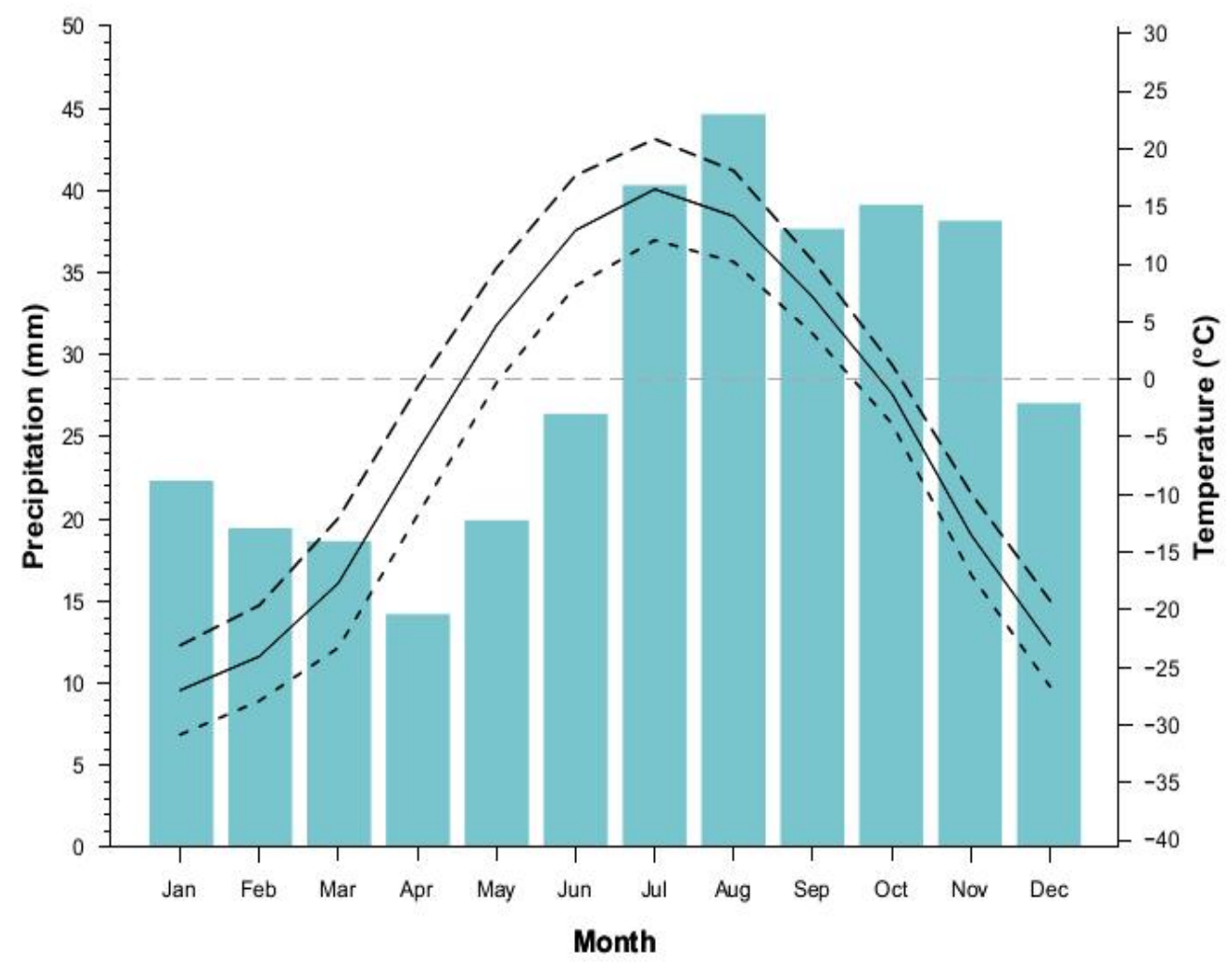

Figure 3.2 Mean monthly precipitation (grey bars) with minimum (short dashed line), mean (solid line), and maximum (long dashed line) monthly temperatures for the Yellowknife, NT climate station 1971-2000 (Environment Canada, 2012). 

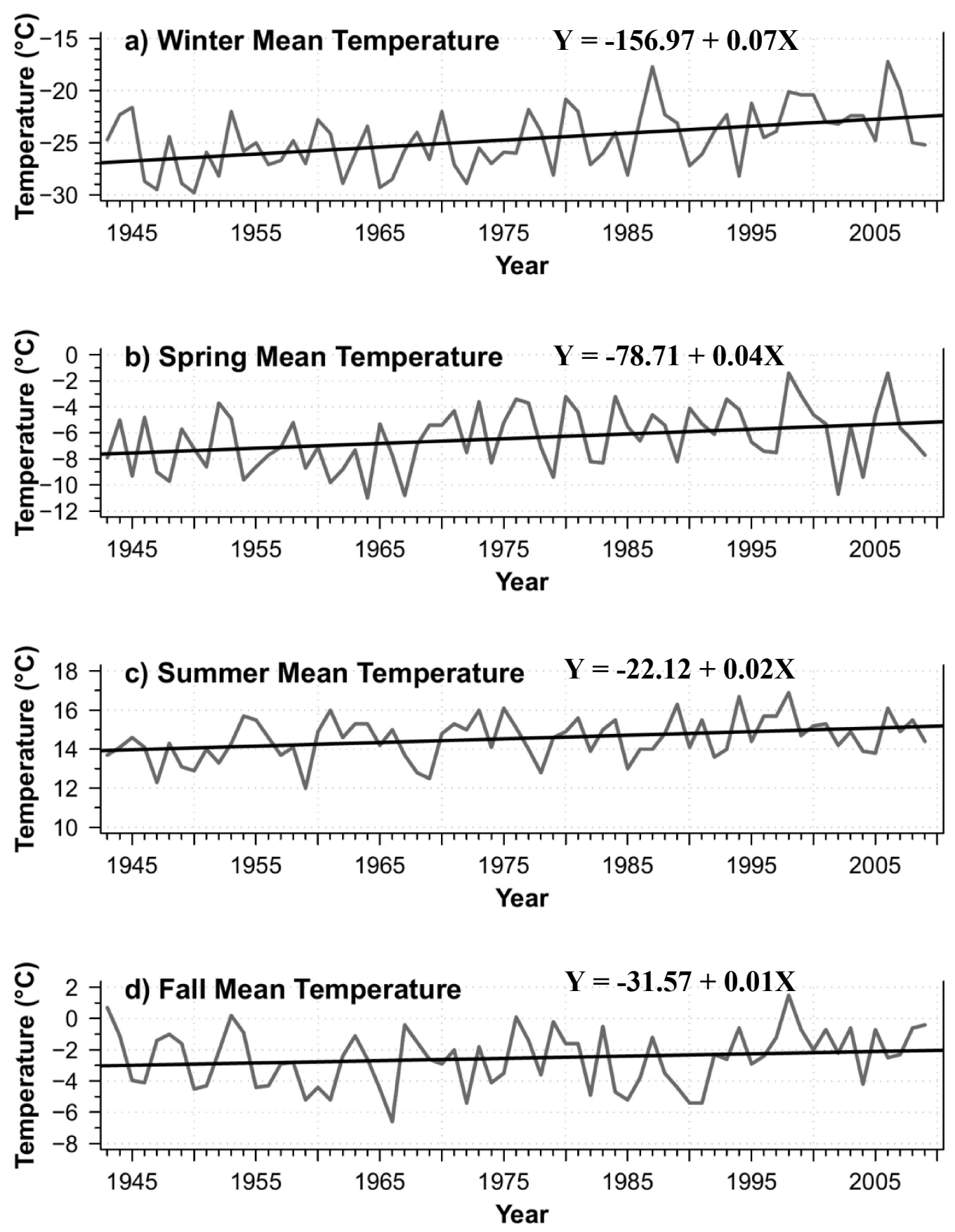

Figure 3.3 Winter (Dec-Feb), spring (Mar-May), summer (Jun-Aug), and fall (Sep-Nov) mean seasonal temperatures (grey lines) and linear trendlines (black lines) for the Yellowknife, NT climate station (1943-2009; Environment Canada, 2012). 

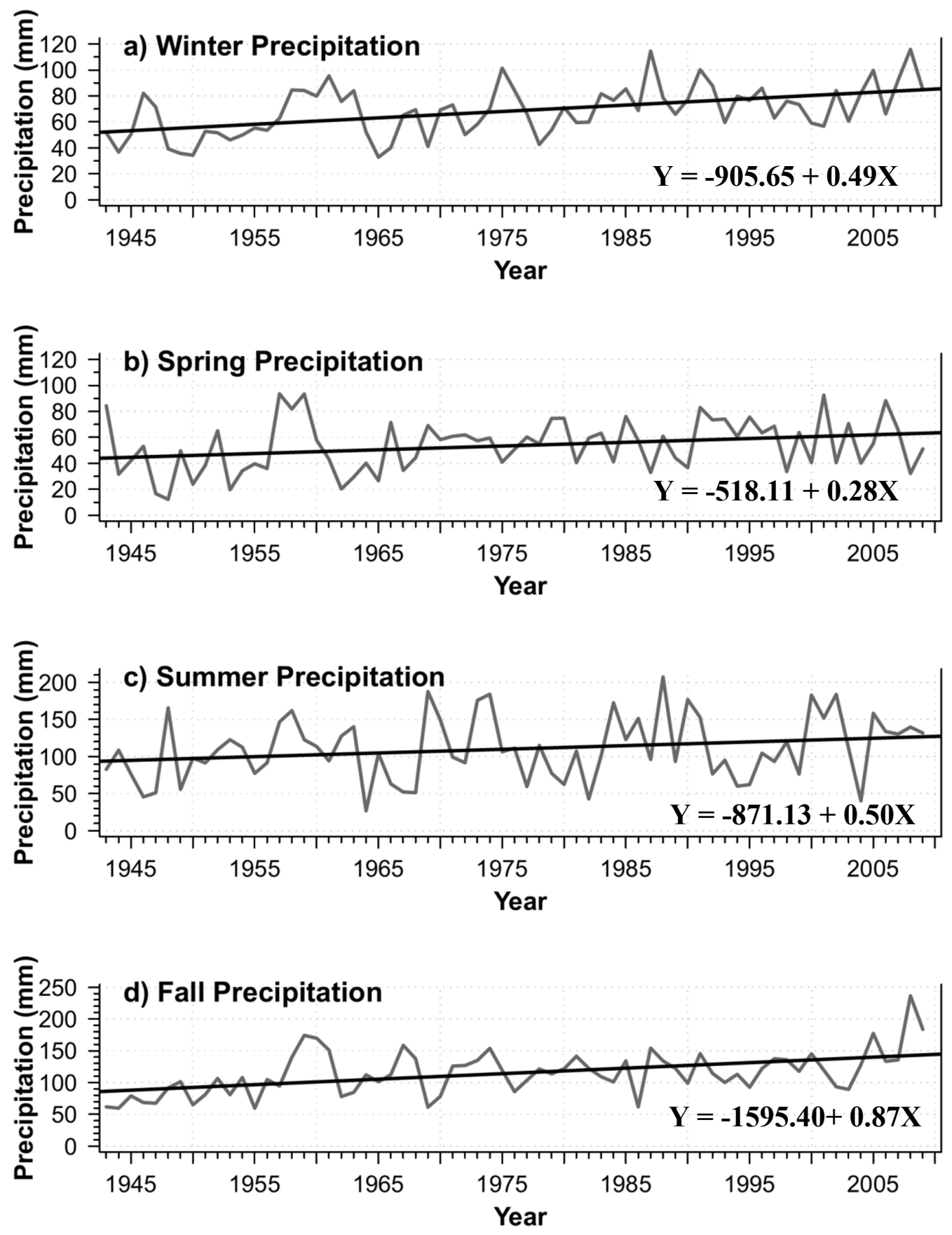

Figure 3.4 Winter (Dec-Feb), spring (Mar-May), summer (Jun-Aug), and fall (Sep-Nov) total seasonal precipitation (grey lines) and linear trendlines (black lines) for the Yellowknife, NT climate station (1943-2009; Environment Canada, 2012). 


\subsection{Site Characteristics}

The study site locations extend from the interior boreal forest at YEL8 (6242'17'” $\left.\mathrm{N}, 113^{\circ} 50^{\prime} 38^{\prime \prime} \mathrm{W}\right)$ almost to the treeline at BLK1 $\left(63^{\circ} 24^{\prime} 48^{\prime \prime} \mathrm{N}, 112^{\circ} 45^{\prime} 04^{\prime \prime} \mathrm{W}\right.$; Fig. 3.1). The topography of the area is generally flat with low-elevation hills and rock outcrops (200-430 m a.s.1.). The area has hundreds of small lakes varying in size from smaller than $1 \mathrm{~km}^{2}$ to larger than $100 \mathrm{~km}^{2}$. YEL8 is the southernmost site and is situated within the GSU HB ecoregion (Ecosystem Classification Group, 2008) with a mix of white spruce and jack pine trees. The nine other sampled sites are within the GSU LS ecoregion with five of the sites located on separate islands in Gordon Lake. The forest cover on the five island sites and YEL3 is primarily comprised of widely spaced white spruce growing on rock outcrops in thin well-drained soil. YEL1, BLK1, and DRY1 consist of young stands of white spruce growing in moderately drained thick soil conditions. The trees at these sites were small in size, in good health, and were found on flat topography with gentle slopes and few exposed rock faces and outcrops.

\subsection{Field Methods}

Site selection focused on identifying sites where tree growth was not limited by local topography or geomorphology (e.g. steep and rocky slopes, hummocky bogs) to maximize the climate sensitivity of the trees ( $c f$. Elliott, 2010). In addition, study sites were selected a priori through analysis of satellite imagery to exclude the influence of disturbances (i.e. fire history) that could limit sample depth and also reduce the climatic information contained in the tree-ring series. In the NT, areas with denser canopies largely have a more recent fire history and appear greener in satellite imagery, while 
older, open-canopied regions have a light brown colour and typically have a more distant fire history (Ecosystem Classification Group, 2008).

Sampling followed recommendations proposed to minimize the potential effects of the divergence problem (Wilson et al., 2007; Büntgen et al., 2008a; D'Arrigo et al., 2008. A sample size of thirty or more trees was chosen based on recommendations by Büntgen et al. (2008a) to increase the number of trees sampled at sites from the traditional dendroclimatological sample size of 15-20. Furthermore, larger sample sizes have been shown to have a pronounced effect on improving the statistical confidence of climate-growth analysis (Mäkinen and Vanninen, 1999).

At individual sites, trees were selected for sampling using a modified targeted sampling method to maximize the length of the tree record and minimize non-climatic ring-width variability. Targeted sampling, used in nearly all subdisciplines of dendrochronology, is a method in which trees are selected based on old age, lack of rot, lack of fire wind damage, sensitive location, and accessibility (Speer, 2010). In the field, old age was assessed using several physical characteristics including, large trunk and limb diameter, gnarled or knotty in shape and structure, cropped tops and/or spiked tops, and growing in high stress ground conditions. Younger trees were also sampled in order to avoid sub-population biases (Esper et al., 2007). Particular attention was taken to locate and sample dead white spruce trees to extend the tree-ring series beyond the living record.

The majority of the samples were taken from trees using a chainsaw (at approximately $90^{\circ}$ to the tree trunk) with the intention of sampling at a height of $0.5 \mathrm{~m}$ above ground-level. This sampling technique provides one complete horizontal transect 
for each tree and guarantees that the sample length is maximized because the pith is present in each sample. The living trees were disked at $0.5 \mathrm{~m}$ above the ground to limit the distortion (i.e. missing and pinched rings) that occurs near branches or the base of the tree (Fritts, 1976). A height of $0.5 \mathrm{~m}$ from the base was estimated for dead samples. Sampling height did vary due to the limited accessibility to some trees and due the presence of knots or rotting sections at $0.5 \mathrm{~m}$ height. Each sample was labeled with site location, species name, and a sample number. Fragile disks were duct taped to protect them during transport back to the laboratory.

\subsection{Laboratory Methods}

Once the tree samples were transported back to the Carleton University Paleoecology Laboratory (CUPL), they were dried, sanded, crossdated, and measured using standard dendrochronological techniques (Fritts, 1976; Speer, 2010). At the CUPL, disks were air-dried to prepare for sanding. Dried samples were progressively sanded to 400 grit with a belt sander to clarify ring boundaries for accurate dating and measurement of ring-widths as recommended by Fritts (1976) and Speer (2010). Particular attention was taken to ensure that the samples were sanded with the tracheids perpendicular to the polished surface area. Vertical alignment of tracheids ensures that individual cells can be seen once the surface of the sample is prepared.

To ensure the proper dating of the tree-rings, both visual and statistical crossdating was performed. Rings were counted by marking the outermost complete ring on each sample with the absolute year '2009' and marking every decade, half-century, and century with a pencil. Marker rings (i.e. disproportionately small rings) were recorded using the list method explained in Yamaguchi (1991). When two transects from 
the same sample had different marker rings, the crossdating process was restarted to find the error. Once proper dating was complete, ring-widths were measured to a precision of $0.001 \mathrm{~mm}$ using a Velmex Unislide sliding bench micrometer interfaced with a computer. For each sample, two bark to pith measurements (known as radii) were taken and the ring-width data was entered into the program Measure J2X (Voortech Consulting, 2007).

Once radii measurements were performed, the computer program COFECHA was used to assess both the crossdating and the accuracy of the measurements (Holmes, 1983). COFECHA calculates correlation coefficients between individual ring-width series and a master site chronology to see if the ring-width measurements match across the site. Correlation coefficients of each measured radii and the site master chronology were calculated over 50-year segments lagged by 25 years. Segments where the correlation between the individual ring-width series and the site master chronology fell below $r=0.3281$ were flagged by COFECHA. If a segment was flagged, the period with possible measurement or dating error was determined and then reassessed under the microscope to see if an error was made during crossdating and measurement. If a measured sample did not significantly correlate with the site chronology and no error in measurement could be determined, it was not included in the site chronology because its growth was determined to be regulated by tree specific rather than stand-wide factors.

\subsection{Standardization}

After the samples from each site were properly measured and crossdated, dimensionless 'standardized' site chronologies were developed to remove age-related growth trends and to eliminate possible biases in the site chronology caused by disproportionally fast-growing trees (Fritts, 1976). Standard 'conservative' approaches 
have been shown to bias the removal of 'non-climate' variance, which distorts the external forcing signal in tree-ring chronologies (Melvin, 2004; D’Arrigo et al., 2008). To overcome this bias, the measured and cross-dated ring-width series from each tree were detrended and standardized using the 'signal-free' regional curve standardization (RCS) methodology (Melvin and Briffa, 2008). The 'signal-free' method of detrending was developed by Melvin (2004) and sequentially removes the estimated common variance from the individual chronology (Anchukaitis et al., 2013). Once this common variance is removed, the development of the site chronology is thought to retain the common climate signal. A more comprehensive and detailed description of 'signal-free' standardization can be found in Melvin and Briffa (2008).

Each of the 'signal-free' RCS site chronologies were calculated using the program TOMB, which is a beta version of the detrending computer program ARSTAN developed by Ed Cook (courtesy of Trevor Porter, personal communication). TOMB first determined the growth curve by calculating the bi-weight robust mean for each ringwidth of a given age. The growth curve can be thought of as the expected growth for a tree at any given age (Briffa and Melvin, 2008). TOMB then calculated a 'first' chronology for each sample by dividing the measured ring-widths with the growth curve to develop a standardized ring-width index value. In the next step, the original measurement value was divided by the 'first' chronology value for that year to calculate the first 'signal-free' chronology. This process was repeated on the first 'signal-free' chronology instead of the 'first' chronology and further repeated until the point where variance in the 'signal-free' chronology was virtually zero. Generally, this took four or five iterations to achieve. In order to study the high-frequency variability of the tree- 
rings, residual chronologies were also calculated in TOMB. Residual chronologies are detrended chronologies with the serial autocorrelation removed.

\subsection{Climate Data}

Climate-growth analysis was undertaken using adjusted precipitation and homogenized temperature records from the Yellowknife, NT climate station (ID\# 2204100) downloaded from the Adjusted Historical Canadian Climate Data (AHCCD; http://ec.gc.ca/dccha-ahccd). These records are developed by the Meteorological Services of Canada (Vincent, 1998; Vincent et al., 2012), and are superior to direct instrumental records because they have been corrected for inhomogeneities and missing data (Vincent, 1998). The Yellowknife, NT records were used because it is the closest weather station and has a complete climate record from 1943 to present. Mean monthly temperature and total monthly precipitation were used in the climate-growth analysis.

Gridded temperature and precipitation data downloaded from the KNMI Climate Explorer website (http://climexp.knmi.nl) was also used in the climate-growth analysis. The gridded monthly mean temperature record used in the analysis is for grid point $62^{\circ} 30^{\prime} \mathrm{N} 112^{\circ} 30^{\prime} \mathrm{W}$ of the CRUTEM4 data set (Jones et al., 2012) and extends from 1913 to 2009 . The gridded total monthly precipitation record used is for grid point $62^{\circ} 30^{\prime}$ N 112 $30^{\prime}$ ' $\mathrm{W}$ of the CRUTEM3 data set (Brohan et al., 2006) and extends from 1901 to 2004. Both of these data sets have a resolution of $0.5^{\circ} \times 0.5^{\circ}$.

Palmer Drought Severity Index (PDSI) data was used in the climate-growth analysis. PDSI is widely used in dendroclimatological studies across the globe (Davi et al., 2010), and along the North American treeline (Cook et al., 2004). Derived using precipitation, temperature, and soil moisture measurements, PDSI is a metric of moisture 
deficit compared to local soil conditions (Palmer, 1965). The PDSI data used in this study are a seasonal average for the months of June, July, and August at the three nearest PDSI data grid points $(62,77$, and 93$)$ from 1901 to 1990 . PDSI data range from +6 and -6 . Positive values indicate wet conditions and negative values indicate drought conditions. Instrumental and reconstructed PDSI data were obtained from North American Drought Atlas website (http://iridl.ldeo.columbia.edu/SOURCES/.LDEO/ .TRL/.NADA2004/.pdsi-atlas.html). Of note, results using PDSI data for the area predating the 1940s need to be interpreted with caution, because many meteorological stations (e.g. Yellowknife Airport) were not established until the early-mid $20^{\text {th }}$ century.

\subsection{Analytical Methods}

\subsubsection{Mean Sensitivity Statistic}

The mean sensitivity statistic quantifies the environmental stress experienced by trees (Strackee and Jansma, 1992). Mean sensitivity quantifies interannual variability in ring-width for a sample by measuring relative differences in width from one ring to the next (Fritts, 1976). Greater mean sensitivity values indicate strong year-to-year variability and a more climatically sensitive series (Fritts, 1976). A chronology is characterized as sensitive if it has a mean sensitivity greater than 0.3 , moderately sensitive if it has a value between 0.2-0.3, and complacent if it has a value less than 0.2 (Cremer, 1977). Importantly, a complacent series may not show strong year-to-year variability, but may still be sensitive to low-frequency climate variation (Fritts, 1976).

\subsubsection{First Order Autocorrelation}

First order autocorrelation (AC1) is the correlation between successive values in a time series that reflects low-frequency variations within that series (Burt et al., 2009). A 
series with a high $\mathrm{AC} 1$ value indicate a persistence caused by the influence of factors from the previous year. In general, chronologies with lower AC1 are more desirable for climate studies (Speer, 2010).

\subsubsection{Expressed Population Signal}

Wigley et al. (1984) developed the Expressed Population Signal (EPS) statistic to evaluate how signal strength decreases as the number of series decreases. Further developed by Briffa and Jones (1990), the EPS statistic has become standard practice in dendroclimatology. The EPS statistic measures changes in signal strength when sample depth changes by quantifying how much a measured site chronology depicts a hypothetically 'perfect' chronology. It achieves this by dividing the signal by the total variance (signal + noise; Briffa and Jones, 1990). It is defined as:

$$
\operatorname{EPS}(t)=\frac{t \bar{r}_{b t}}{t \bar{r}_{b t}+\left(1-\bar{r}_{b t}\right)}
$$

Where $t$ is the number of tree-ring series averaged and $t \bar{r}_{b t}$ the mean between-tree $(b t)$ correlation (Wigley et al., 1984; Briffa and Jones, 1990). When calculated iteratively, a moving EPS approach can help pin-point signal quality for different intervals of a chronology. Given that signal strength is related to sample depth, EPS will decrease as sample depth decreases, between-tree correlation decreases, or both decrease.

Expressed population signal values were calculated for 50-year moving interval segments lagged by 10 years starting from the final year of the chronology. For example, the EPS calculations were made for the periods 1960-2009, 1950-1999, 1940-1989, etc. Standard dendroclimatological practice uses an EPS value of 0.85 as the lower limit for signal acceptance (Wigley et al., 1984) and this cutoff is used in this study. The last year 
of acceptable signal strength was determined to be the central year of the first 50 year interval with EPS $<0.85$ (Wigley et al., 1984).

\subsubsection{Correlation Analysis}

Correlation analysis is a useful first step in determining the relationship between site chronologies as well as the relationship between radial growth and climatic variables (e.g. Porter and Pisaric, 2011). Throughout this thesis, correlations are frequently discussed and, unless otherwise stated, refer to Pearson's product-moment correlation. The correlation coefficient $(r)$ describes the relationship between two variables with values that range between -1 and 1 (Burt et al., 2009). A value of 1 represents a perfect linear relationship, a value of -1 represents a perfect negative relationship, and a value of 0 represents no statistical relationship between the two variables (Burt et al., 2009). Correlation coefficients were deemed statistically significant if they had a $\mathrm{p} \leq 0.05$ based on Student's $t$-test.

\subsubsection{Moving Correlation Analysis}

To test the time-stability of the climate-growth relationships, moving window interval correlation analysis was performed using DENDROCLIM2002 (Biondi and Waikul, 2004). DENDROCLIM2002 works by correlating a tree-ring chronology and monthly climate data by iteratively calculating correlations for moving intervals. In this study, the length of the moving window used was 32 years and windows were progressively shifted forward in time by one year. For example, the correlation coefficient was calculated for the interval 1943-1974, 1944-1975, 1945-1976 and so on

until the last year of the interval is the last year of the variables being tested. A second type of analysis performed by DENDROCLIM2002 is evolutionary moving interval 
analysis. This type of interval analysis progressively increases the length of the moving interval by one year, but does not shift the first year of the window. For example, a forward evolutionary analysis would calculate correlations for 1943-1974, 1943-1975, 1943-1976 and so on until the last year of analysis.

\subsubsection{Pointer Year Analysis}

Tree-rings from a chronology or a collection of chronologies that are particularly thin or wide are termed 'pointer years' (Schweingruber et al., 1990). Pointer years are useful to decipher local and regional climatic influences on tree growth and can be consistent over wide geographical areas (Briffa et al., 1998b; Neuwirth et al., 2007; Génova, 2012). To determine pointer years many approaches have been used successfully (cf. Schweingruber et al., 1990; Neuwirth et al., 2007; Elferts, 2007; Génova, 2012). The method used in this study was originally presented by Schweingruber et al. (1990) and successfully reapplied by Wilson (1999). Pointer years were defined on the basis of treering index values greater than 1.0 standard deviation away from the residual chronology mean.

\subsubsection{Principal Component Analysis}

Since correlation analysis is not able to quantitatively identify similar groupings within the network of site chronologies, principal component analysis (PCA) was used in this study. When analyzing a data set with a large number of interrelated variables, PCA can be used to reduce the data set's dimensionality (Jackson, 1991). The central purpose of PCA is to reduce the dimensionality, while maintaining the variation contained within the data set (Joliffe, 1986). This is achieved by transforming the original data set into a new set of variables called principal components. The principal components are 
uncorrelated and ordered so that the first few retain most of the variation present in the original data set. PCA takes occurrences that are not directly observable and identifies groups of variables that are interrelated (Jackson, 1991). In order to do this, PCA assumes that observed (manifest) variables are correlated with a small number of underlying phenomena, which cannot be measured directly (latent variables; Burstyn, 2004). Statistically speaking, the observed correlation matrix is used to make inferences about the identities of any latent variables. Burstyn (2004) defines PCA as an "automated and systematic examination of correlations among manifest variables, aimed at identifying underlying latent principal components" (p. 656). This outlines why PCA is a proper method to use when analyzing a network of 10 site chronologies because it can determine chronologies that have a common, likely climate related, signal.

Principal component analysis was undertaken in the open-sourced program $\mathrm{R}$ using the principal function included in the psych package. The statistical significance of the components was computed using parallel analysis with the faparallel function. Parallel analysis is an efficient and robust means for determining the number of principal components to retain for further analysis and interpretation when de-composing a correlation matrix (Jackson, 1991). Parallel analysis is a way to determine the number of significant components by comparing the solution to random data with the same properties as the real data set. fa.parallel also includes random samples from the real data, as well as normally distributed random data with the same number of subjects and variables. 


\section{Chapter Four}

\section{Results}

\subsection{Assessment of Descriptive Chronology Statistics}

The sites are situated in a range of ecological settings and some chronologies likely have a stronger climate signal than others. This section assesses the quality of the chronologies and intends to help determine which chronologies are best suited for climate-growth analysis. The statistics presented in this section are: chronology length, mean series correlation, mean ring-width measurement, standard deviation and coefficient of variation, mean sensitivity, and first order autocorrelation.

\subsubsection{Chronology Length}

Summary chronology statistics are presented in Table 4.1 and signal-free standardized chronologies are presented in Fig. 4.1. Four site chronologies are greater than 300 years in length: YEL2, YEL3, YEL6, and YEL7. YEL2 is the longest chronology at 366 years, while YEL1 and BLK1 are the shortest chronologies at 205 years. The common period of all chronologies is 1804-2009 with an average site chronology length of 168.5 years and an average series length of 173.7 years.

\subsubsection{Mean series correlation}

The mean series correlation (MSC) is a description of the strength of the common signal in a chronology calculated by averaging internal correlations for all series in the chronology (Holmes, 1986). A chronology with low MSC requires a greater sample size to maintain reliability than a chronology with a stronger common signal. The MSC for the chronologies is 0.553 (median $=0.552$ ), ranging from 0.515 (YEL8) to 0.590 (YEL2). None of the chronologies have an MSC greater than 0.600 which suggests any highfrequency signals may not be common across the network. Nonetheless, these MSC 
Table 4.1 Chronology statistics.

\begin{tabular}{ccccccccccc}
\hline $\begin{array}{c}\text { Site } \\
\text { Name }\end{array}$ & $\begin{array}{c}\text { Chronology } \\
\text { Length } \\
\text { (yrs) }\end{array}$ & $\begin{array}{c}\text { Number } \\
\text { of } \\
\text { Measured } \\
\text { trees }\end{array}$ & $\begin{array}{c}\text { Number } \\
\text { of radii }\end{array}$ & $\begin{array}{c}\text { Mean } \\
\text { sample } \\
\text { length } \\
\text { (yrs) }\end{array}$ & $\begin{array}{c}\text { Mean } \\
\text { series } \\
\text { correlation }\end{array}$ & $\begin{array}{c}\text { Mean ring- } \\
\text { width (mm) }\end{array}$ & $\begin{array}{c}\text { Standard } \\
\text { Deviation }\end{array}$ & $\begin{array}{c}\text { Coefficient } \\
\text { of Variation }\end{array}$ & $\begin{array}{c}\text { Mean- } \\
\text { sensitivity }\end{array}$ & $\begin{array}{c}\text { Auto- } \\
\text { correlation }\end{array}$ \\
\hline YEL1 & 205 & 27 & 54 & 154.9 & 0.587 & 0.341 & 0.179 & 0.526 & 0.182 \\
YEL2 & 366 & 28 & 56 & 169.4 & 0.590 & 0.256 & 0.141 & 0.542 & 0.238 & 0.852 \\
YEL3 & 359 & 28 & 28 & 180.6 & 0.556 & 0.301 & 0.168 & 0.560 & 0.191 & 0.850 \\
YEL4 & 265 & 30 & 60 & 168.2 & 0.557 & 0.318 & 0.215 & 0.672 & 0.184 & 0.915 \\
YEL5 & 236 & 22 & 44 & 174.9 & 0.530 & 0.327 & 0.189 & 0.573 & 0.181 & 0.890 \\
YEL6 & 315 & 34 & 68 & 192.3 & 0.582 & 0.284 & 0.143 & 0.511 & 0.228 & 0.765 \\
YEL7 & 331 & 29 & 58 & 202.2 & 0.525 & 0.259 & 0.126 & 0.485 & 0.189 & 0.843 \\
YEL8 & 261 & 22 & 44 & 181.7 & 0.515 & 0.321 & 0.187 & 0.584 & 0.180 & 0.875 \\
BLK1 & 205 & 21 & 21 & 127.3 & 0.541 & 0.446 & 0.211 & 0.480 & 0.163 & 0.872 \\
DRY1 & 214 & 24 & 24 & 133.4 & 0.547 & 0.359 & 0.170 & 0.472 & 0.186 & 0.833 \\
\hline & & & Mean: & 168.5 & 0.553 & 0.321 & 0.173 & 0.540 & 0.192 & 0.848 \\
& & & Median: & 172.2 & 0.552 & 0.320 & 0.175 & 0.534 & 0.185
\end{tabular}



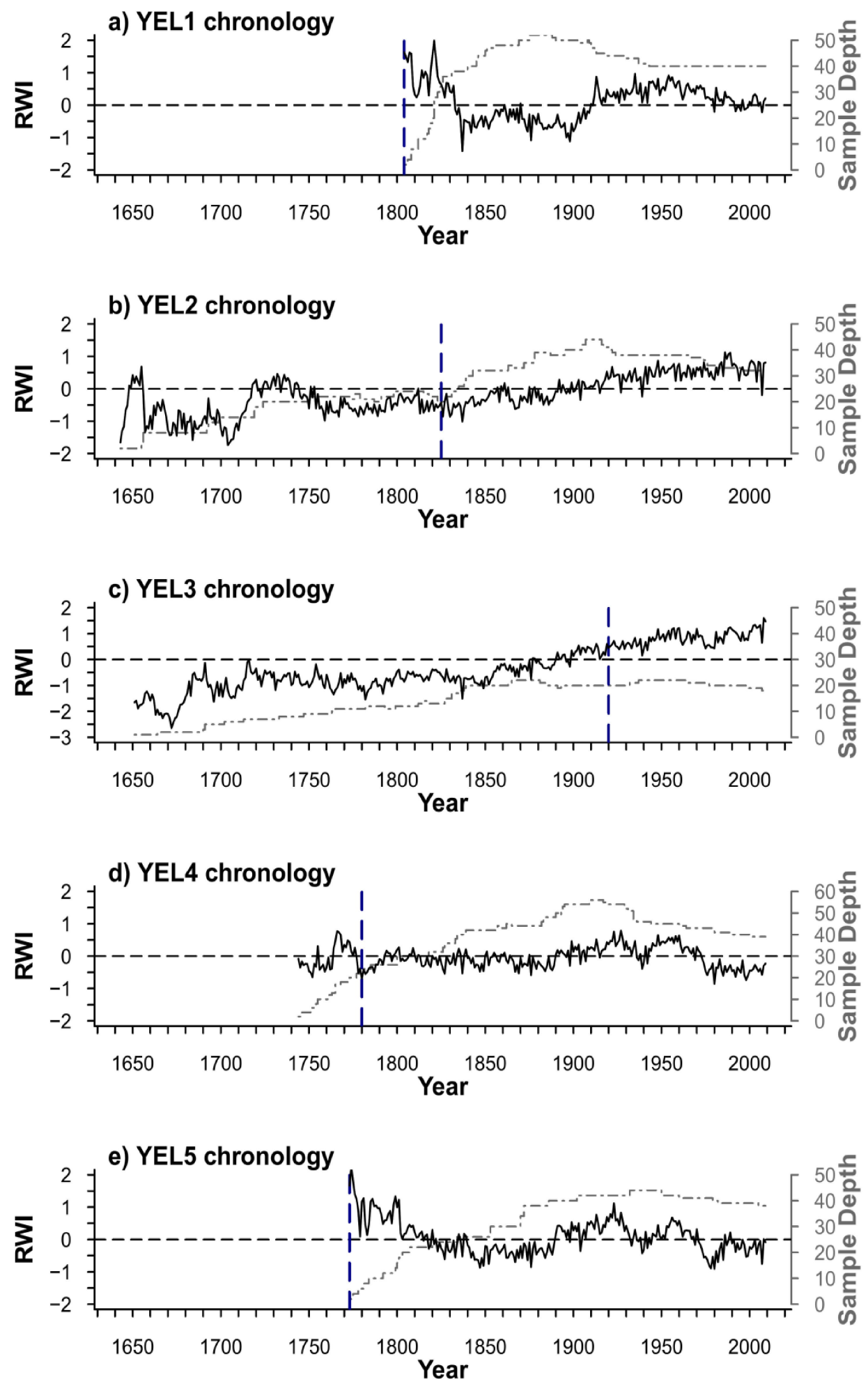

Figure 4.1 Signal-free standardized chronologies (black) plotted with sample depth (grey dashes). Sample depth refers to the number of radii used to develop the site chronology for that year. EPS $<0.85$ cutoff years are presented with a vertical dashed line. 

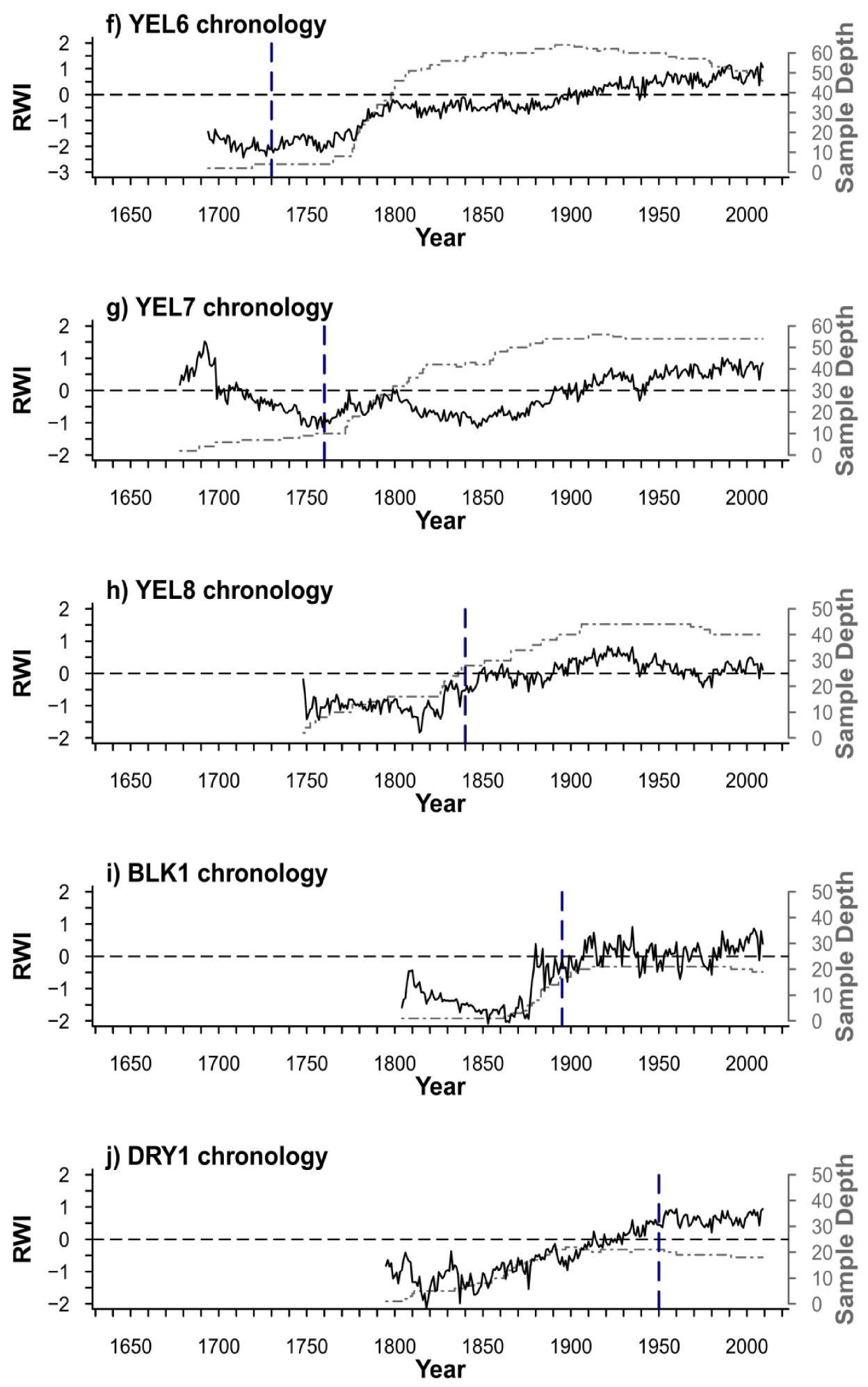

Figure 4.1 (con't.) Signal-free standardized chronologies (black) plotted with sample depth (grey dashes). Sample depth refers to the number of radii used to develop the site chronology for that year. EPS $<0.85$ cutoff years are presented with a vertical dashed line. 
values are similar to white spruce chronologies developed by others in the region (e.g. Schweingruber at al., 1993; ITRDB, 2012), and exceed the 'desirable' threshold of 0.500 (Grissino-Mayer, 2001).

\subsubsection{Mean Ring-Width Measurements}

Sites with more climatically sensitive growing conditions typically have smaller ring-widths (Fritts, 1976). The average ring-width of the network is $0.321 \mathrm{~mm}$ ranging from $0.256 \mathrm{~mm}$ for YEL2 to $0.446 \mathrm{~mm}$ for BLK1. However, results from previous treeline spruce studies (e.g. Szeicz and MacDonald, 1994; Wilson, 1999) indicate that mean ring-width for a chronology is in part related to mean sample age. Ring-width decreases as mean tree age increases, and this relationship likely accounts for much of the difference among site mean ring-widths.

\subsubsection{Standard Deviation and Coefficient of Variation}

The standard deviation is a measure of dispersion and is widely used to compare the difference in variance of individual ring-width series' within a site. Theoretically, chronologies with a greater standard deviation are more sensitive to changes in climate (Fritts, 1976). Mean standard deviation is $0.173($ median $=0.175)$ with a range from 0.126 (YEL7) to 0.215 (YEL4). However, due to the high variability of mean ring-widths between sites, the coefficient of variation (CV) is a more appropriate statistic to compare differences in variance. The coefficient of variation is a dimensionless number that represents the value of deviations about the mean; it is calculated by dividing the standard deviation by the mean (Burt et al., 2009). Mean CV of the network is 0.540 (median $=$ 0.534) with a range from 0.472 (DRY1) to 0.672 (YEL4). With high CV values, YEL4, YEL5, and YEL8 are likely responding to a wider range of growth variables. YEL7, 
BLK1, and DRY1 each have a relatively low CV value which indicates a growth signal less variable at the site level.

\subsubsection{Mean Sensitivity Statistic}

The average mean sensitivity of the 10 chronologies is $0.192($ median $=0.185)$ with a range from 0.163 (BLK1) to 0.238 (YEL2). YEL2 and YEL6 are moderately sensitive series; the eight other chronologies can be described as complacent.

\subsubsection{First Order Autocorrelation}

Mean AC1 for the chronologies is 0.848 (median $=0.851$ ) with a range from 0.765 (YEL6) to 0.915 (YEL4). These values are relatively high and indicate these chronologies contain considerable persistence reflecting long term persistence in ringwidth.

\subsection{Results from chronology building}

The ten chronologies show patterns of low, medium, and high frequency variability (Fig. 4.1). At the low-frequency, the chronologies exhibit below average growth before 1880-1890 with a gradual increase in ring-width until the 1920s. Following the 1920s, the chronologies begin to diverge in trend. From the 1920s onward, YEL2, YEL3, YEL6, YEL7 and DRY1 demonstrate increased growth until the 1950s where they level off, except YEL3 which continues to increase. Conversely, YEL4 and YEL5 peak in the 1920s and gradually decline to below average growth by the 1970s. YEL1 demonstrates a unique pattern of growth as it increases until the 1950s and then gradually declines until 2009.

At the decadal scale, the chronologies are fairly synchronous. The chronologies are suppressed during the 1750s, 1810s, 1870s, late-1930s to early-1940s, 1970s and 
2000 s. Periods of growth release occurred during the early 1800 s, 1850 s, late-1940s to early-1950s, and 1980s.

\subsection{Assessment of chronology signal strength: EPS}

Summary results of the EPS analysis displaying the 0.85 cut-off for each chronology are presented in Table 4.2; these cut-off years are also presented with the chronologies in Fig. 4.1. The common interval for the chronologies that pass the cut-off is 60 years (1950-2009) due to the low between-tree correlation and sample depth of DRY1 (Fig. 4.1j). The EPS statistic of a chronology is affected by changes in sample size (Figs. 4.1 and 4.2). The three earliest chronology EPS cut-off dates are for chronologies with only 1 radii measured per sample (YEL3, BLK1, and DRY1). In this analysis, the YEL1, YEL4, YEL5, and YEL6 chronologies are shown to have high signal strength for most of the length of their series.

The portion of a chronology with EPS $>0.85$ possesses greater signal strength; however, an EPS value of 0.85 is widely thought of as a conservative threshold (Wilson, 1999), and increasing sample size may lead to greater improvements in EPS values, but not the climate-growth relationships (Mérian et al., 2013). Furthermore, small sample depth and low EPS values at the site level do not weaken the signal strength preserved in a multi-site composite chronology (Mérian et al., 2013). It is for this reason that full chronologies are included in climate analysis; however, years preceding the EPS cut-offs are judged with caution and an understanding of weakened statistical strength.

\subsection{Signal strength analysis of the chronology network}

To better understand how radial growth has varied across the study area, the common signal between chronologies was examined. Sections 4.2 and 4.3 show that site 
Table 4.2 EPS $<0.85$ cutoff years for each chronology.

\begin{tabular}{ccc}
\hline Site Name & $\begin{array}{c}\text { Chronology Duration } \\
\text { (years CE) }\end{array}$ & 0.85 EPS Cut Off \\
\hline YEL1 & $1804-2009$ & 1804 \\
YEL2 & $1643-2009$ & 1825 \\
YEL3 & $1651-2009$ & 1920 \\
YEL4 & $1744-2009$ & 1780 \\
YEL5 & $1773-2009$ & 1773 \\
YEL6 & $1694-2009$ & 1730 \\
YEL7 & $1678-2009$ & 1760 \\
YEL8 & $1748-2009$ & 1840 \\
BLK1 & $1804-2009$ & 1804 \\
DRY1 & $1795-2009$ & 1950 \\
\hline
\end{tabular}


a) YEL1 50 year running EPS

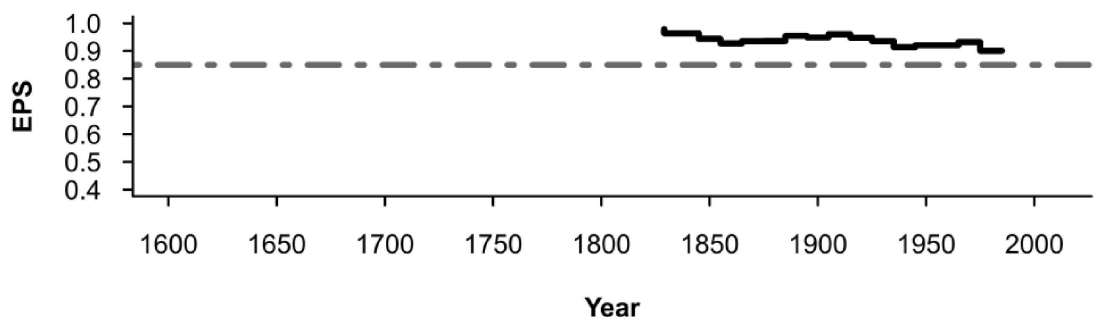

b) YEL2 50 year running EPS

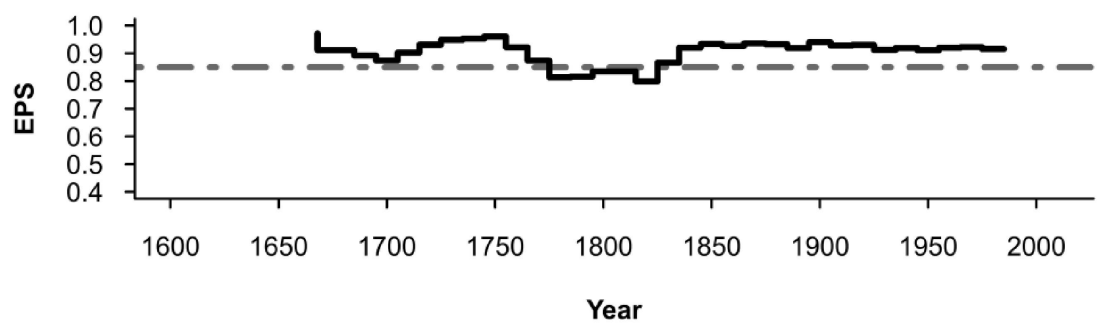

c) YEL3 50 year running EPS

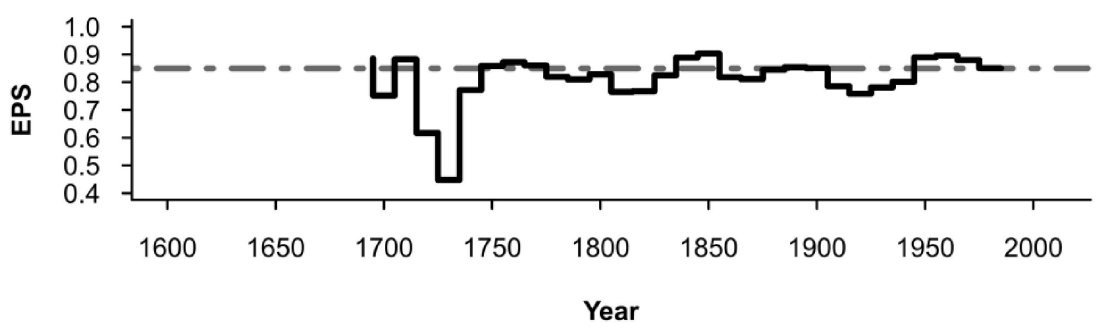

d) YEL4 50 year running EPS

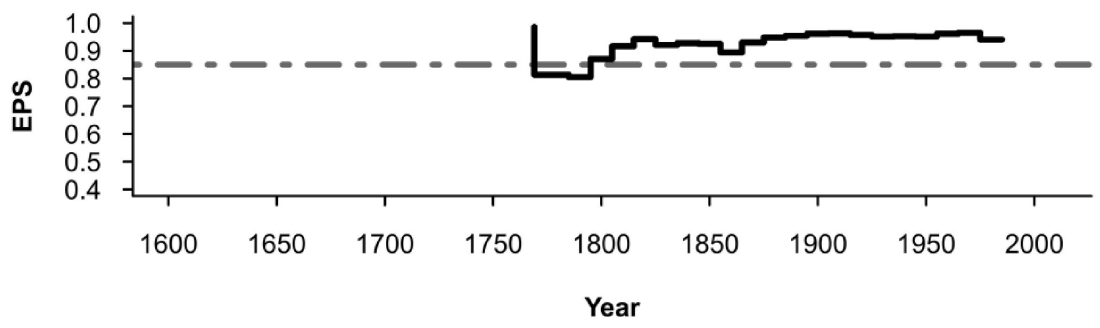

e) YEL5 50 year running EPS

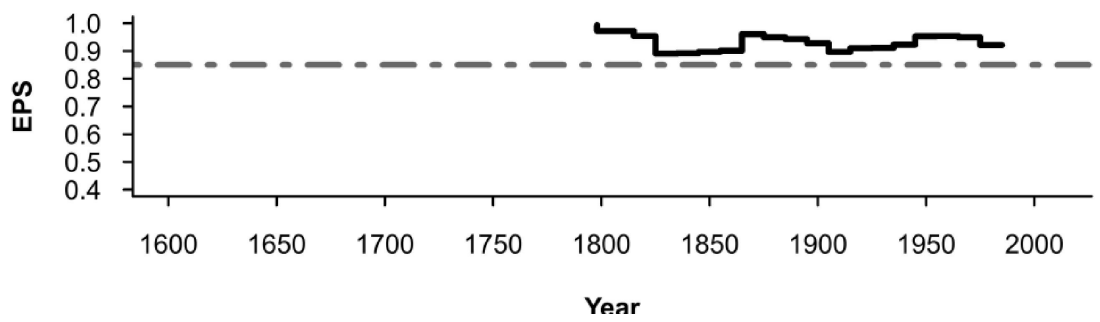

Figure 4.2 EPS plots for the signal free detrended chronologies. The black line is the EPS value for the chronology and the dashed line is the 0.85 EPS threshold. 


\section{f) YEL6 50 year running EPS}

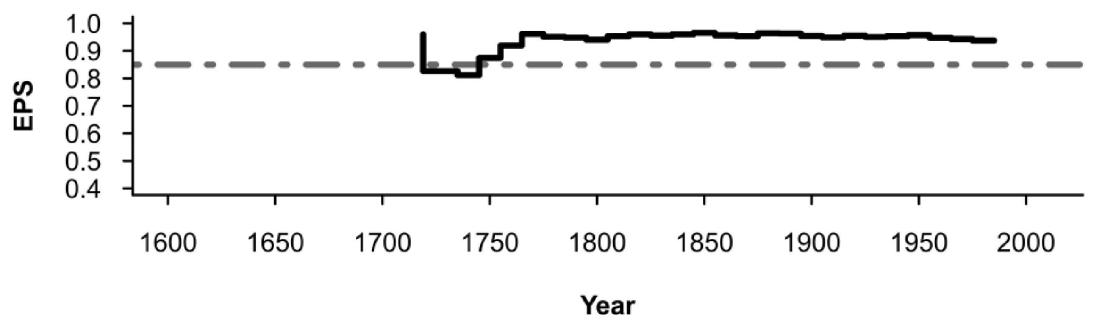

g) YEL7 50 year running EPS

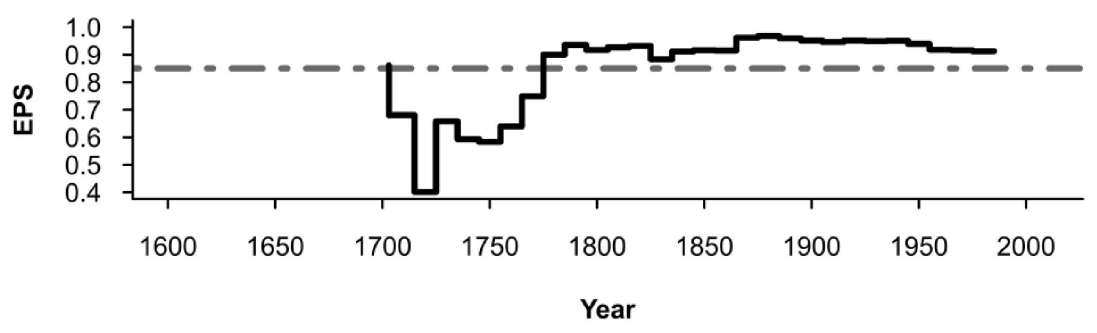

h) YEL8 50 year running EPS

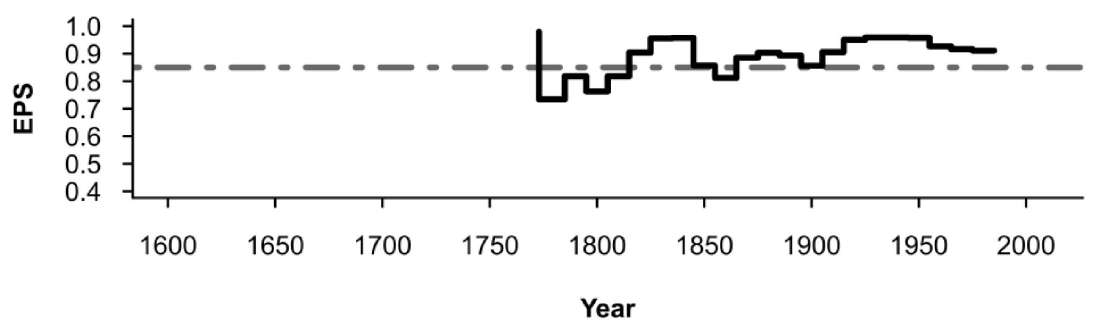

i) BLK1 50 year running EPS

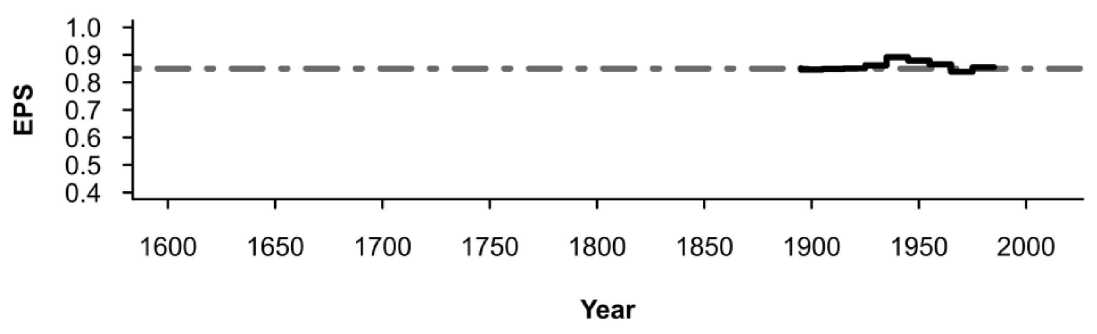

j) DRY1 50 year running EPS

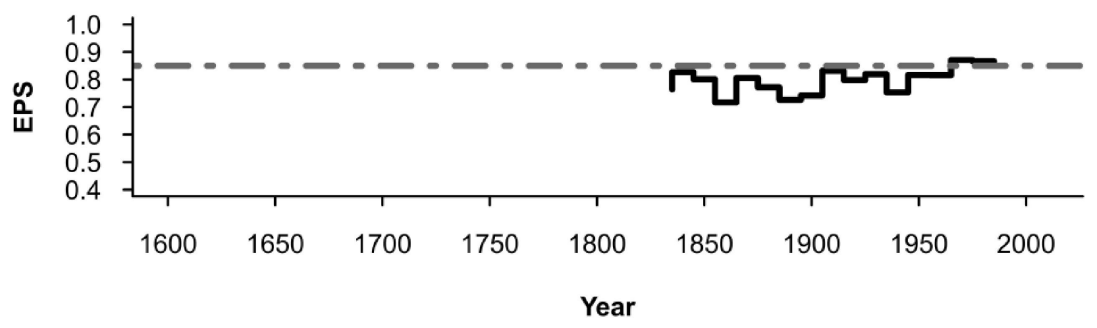

Figure 4.2 (con't.) EPS plots for the signal free detrended chronologies. The black line is the EPS value for the chronology and the dashed line is the 0.85 EPS threshold. 
chronologies have differing signal strength and low-frequency trends. The following section describes methods to further assess high and low frequency signals in the chronology network to better understand the chronologies and develop a composite chronology. The methods used are pointer year analysis, correlation matrix analysis, and principal component analysis.

\subsubsection{Pointer Year Analysis}

Pointer year analysis revealed a high-frequency signal present across the network indicative of a regional climate signal (Table 4.3; Fig. 4.3). In total, 26 regional pointer years are identified, of which 13 are negative and 13 are positive pointer years, representing $8 \%$ of the total number of years (331 years, 1678-2009). There are 6 narrow pointer years before 1890 , whereas there are only 3 wide pointer years before 1890 . Wide pointer years indicate relatively favourable growing conditions for the period 1890-1930 and 1940-1960. While it is true that there are few narrow pointer years for the period 1650-1780, when examining pointer years at the site level, the chronologies for YEL2, YEL6 and YEL7 have numerous pointer years during this time span indicating unfavourable growing conditions.

\subsubsection{Correlation Matrices}

Correlation matrices are commonly used to analyze two aspects of a tree-ring network: (i) to interpret the commonality of a whole network; and, (ii) to identify one or many asynchronous series. Correlation analyses for the ten chronologies were carried out over the common period of 1804-2009 (Table 4.4). The mean correlation between all chronologies is $r=0.574$ with a range from $r=0.332$ (YEL1) to $r=0.708$ (YEL7) for individual sites, which indicates a significant common variance between 1804-2009. 
Table 4.3 Narrow and wide pointer years found in $70 \%$ or more of the chronologies (given a chronology depth greater than 3 series).

\begin{tabular}{cccc}
\hline \multicolumn{2}{c}{ Narrow Years } & \multicolumn{2}{c}{ Wide Years } \\
Year & $\begin{array}{c}\text { Narrow rings / } \\
\text { \# Chronologies }\end{array}$ & Year & $\begin{array}{c}\text { Wide rings / } \\
\text { \# Chronologies }\end{array}$ \\
\hline 1756 & $5 / 6$ & 1698 & $3 / 4$ \\
1778 & $5 / 7$ & 1736 & $3 / 4$ \\
1797 & $6 / 8$ & 1828 & $7 / 10$ \\
1837 & $10 / 10$ & 1891 & $9 / 10$ \\
1867 & $8 / 10$ & 1899 & $9 / 10$ \\
1876 & $9 / 10$ & 1913 & $9 / 10$ \\
1904 & $8 / 10$ & 1919 & $10 / 10$ \\
1915 & $8 / 10$ & 1935 & $7 / 10$ \\
1936 & $7 / 10$ & 1941 & $8 / 10$ \\
1939 & $10 / 10$ & 1943 & $7 / 10$ \\
1942 & $7 / 10$ & 1948 & $8 / 10$ \\
1961 & $9 / 10$ & 1981 & $7 / 10$ \\
2007 & $10 / 10$ & 1986 & $8 / 10$ \\
\hline
\end{tabular}




\section{a) Narrow pointer years}

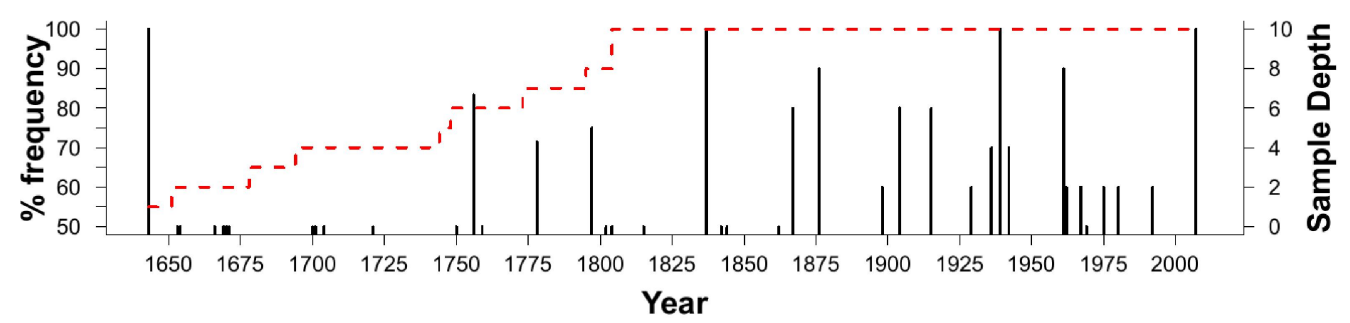

b) Wide pointer years

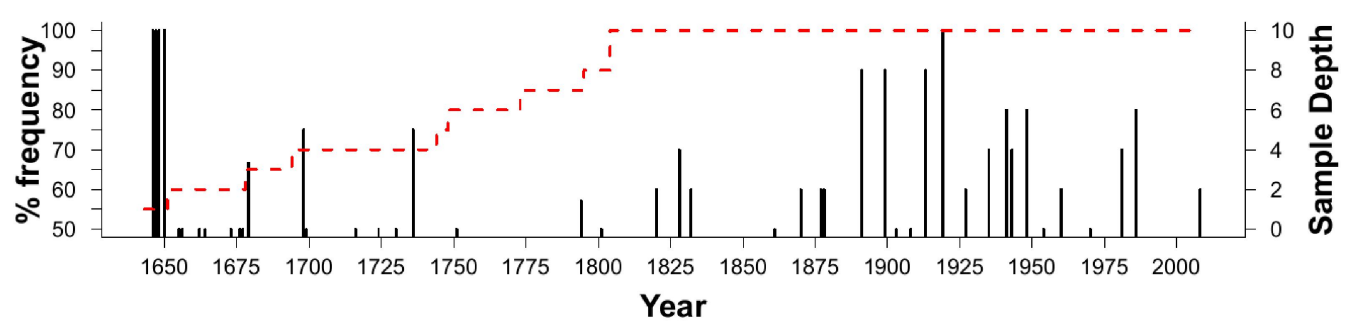

Figure 4.3 Negative pointer years (a) and wide pointer years (b) that occur in more than $50 \%$ of the chronologies for that year. The dashed line shows the sample depth, which is the number of chronologies at that particular time. 
There are obvious dissimilarities among chronologies. The YEL2, YEL3, YEL6, YEL7, and DRY1 chronologies are all highly correlated with each other in one grouping. Conversely, YEL4 and YEL5 are not well correlated with other chronologies, but are highly correlated with each other $(r=0.828)$.

Correlation analysis for the period 1901-2009 reveals a weakening of chronology synchroneity in the $20^{\text {th }}$ century (Table 4.5 ). There is an appreciable drop in statistically significant positive correlations and emergence of statistically significant negative relationships. For the 1901-2009 period, the mean correlation between all sites is $r=$ 0.319 with a range from $r=0.128$ (YEL4) to $r=0.434$ (YEL3). The grouping of YEL2, YEL3, YEL6, YEL7, and DRY1 are significantly correlated with one another, but the relationships are statistically weaker than for the whole period (1804-2009). For the period 1901-2009, the relationship between YEL4 and YEL5 remains strong $(r=0.852)$; however, YEL4 and YEL5 are negatively correlated with YEL2, YEL3, YEL6, YEL7, and DRY1 after 1901.

\subsubsection{Principal Component Analysis (PCA)}

A varimax orthogonal rotation PCA was undertaken on the network of chronologies for the period 1901-2009 (Table 4.6). The chronologies were grouped into 4 different ensembles (Table 4.7), explaining 90\% of the cumulative proportion of variance. The first two components were determined to be statistically significant following parallel analysis. YEL6, YEL7, YEL2, YEL3 and DRY1 load most heavily on the first component (PC1); YEL5, YEL4, and YEL8 load most heavily on the second component (PC2); YEL1 and BLK1 chronologies are loaded on the statistically insignificant third and fourth components, respectively. Nevertheless, YEL1 and BLK1 
Table 4.4 Correlation matrix of the ten sites for the period 1804-2009. Bolded values are statistically significant at $\mathrm{p}$ $\leq 0.05$. The mean correlation between all sites is $r=0.574$.

\begin{tabular}{lcccccccccc}
\hline & YEL1 & YEL2 & YEL3 & YEL4 & YEL5 & YEL6 & YEL7 & YEL8 & BLK1 & DRY1 \\
\hline YEL1 & $\mathrm{X}$ & $\mathbf{0 . 3 5 6}$ & $\mathbf{0 . 4 1 4}$ & $\mathbf{0 . 3 5 0}$ & $\mathbf{0 . 3 7 6}$ & $\mathbf{0 . 3 9 6}$ & $\mathbf{0 . 3 9 1}$ & -0.038 & $\mathbf{0 . 3 6 2}$ & $\mathbf{0 . 3 8 4}$ \\
YEL2 & & $\mathrm{X}$ & $\mathbf{0 . 9 2 4}$ & $\mathbf{0 . 2 3 6}$ & $\mathbf{0 . 3 5 3}$ & $\mathbf{0 . 9 3 5}$ & $\mathbf{0 . 9 1 0}$ & $\mathbf{0 . 6 4 2}$ & $\mathbf{0 . 7 7 0}$ & $\mathbf{0 . 8 7 9}$ \\
YEL3 & & & $X$ & $\mathbf{0 . 2 6 3}$ & $\mathbf{0 . 4 1 7}$ & $\mathbf{0 . 9 3 2}$ & $\mathbf{0 . 9 5 8}$ & $\mathbf{0 . 6 4 4}$ & $\mathbf{0 . 8 6 8}$ & $\mathbf{0 . 9 4 6}$ \\
YEL4 & & & & $X$ & $\mathbf{0 . 8 2 8}$ & $\mathbf{0 . 2 2 6}$ & $\mathbf{0 . 2 6 5}$ & $\mathbf{0 . 4 8 5}$ & $\mathbf{0 . 2 6 4}$ & $\mathbf{0 . 2 0 1}$ \\
YEL5 & & & & & $X$ & $\mathbf{0 . 3 7 5}$ & $\mathbf{0 . 4 5 3}$ & $\mathbf{0 . 4 8 8}$ & $\mathbf{0 . 5 0 5}$ & $\mathbf{0 . 3 0 7}$ \\
YEL6 & & & & & & $X$ & $\mathbf{0 . 9 4 3}$ & $\mathbf{0 . 6 0 1}$ & $\mathbf{0 . 8 1 0}$ & $\mathbf{0 . 9 1 0}$ \\
YEL7 & & & & & & & $X$ & $\mathbf{0 . 6 2 5}$ & $\mathbf{0 . 9 0 0}$ & $\mathbf{0 . 9 2 7}$ \\
YEL8 & & & & & & & & $X$ & $\mathbf{0 . 6 0 0}$ & $\mathbf{0 . 6 1 0}$ \\
BLK1 & & & & & & & & & $X$ & $\mathbf{0 . 8 3 8}$ \\
DRY1 & & & & & & & & & \\
\hline Mean & 0.332 & 0.667 & 0.707 & 0.346 & 0.456 & 0.681 & 0.708 & 0.517 & 0.657 & 0.667
\end{tabular}

Table 4.5 Correlation matrix of the ten sites for the period 1901-2009. Bolded values are statistically significant at $\mathrm{p} \leq 0.05$. The mean correlation between all sites is $r=0.319$.

\begin{tabular}{lcccccccccc}
\hline & YEL1 & YEL2 & YEL3 & YEL4 & YEL5 & YEL6 & YEL7 & YEL8 & BLK1 & DRY1 \\
\hline YEL1 & $\mathrm{X}$ & $\mathbf{0 . 3 8 1}$ & $\mathbf{0 . 3 5 9}$ & $\mathbf{0 . 5 2 2}$ & $\mathbf{0 . 3 2 3}$ & $\mathbf{0 . 3 3 1}$ & $\mathbf{0 . 3 3 4}$ & 0.132 & $\mathbf{0 . 2 7 8}$ & $\mathbf{0 . 5 1 8}$ \\
YEL2 & & $X$ & $\mathbf{0 . 7 7 9}$ & -0.151 & -0.079 & $\mathbf{0 . 8 5 0}$ & $\mathbf{0 . 7 5 7}$ & -0.070 & $\mathbf{0 . 3 8 1}$ & $\mathbf{0 . 7 0 7}$ \\
YEL3 & & & $X$ & -0.131 & -0.052 & $\mathbf{0 . 8 6 5}$ & $\mathbf{0 . 7 7 9}$ & -0.068 & $\mathbf{0 . 5 3 6}$ & $\mathbf{0 . 8 3 8}$ \\
YEL4 & & & & $X$ & $\mathbf{0 . 8 5 2}$ & $\mathbf{- 0 . 2 0 8}$ & -0.127 & $\mathbf{0 . 5 8 0}$ & 0.049 & $\mathbf{- 0 . 2 3 1}$ \\
YEL5 & & & & & $X$ & -0.096 & -0.016 & $\mathbf{0 . 7 1 8}$ & $\mathbf{0 . 2 5 9}$ & $\mathbf{- 0 . 2 8 0}$ \\
YEL6 & & & & & & $X$ & $\mathbf{0 . 8 7 7}$ & -0.100 & $\mathbf{0 . 4 8 6}$ & $\mathbf{0 . 8 1 3}$ \\
YEL7 & & & & & & & $X$ & -0.051 & $\mathbf{0 . 5 3 5}$ & $\mathbf{0 . 7 5 4}$ \\
YEL8 & & & & & & & & $X$ & $\mathbf{0 . 4 2 3}$ & $\mathbf{- 0 . 3 6 7}$ \\
BLK1 & & & & & & & & & $X$ & $\mathbf{0 . 3 7 5}$ \\
DRY1 & & & & & & & & & $X$ \\
\hline Mean & 0.353 & 0.395 & 0.434 & 0.128 & 0.181 & 0.424 & 0.427 & 0.133 & 0.369 & 0.347
\end{tabular}


are significantly correlated with the first component which indicates that the regional climate signal is present in their growth, but is not the dominant factor.

The first two principal components exhibit opposing trends during the $20^{\text {th }}$ century (Fig. 4.4). The first principal component shows an upward sloping trend for the period of analysis; inversely, the second principal component displays a negative trend. PC1 values are below average from 1901 until the late 1940s. After the late 1940s, values for PC1 are generally above average. The PC2 values are above average from 1901 to the mid-1930s and from the mid-1940s to the mid-1960s. The PC2 chronology decreases during the 1970s and remains below average until 2009.

\subsubsection{Final chronology assessment and development of the composite chronologies}

The previous sections have assessed the network of ten ring-width chronologies. Descriptive and quantitative measures have uncovered the chronologies best suited to develop two composite chronologies. Looking at the descriptive statistics it appears that YEL2, YEL3, YEL4, and YEL6 are likely best suited for climate analysis; however, all sites demonstrate the potential to be climatically sensitive. Additionally, correlation and principal component analysis identified the grouping of YEL2, YEL3, YEL6, YEL7, and DRY1 as being most similar and recording the dominant regional signal.

Therefore, the COMP1 and COMP2 composite chronologies were developed (Fig. 4.5). For COMP1, the average of the index values of the five sites loaded on the first principal component was used: YEL2, YEL3, YEL6, YEL7, and DRY1. The COMP1 chronology is strongly correlated with the PC1 chronology $(r=0.959 ; 1901-$ 2009). For COMP2, the average of the index values of the three sites loaded on the second principal component was used: YEL4, YEL5, and YEL8. 
Table 4.6 Principal component analysis summary table. The first two components were found to be statistically significant $(p \leq 0.05)$ following parallel analysis.

\begin{tabular}{cccc}
\hline Component & Eigenvalues & Proportion of Variance & Cumulative Proportion \\
\hline $\mathbf{1}$ & 4.76 & 0.42 & 0.42 \\
$\mathbf{2}$ & 2.80 & 0.25 & 0.67 \\
$\mathbf{3}$ & 1.05 & 0.12 & 0.79 \\
$\mathbf{4}$ & 0.51 & 0.11 & 0.90 \\
\hline
\end{tabular}

Table 4.7 Loadings of the site chronologies on the first four principal components. Statistically significant correlations $(\mathrm{p} \leq 0.05)$ are bolded.

\begin{tabular}{cc|ccc}
\hline Site & Component 1 & Component 2 & Component 3 & Component 4 \\
\hline YEL 6 & $\mathbf{0 . 9 5}$ & -0.09 & 0.07 & 0.13 \\
YEL 7 & $\mathbf{0 . 9 1}$ & 0.01 & 0.03 & $\mathbf{0 . 2 0}$ \\
YEL 2 & $\mathbf{0 . 8 9}$ & -0.07 & 0.17 & -0.02 \\
YEL 3 & $\mathbf{0 . 8 9}$ & -0.06 & 0.15 & $\mathbf{0 . 2 3}$ \\
DRY 1 & $\mathbf{0 . 7 9}$ & $\mathbf{- 0 . 3 0}$ & $\mathbf{0 . 4 3}$ & 0.11 \\
YEL 5 & -0.03 & $\mathbf{0 . 9 7}$ & 0.04 & 0.12 \\
YEL 4 & -0.15 & $\mathbf{0 . 9 0}$ & $\mathbf{0 . 3 6}$ & -0.07 \\
YEL 8 & -0.12 & $\mathbf{0 . 7 2}$ & -0.09 & $\mathbf{0 . 4 5}$ \\
YEL 1 & $\mathbf{0 . 2 9}$ & $\mathbf{0 . 2 9}$ & $\mathbf{0 . 9 0}$ & 0.06 \\
BLK 1 & $\mathbf{0 . 4 0}$ & 0.15 & 0.08 & $\mathbf{0 . 8 8}$ \\
\hline
\end{tabular}



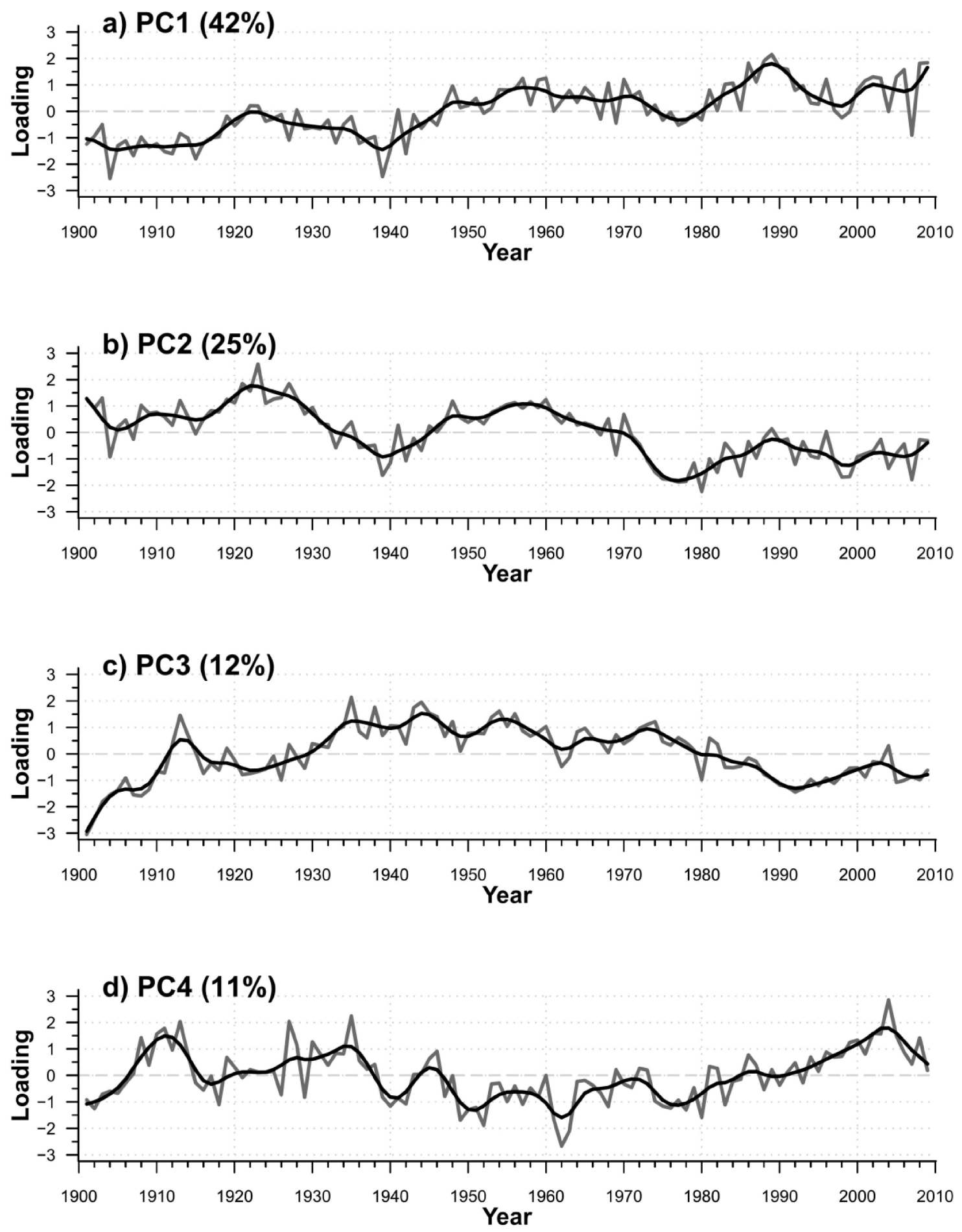

Figure 4.4 The first four principal component chronologies (grey line) plotted with a smoothing spline (black line). The common variance explained by each chronology is included in the title for each plot. The period of analysis for the PCA is 1901-2009. 

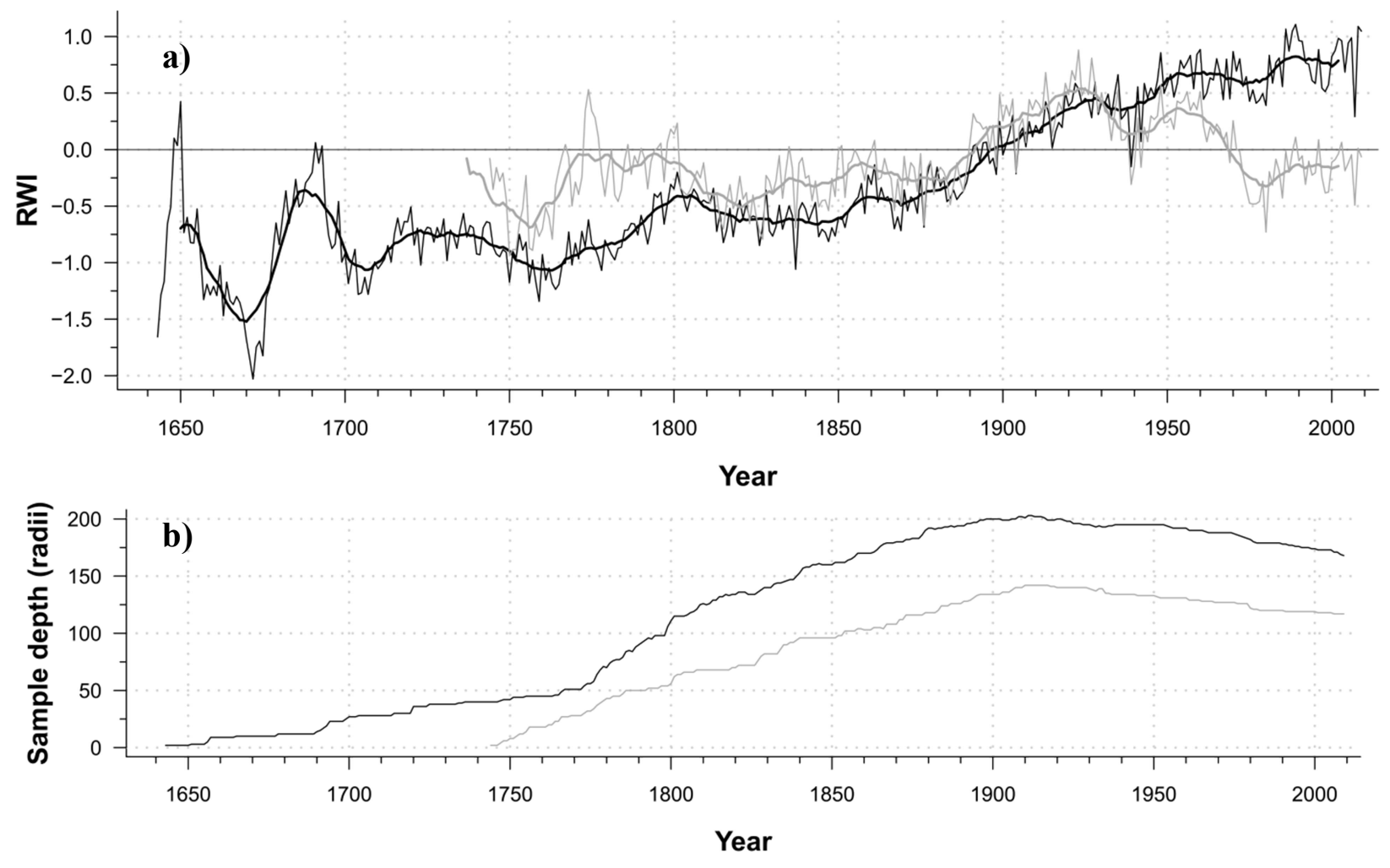

Figure 4.5 a) COMP1 (black) and COMP2 (grey) chronologies. The COMP1 chronology was computed by taking the average of the YEL2, YEL3, YEL6, YEL7, and DRY1 chronologies. The COMP2 chronology was computed by taking the average of the YEL4, YEL5, and YEL8 chronologies. The COMP1 chronology extends from 1643 to 2009 and the COMP2 chronology extends from 1744 to 2009. b) Radii sample depth of the COMP1 (black) and COMP2 (grey) chronologies. 
The COMP2 chronology is strongly correlated with the PC2 chronology $(r=0.968$; 1901-2009).

\subsection{Climate-Growth Relationships}

To better understand the climatic factors controlling growth of white spruce in the study area, statistical analysis was undertaken with instrumental and gridded monthly climatic variables. The following section describes the complex climate-growth relationships.

\subsubsection{Full Period Correlation Analysis}

Correlation analysis was undertaken using a 17-month climate window from April of the previous-year to August of the current-year. Previous-year climate data was included because current-year tree growth is sometimes influenced by previous-year growing conditions (e.g. Szeicz and MacDonald 1996; Porter and Pisaric, 2011). Site chronologies, principal component chronologies and composite chronologies were correlated with data from the Yellowknife, NT climate station for the period 1943-2009 (Table 4.8). Correlations with maximum and minimum monthly temperatures did not differ significantly from mean monthly temperatures are not presented in this thesis. Seasonal (e.g. total June-August precipitation) indices were developed and correlated because tree growth is often more responsive to seasonal climate variables (e.g. Wilson and Luckman, 2003; Youngblut and Luckman, 2008; Büntgen et al., 2009). Additionally, correlation analysis was undertaken with gridded temperature and precipitation data to extend the analysis to the start of the $20^{\text {th }}$ century (Table 4.9). 


\subsubsection{Precipitation and Temperature}

For the instrumental period measured at the Yellowknife, NT climate station between 1943 and 2009, white spruce radial growth at COMP1 sites is regulated by previous-year and current-year summer precipitation (Table 4.8a). COMP1 is highly correlated with current-year June precipitation ( $r=0.472 ; \mathrm{p} \leq 0.001$; Fig. 4.6a), currentyear July precipitation ( $r=0.252 ; \mathrm{p} \leq 0.05$; Fig. $4.6 \mathrm{~b})$, and current-year total June-July precipitation $(r=0.471 ; \mathrm{p} \leq 0.001$; Fig. 4.6c). Similarly, correlation analysis with gridded climate data for the period 1901-2004 determined that COMP1 is most significantly correlated with current-year summer precipitation (Table 4.9a). The relationship of total current-year June-July gridded precipitation data with COMP1 is $r=$ $0.246(\mathrm{p} \leq 0.010)$. Unlike the results with the Yellowknife station data, COMP1 is more positively correlated with current-year gridded July precipitation than June precipitation (1901-2004). The relationship with current-year July precipitation is significant for YEL2 $(r=0.236)$, YEL6 $(r=0.222)$, PC1 $(r=0.198)$, and COMP1 $(r=0.201)$.

White spruce radial growth at COMP1 is also positively related to current-year and previous-year instrumental summer temperatures (Table 4.8b). The relationship of the PC1 chronology with current-year mean temperature is positive and significant for June $(r=0.353)$, July $(r=0.245)$, June-July $(r=0.355)$, and June-August $(r=0.371)$. Surprisingly, COMP1 does not have any statistically significant correlations. However, looking at relationships with CRUTEM4 temperature data (1913-2009; Table 4.9b), COMP1 is positively correlated with current-year March, June, July, June-July, JuneAugust, and May-August mean temperatures, and COMP1 displays a significant relationship with previous-year June $(r=0.210)$ and previous-year June-July $(r=0.202)$ 
Table 4.8 Pearson product moment correlation values of the site, principal component, and composite chronologies with (a) total monthly precipitation, and, (b) mean monthly temperatures from instrumental data from the Yellowknife, NT climate station (1943-2009; Environment Canada, 2012). PDSI correlations with the nearest grid point are presented in (c) (1901-1990). All values are significant at $\mathrm{p} \leq 0.05$. Bold values are positively related. $p$ signifies previous year.

\begin{tabular}{|c|c|c|c|c|c|c|c|c|c|c|c|c|c|c|}
\hline & \multicolumn{5}{|c|}{ COMP1 } & \multicolumn{3}{|c|}{ COMP2 } & \multicolumn{2}{|c|}{ Not Included } & \multicolumn{2}{|c|}{ PC } & \multicolumn{2}{|c|}{ Composites } \\
\hline & YEL2 & YEL3 & YEL6 & YEL7 & DRY1 & YEL4 & YEL5 & YEL8 & YEL1 & BLK1 & PC1 & PC2 & Comp1 & Comp2 \\
\hline \multicolumn{15}{|l|}{ a) Precipitation } \\
\hline May & & & & & & & & & & & & & & -0.252 \\
\hline June & 0.554 & 0.338 & 0.446 & 0.312 & & -0.279 & & & & 0.265 & 0.489 & & 0.472 & \\
\hline July & 0.241 & & 0.255 & & & & & & & & & & 0.252 & \\
\hline June-Juyl & 0.510 & 0.353 & 0.459 & 0.327 & & & & & & & 0.444 & & 0.471 & \\
\hline June-August & 0.430 & 0.340 & 0.354 & 0.313 & & & & & & & 0.413 & & 0.411 & \\
\hline May-August & 0.400 & 0.284 & 0.314 & 0.285 & & & & & & & 0.402 & & 0.366 & \\
\hline$p$ June-August & & & 0.254 & 0.256 & 0.252 & & & & & & 0.296 & & & \\
\hline$p$ May-August & & & & & & & & & & & 0.271 & & & \\
\hline$p$ June & & & & & & -0.288 & & & -0.326 & & & & & \\
\hline$p$ July & & & 0.264 & & 0.249 & & & & & & & & & \\
\hline \multicolumn{15}{|l|}{ b) Temperature } \\
\hline April & & & & & & -0.466 & -0.357 & -0.286 & -0.452 & & & -0.355 & & -0.447 \\
\hline June & & & & & & -0.316 & & & -0.295 & & 0.353 & & & -0.267 \\
\hline July & & & & & 0.284 & -0.264 & & & & 0.319 & 0.245 & & & \\
\hline June-July & & & 0.260 & & & -0.343 & & & -0.312 & 0.251 & 0.355 & & & -0.266 \\
\hline June-August & & & 0.291 & 0.254 & 0.242 & -0.245 & & & & 0.264 & 0.371 & & & \\
\hline May-August & & & & & & -0.282 & & & & & 0.278 & & & -0.240 \\
\hline$p$ June-July & & & & & & -0.486 & -0.347 & & -0.416 & & 0.277 & -0.354 & & -0.436 \\
\hline$p$ June-August & & & & & & -0.407 & -0.321 & & -0.359 & & & -0.313 & & -0.392 \\
\hline$p$ May-August & & & & & & -0.384 & -0.408 & -0.299 & -0.288 & & & -0.376 & & -0.434 \\
\hline$p$ August & & & & & & & & & & & & & -0.241 & \\
\hline \multicolumn{15}{|l|}{ c) PDSI } \\
\hline Grid Point 93 & 0.218 & & & & & & & & & & 0.212 & & & \\
\hline$p$ Grid Point 93 & & & & & & -0.293 & & -0.277 & & & & & & -0.242 \\
\hline
\end{tabular}


Table 4.9 Pearson product moment correlation values of the site, principal component, and composite chronologies with (a) area CRUTEM3 total monthly precipitation data (1901-2004), and with (b) CRUTEM4 mean monthly temperatures (1914-2009). All values are significant at $\mathrm{p} \leq 0.05$. Bold values are positively related. $p$ signifies previous year.

\begin{tabular}{|c|c|c|c|c|c|c|c|c|c|c|c|c|c|c|}
\hline & \multicolumn{5}{|c|}{ COMP1 } & \multicolumn{3}{|c|}{ COMP2 } & \multicolumn{2}{|c|}{ Not Included } & \multicolumn{2}{|c|}{ PC } & \multicolumn{2}{|c|}{ Composites } \\
\hline & YEL2 & YEL3 & YEL6 & YEL7 & DRY1 & YEL4 & YEL5 & YEL8 & YEL1 & BLK1 & PC1 & PC2 & Comp1 & Comp2 \\
\hline \multicolumn{15}{|l|}{ a) Precipitation } \\
\hline May & & & & & & -0.214 & -0.212 & & -0.208 & & & & & -0.218 \\
\hline June & 0.236 & & & & & -0.214 & & & & & & & & \\
\hline July & 0.246 & & 0.222 & & & & & & & & 0.198 & & 0.201 & \\
\hline June-July & 0.313 & 0.191 & 0.258 & & & & & & & & 0.236 & & 0.246 & \\
\hline June-August & 0.239 & & & & & & & & & & & & 0.197 & \\
\hline May-August & 0.238 & & & & & & & & & & & & & \\
\hline$p$ July & & & & & & -0.220 & & & -0.234 & & & & & \\
\hline \multicolumn{15}{|l|}{ b) Temperature } \\
\hline March & & 0.307 & 0.209 & & 0.347 & -0.392 & -0.353 & -0.302 & -0.231 & & 0.209 & -0.373 & 0.227 & -0.391 \\
\hline April & & & & & & -0.491 & -0.401 & -0.343 & -0.380 & & & -0.438 & & -0.463 \\
\hline May & & & & & & -0.374 & -0.381 & -0.368 & & & & -0.415 & & -0.414 \\
\hline June & 0.271 & 0.361 & 0.411 & 0.324 & 0.401 & -0.366 & -0.275 & -0.241 & -0.202 & & 0.364 & -0.293 & 0.377 & -0.331 \\
\hline July & & 0.300 & 0.292 & 0.225 & 0.325 & -0.269 & & & & 0.331 & 0.210 & & 0.253 & \\
\hline June-July & 0.219 & 0.382 & 0.411 & 0.321 & 0.420 & -0.370 & -0.250 & & -0.203 & 0.288 & 0.340 & -0.287 & 0.370 & -0.308 \\
\hline June-August & 0.241 & 0.410 & 0.399 & 0.343 & 0.452 & -0.366 & -0.221 & -0.218 & & 0.279 & 0.365 & -0.272 & 0.386 & -0.302 \\
\hline May-August & 0.200 & 0.320 & 0.325 & 0.248 & 0.388 & -0.429 & -0.327 & -0.319 & -0.207 & & 0.276 & -0.379 & 0.303 & -0.401 \\
\hline$p$ June-July & & 0.253 & 0.239 & & 0.275 & -0.575 & -0.467 & -0.353 & -0.398 & & & -0.508 & 0.210 & -0.529 \\
\hline pJune-August & & 0.236 & 0.241 & & 0.302 & -0.542 & -0.479 & -0.376 & -0.379 & & & -0.500 & & -0.527 \\
\hline$p$ May-August & & & & & 0.302 & -0.542 & -0.556 & -0.415 & -0.330 & & & -0.556 & & -0.570 \\
\hline$p$ April & & & & & 0.200 & -0.385 & -0.380 & -0.263 & -0.228 & & & -0.391 & & -0.390 \\
\hline$p$ May & & & & & & -0.341 & -0.477 & -0.328 & & & & -0.444 & & -0.430 \\
\hline$p$ June & & 0.230 & 0.221 & & 0.315 & -0.533 & -0.461 & -0.395 & -0.304 & & & -0.502 & 0.202 & -0.521 \\
\hline$p$ July & & 0.210 & & & & -0.467 & -0.341 & & -0.411 & & & -0.370 & & -0.388 \\
\hline
\end{tabular}




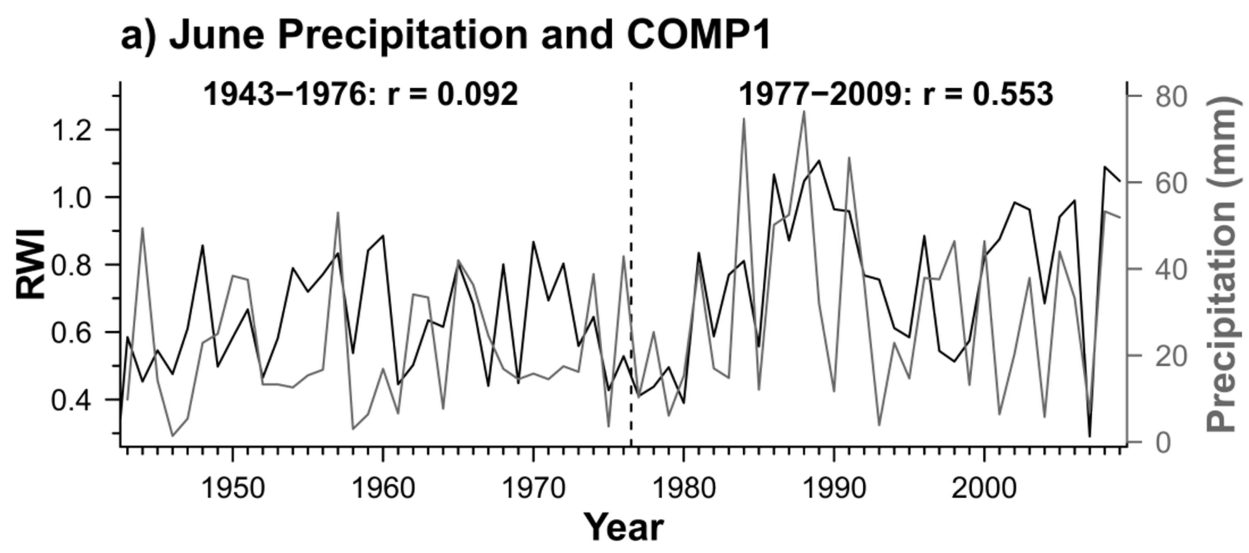

b) July Precipitation and COMP1

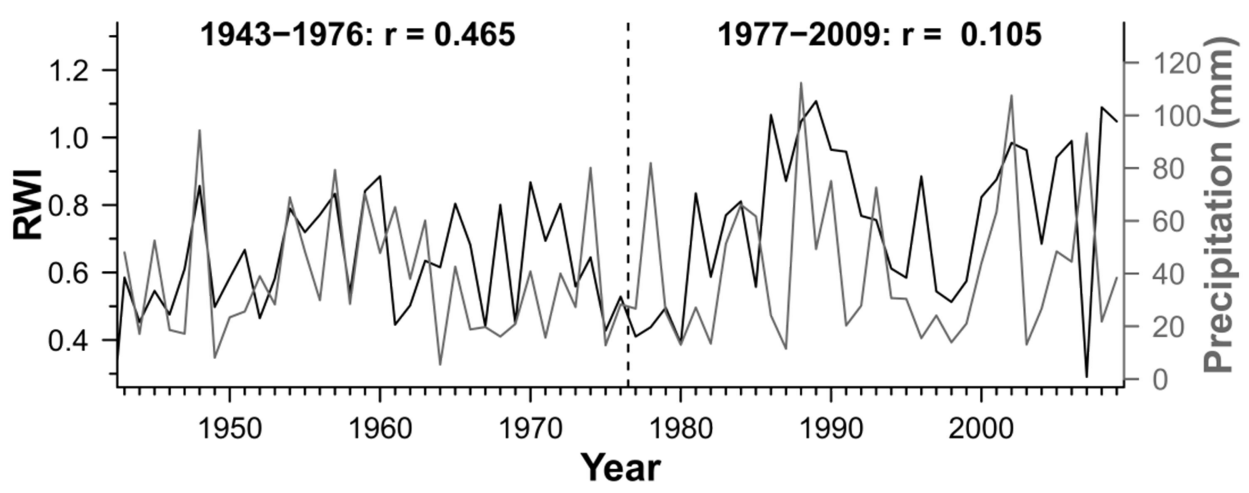

c) June + July Precipitation and COMP1

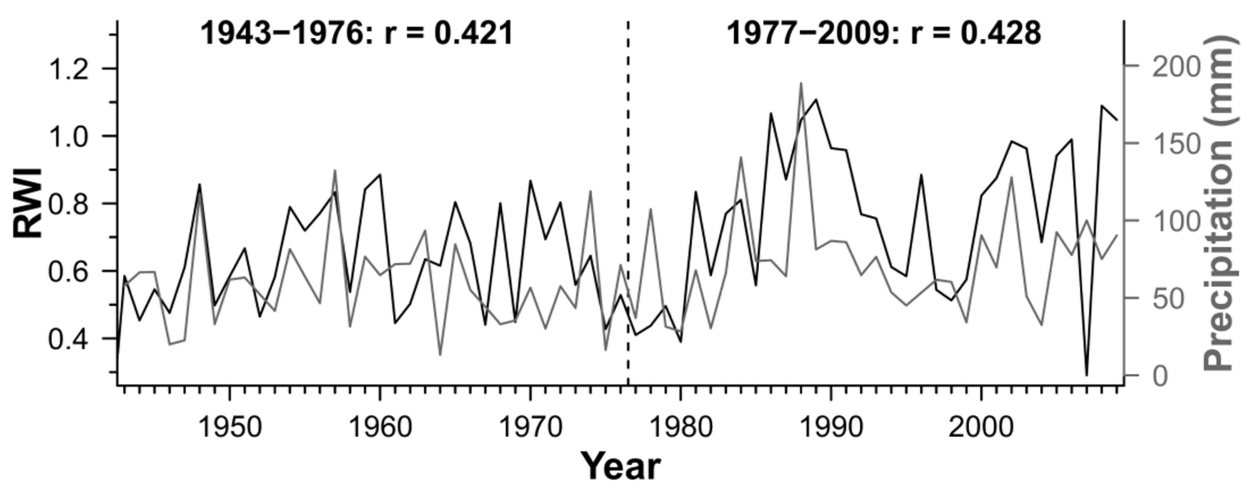

Figure 4.6 June (a), July (b), and June + July (c) total precipitation plotted with the COMP1 chronology. Pearson product moment correlation values for split periods (1943-1976, 1977-2009) are presented and separated by the dashed vertical line. 


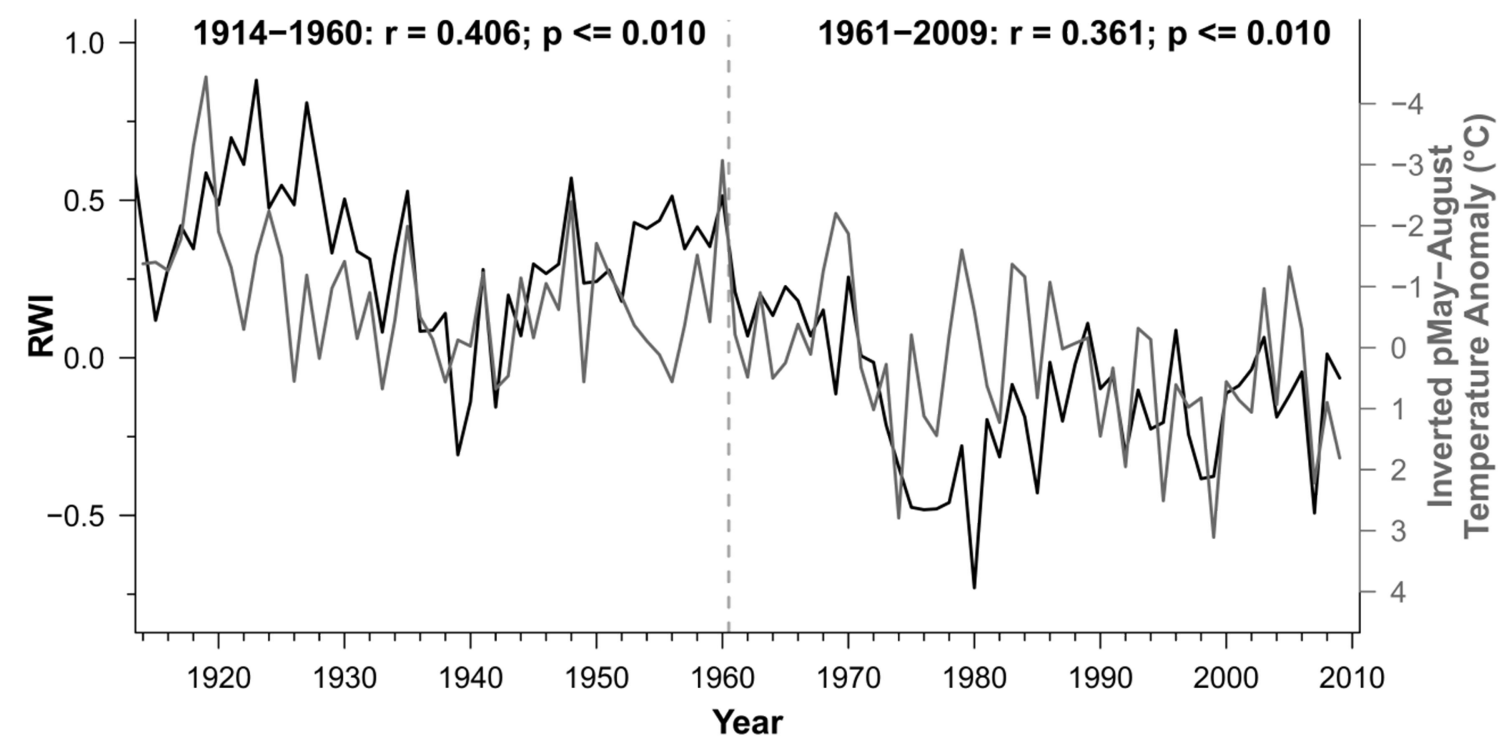

Figure 4.7 The COMP2 chronology is plotted with inverted previous-year May-August gridded mean temperature anomalies. Pearson product moment correlation values for split periods (1914-1960, 1961-2009) are presented and separated by the dashed vertical line. 
CRUTEM4 temperatures. Of note, COMP2 is negatively related to current-year May precipitation for the instrumental period $(r=-0.252$; Table 4.8a) and the CRUTEM3 gridded period $(r=-0.218$; Table $4.9 \mathrm{a})$.

Radial growth of COMP2 is negatively correlated with current-year and previous year spring and summer temperatures (Tables 4.8 and 4.9). The negative relationship is stronger for the climate-growth relations derived with the CRUTEM4 temperature data. For the gridded period, COMP2 is negatively correlated with current-year spring (e.g. $r=$ -0.463 for April), current-year summer (e.g. $r=-0.401$ for May-August), and previousyear summer (e.g. $r=-0.570$ for May-August; Fig. 4.7).

\subsubsection{Palmer Drought Severity Index (PDSI)}

Correlations between chronologies and the closest PDSI grid point were calculated for the period 1900-1990 (Table 4.8c). The YEL2 and PC1 chronologies are both positively related to local PDSI. Conversely, previous-year PDSI values negatively affect radial growth for YEL1, YEL4, YEL8, and COMP2.

\subsubsection{Split Period and Moving Correlation Analysis}

Results of correlation analysis with the instrumental and gridded data demonstrate that white spruce radial growth at COMP1 sites is positively related to precipitation and temperature. White spruce radial growth at COMP2 sites is negatively related to temperature. To test the time-stability of the relationships, this section presents the results of split period and moving correlation analysis between the two composite chronologies and the climate data. 


\subsubsection{Precipitation}

Split period analysis and moving correlation analysis reveals that white spruce growing at COMP1 sites experienced a shift in its climate signal during the 1970s. Over the instrumental period, COMP1 experiences a significant shift from being positively correlated with current-year July precipitation to current-year June precipitation (Fig. 4.6). For 1943-1976, COMP1 is significantly correlated with current-year July precipitation $(r=0.465 ; \mathrm{p} \leq 0.01)$, but not for current-year June $(r=0.092)$. For $1977-$ 2009 , the current-year July precipitation correlation is not significant $(r=0.105)$, while current-year June precipitation is significantly correlated $(r=0.553 ; \mathrm{p} \leq 0.0001)$.

Moving correlation analysis reveals a period of climate-growth transition between 1978 and 1985 (Fig. 4.8). Current-year July precipitation is positively related with COMP1 when moving intervals end between 1974 and 1977. Current-year June precipitation is positively related when the last year of the moving interval is between 1985 and 2009. COMP1 white spruce growth has a time-stable positive relationship with current-year June-July precipitation $(r=0.421$ for $1943-1976$ and $r=0.428$ for $1977-$ 2009, Fig. 4.6c). COMP2 does not have significant relationships with current-year or previous-year summer precipitation over the full period. However, moving correlation analysis reveals a strengthened positive relationship between COMP2 and current-year June precipitation for the period 1972-2009 (Fig. 4.9).

\subsubsection{Temperature}

There is evidence that COMP1 trees are more sensitive to summer temperature since the early 1970s. Forward evolutionary analysis with gridded mean temperature indicates that COMP1 white spruce is positively related with current-year June mean 
temperatures after 1971, and current-year July mean temperatures after 1993 (Fig. 4.10). The negative relationship between COMP2 and current-year and previous-year summer temperature is time-stable (Fig. 4.11). COMP2 is negatively correlated with previousyear May-August temperatures for both 1914-1960 ( $r=-0.408$; $\mathrm{p} \leq 0.010$; Fig. 4.7) and 1961-2009 ( $r=-0.361 ; \mathrm{p} \leq 0.010 ;$ Fig. 4.7). Forward evolutionary analysis with gridded mean temperature indicates that since the 1970 s COMP2 is more negatively related to current-year and previous-year growing season temperatures.

\subsubsection{Medium-Frequency Relationships}

At the decadal scale, it is visually evident that COMP1 radial growth is highly correlated with current-year June-July precipitation (Fig. 4.12). It is also evident that medium-frequency changes to current-year July precipitation are more synchronous with growth before the 1970s, after which it shifts and becomes more synchronous with current-year June precipitation. These visual observations are supported by correlation analysis. The 11-year running average composite chronology is highly correlated with 11-year current-year July precipitation ( $\mathrm{r}=0.631)$, 11-year current-year June precipitation $(\mathrm{r}=0.830)$, and total current-year June-July precipitation $(\mathrm{r}=0.861)$. Unfortunately, these moving average series have such a high autocorrelation that statistical significance testing was prohibited. The relationship of COMP2 and previousyear May-August mean temperature is also present at the decadal scale (Fig. 4.13). The correlation between 11-year COMP2 and 11-year previous-year May-August temperatures is $r=-0.831$. The relationship is especially strong until the late $1980 \mathrm{~s}$ at which point the COMP2 chronology does not demonstrate decreasing growth with 
greater warming. Of note, the 11-year average COMP1 and COMP2 chronologies lag behind the climate variables by a few years. 


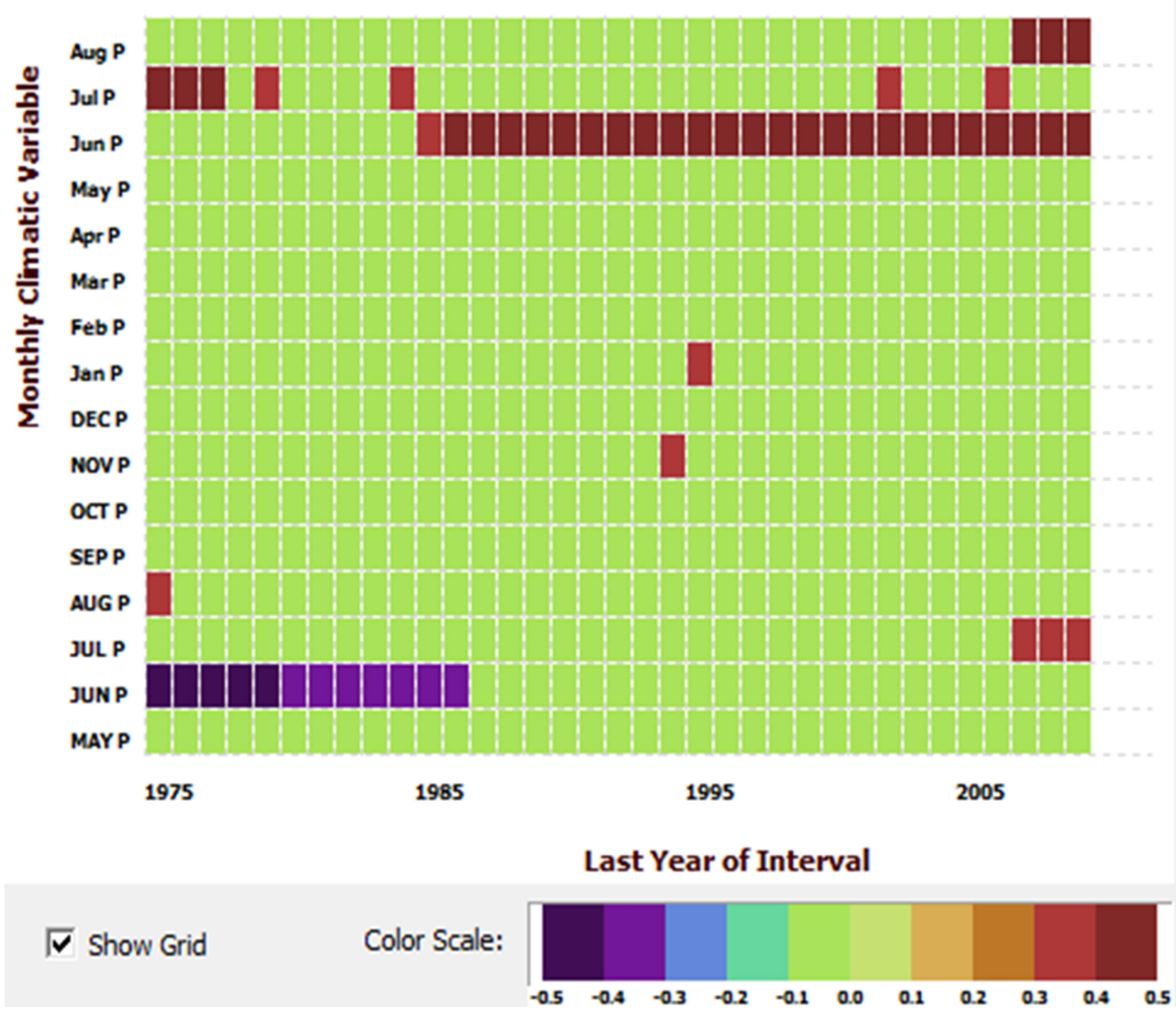

Figure 4.8 Moving correlation analysis between Yellowknife Station total monthly precipitation and the COMP1 chronology using a 32-year moving window, for the period 1943-2009. Total monthly precipitation is plotted on the y-axis. Previous-year May precipitation is at the bottom of the axis and current-year August precipitation is at the top. The $\mathrm{x}$-axis indicates the last year of the 32-year moving interval. 


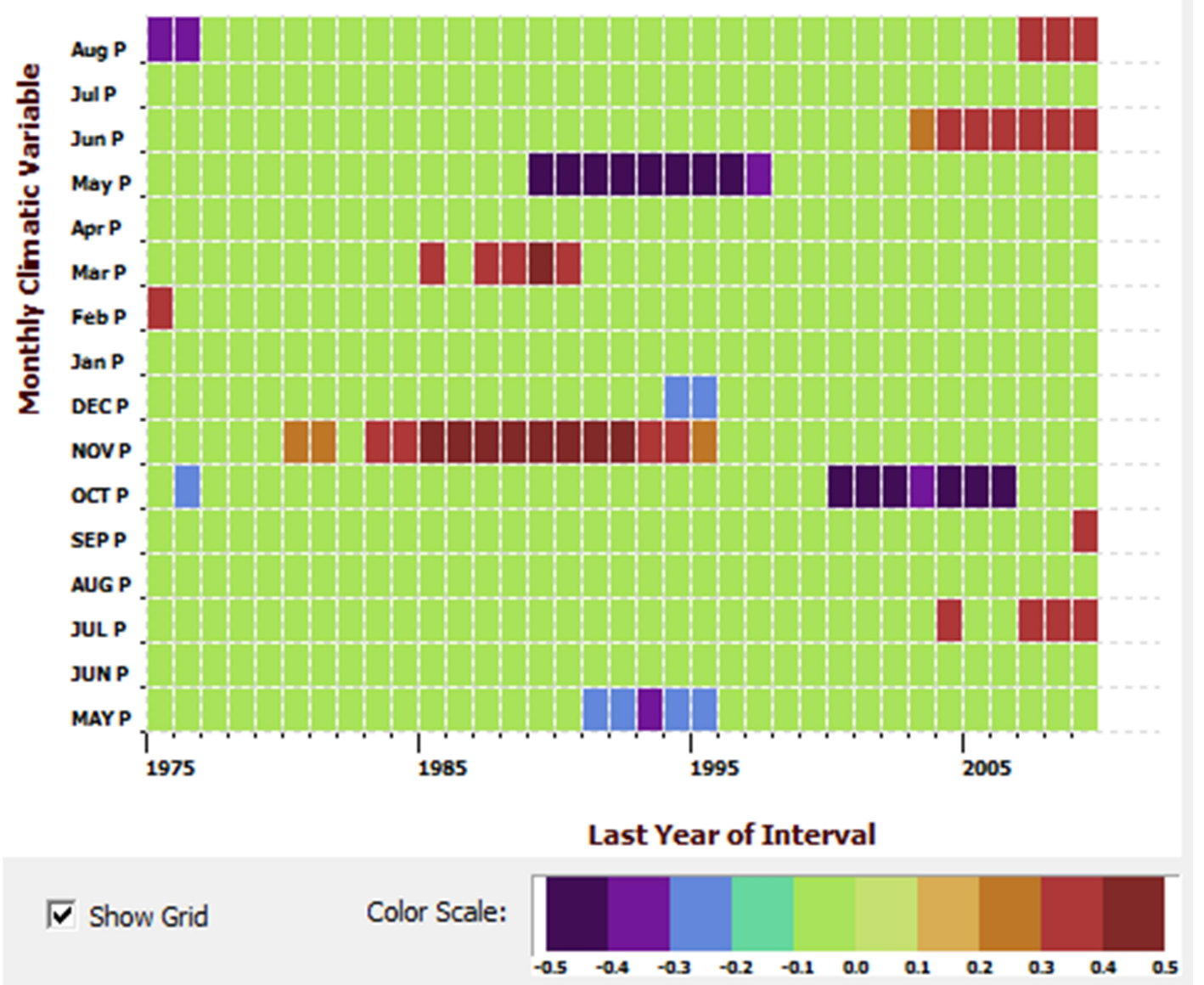

Figure 4.9 Moving correlation analysis between Yellowknife Station total monthly precipitation and the COMP2 chronology using a 32-year moving window, for the period 1943-2009. Total monthly precipitation is plotted on the y-axis. Previous-year May precipitation is at the bottom of the axis and current-year August precipitation is at the top. The $\mathrm{x}$-axis indicates the last year of the 32-year moving interval. 


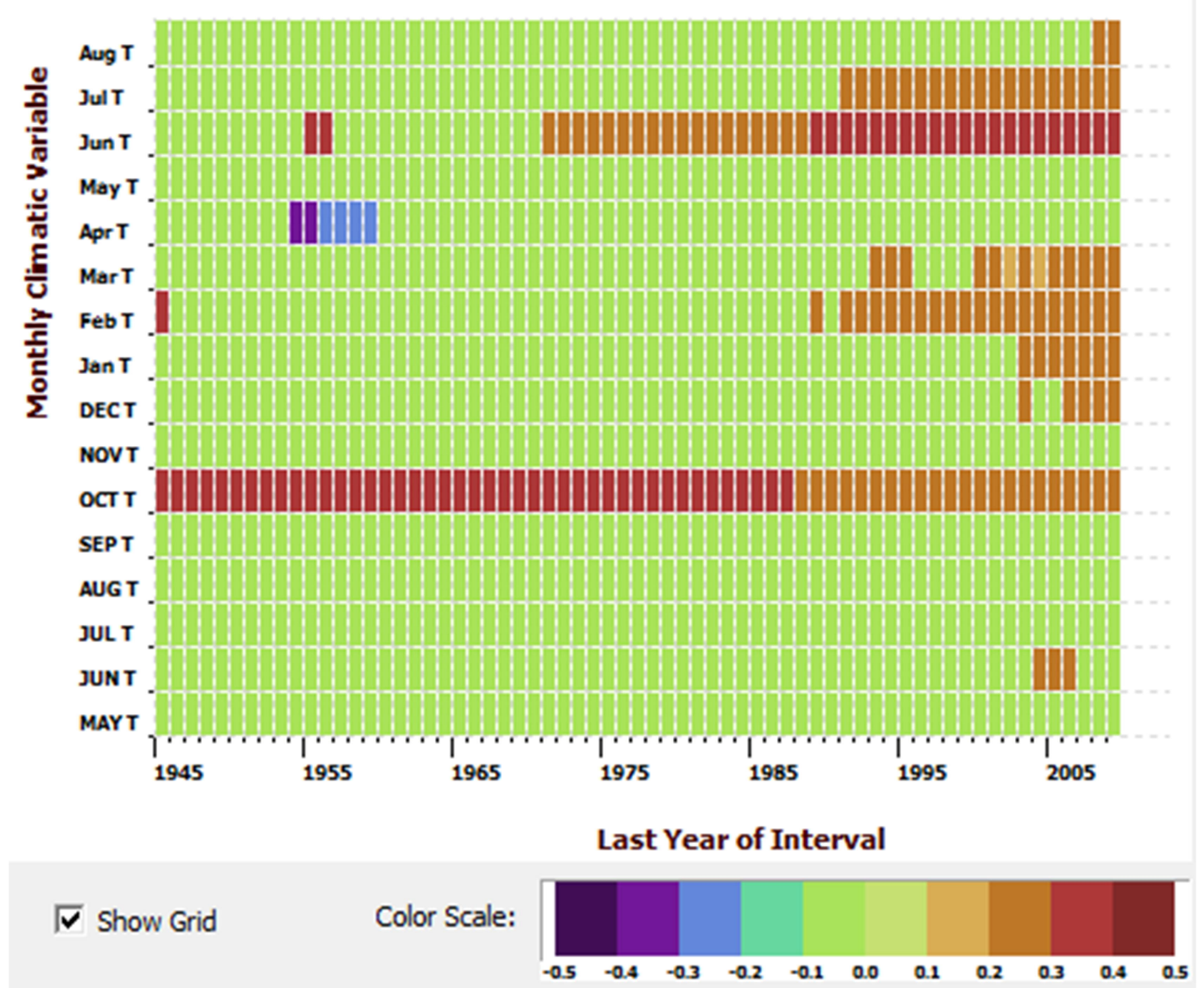

Figure 4.10 Evolutionary moving correlation analysis between CRUTEM4 mean monthly temperature and the COMP1 chronology starting with a 32-year interval, for the period 1914-2009. Mean monthly temperature is plotted on the y-axis. Previousyear May mean temperature is at the bottom of the axis and current-year August mean temperature is at the top. The start year of each interval is 1914, and for each iteration the end year is incremented by one and is represented on the $\mathrm{x}$-axis. 


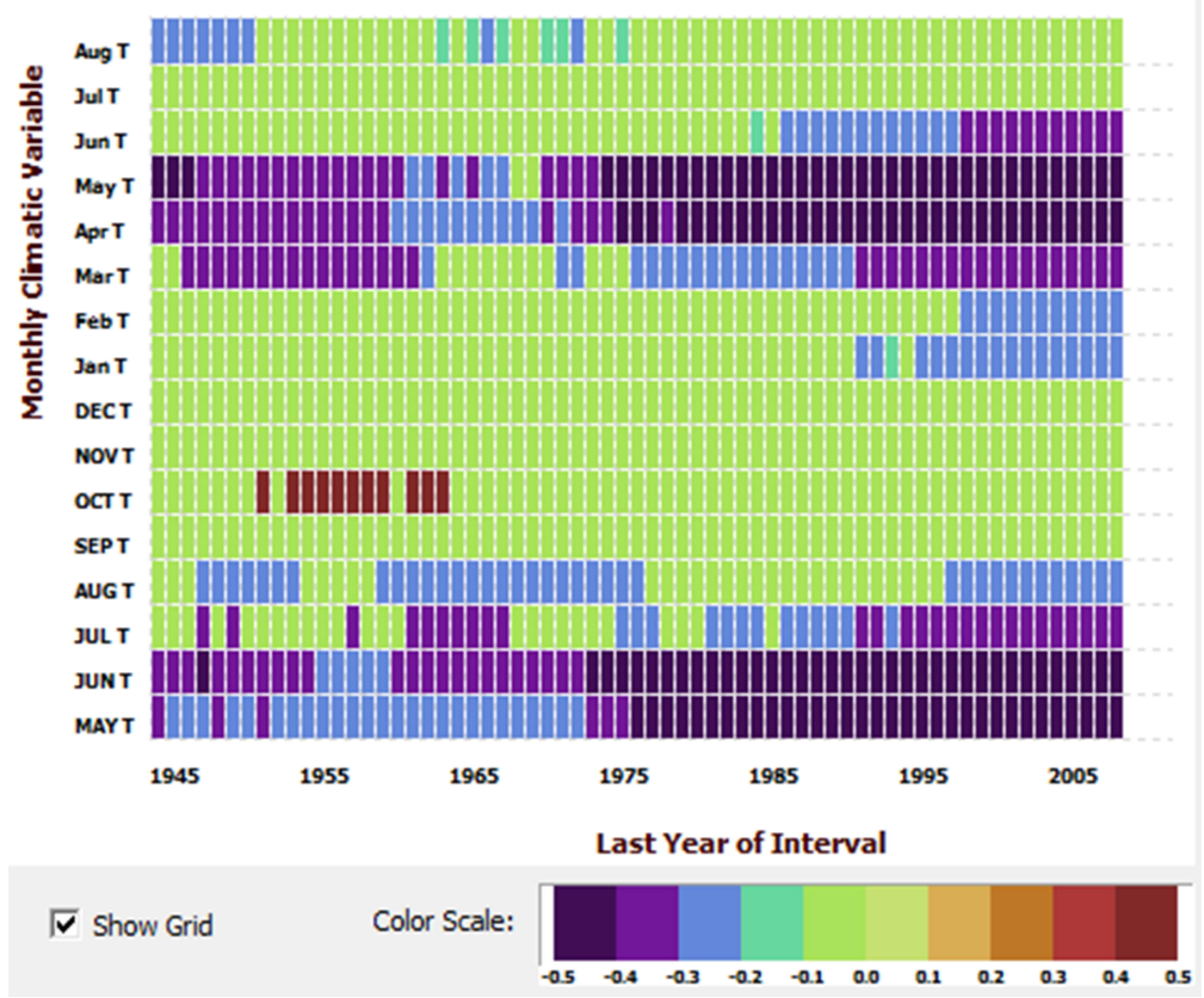

Figure 4.11 Evolutionary moving correlation analysis between CRUTEM4 mean monthly temperature and the COMP2 chronology starting with a 32-year interval, for the period 1914-2009. Mean monthly temperature is plotted on the y-axis. Previousyear May mean temperature is at the bottom of the axis and current-year August mean temperature is at the top. The start year of each interval is 1914, and for each iteration the end year is incremented by one and is represented on the $\mathrm{x}$-axis. 


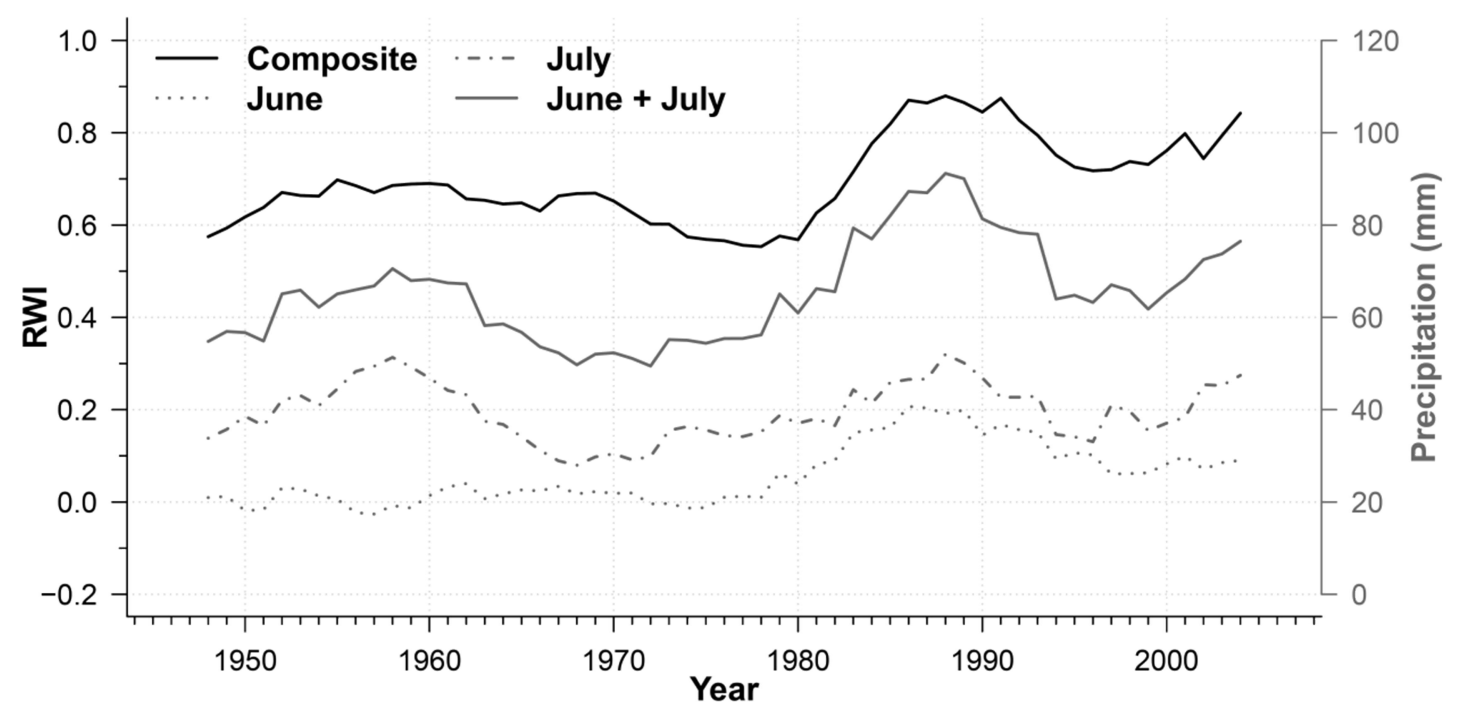

Figure 4.12 Composite chronology (11-year running average) plotted with 11-year running average of June, July, and June + July precipitation. Climate data used is from Yellowknife Station (1943-2009; Environment Canada, 2012).

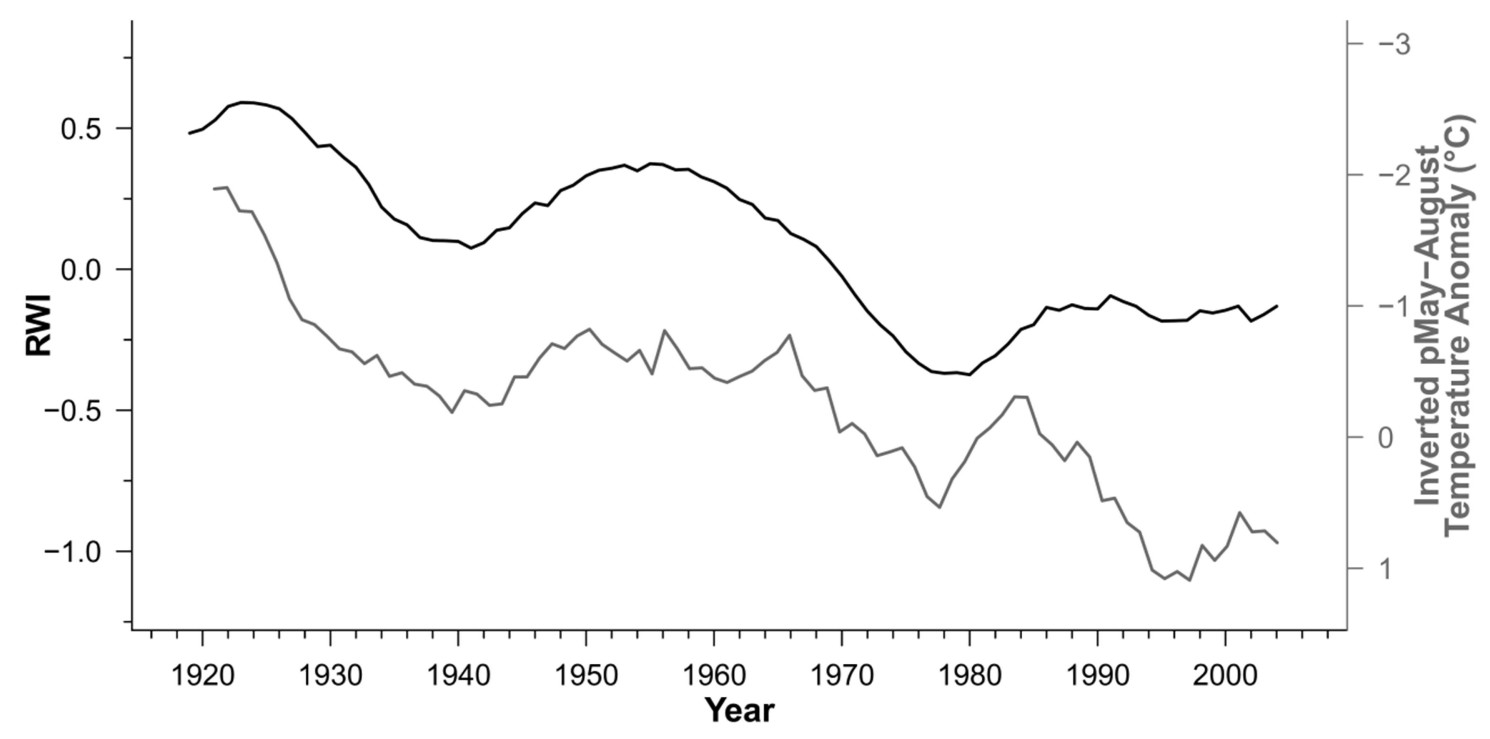

Figure 4.13 11-year running average COMP2 chronology and 11-year running average inverted previous-year mean May-August temperatures. Climate data used is from the CRUTEM4 dataset (1914-2009; Jones et al., 2012). 


\section{Chapter Five}

\section{Discussion}

\subsection{Soil moisture availability and COMP1 radial growth}

The radial growth of white spruce at treeline in northern Canada is commonly correlated with summer temperatures (e.g. Szeicz and MacDonald, 1995; D’Arrigo et al., 2009). In the Yellowknife region, white spruce seems to be responding to a combination of precipitation and temperature inputs during the growing season. COMP1 is most strongly correlated with total June-July precipitation and moderately correlated with summer temperature (Tables 4.8 and 4.9 ). The positive association of the COMP1 chronology with wet and warm conditions suggests that soil moisture availability is important at sites with abundant exposed bedrock and thin soil cover. Only the YEL2 and the PC1 chronologies demonstrate a significant positive relationship with PDSI (19011990; Table 4.8). The COMP1 chronology is not, however, significantly correlated with PDSI.

In many studies, soil moisture availability is identified as an important driver of decadal scale tree growth (Aakala and Kuuluvainen, 2011). Medium-frequency analysis showed a clear relationship between COMP1 and total June-July precipitation (Fig. 4.12). Periods of relatively greater summer precipitation between 1953-1960, 1977-1993, and 2000-2009 promoted radial growth. Relatively dry periods from 1961-1976 and 19942000 resulted in less radial growth. The connection to decadal scale variability is possibly related to the acclimation of trees to slower changes in soil moisture conditions caused by gradual changes in climate (Aakala and Kuuluvainen, 2011). In periods with favourable soil moisture availability, white spruce may distribute a higher proportion of photosynthetic activity to radial growth; whereas, in periods of greater soil moisture 
stress, white spruce resources may be allocated to the root system resulting in less growth (Fritts, 1976; Ibrahim et al., 1997).

\subsection{Shift in the climate-growth relationship}

Between 1943 and 2009, mean annual temperature at Yellowknife, NT increased by $1.3{ }^{\circ} \mathrm{C}$ (Environment Canada, 2012). In the central NT, $20^{\text {th }}$ century climatic trends have been shown to follow phase shifts of the Pacific Decadal Oscillation (PDO; Pisaric et al., 2009). Concordantly, during the negative phase of the PDO (1946-1976) the warming in the area was gradual before accelerating during the positive PDO phase (1977-2007). Additionally, CRUTEM4 gridded temperature records indicate that the rate of increase and average temperatures during the 1977-2007 positive PDO phase exceeded temperatures during the preceding positive PDO phase (1923-1945). Analogously, annual, seasonal, and monthly precipitation increased throughout the $20^{\text {th }}$ century in the study area, particularly during summer and early fall months of the 19772007 positive PDO phase.

Several northwestern North American dendroclimatological studies have observed shifts in the limiting factors influencing growth of white spruce along with PDO phase shifts (e.g. Ohse et al., 2012; Chavardès et al., 2013). Similarly, the amplified warming and precipitation associated with the 1977 PDO phase shift resulted in changes to the climatic factors that limited COMP1 growth. Effectively, rising temperatures extended the growing season into the months of June and August leading to a significant shift in the climate-growth relationship during the 1970s due to the earlier initiation of cambial activity (Figs. 4.6 and 4.8). During the negative PDO phase from 1943-1976, COMP1 was positively correlated with July precipitation, but was not correlated with 
summer temperatures (Figs. 4.6, 4.8, and 4.10). In conjunction with the 1977 PDO phase shift, the COMP1 limiting factor for growth shifted from July to June precipitation for the period 1977-2009. Additionally, the COMP1 chronology became more sensitive to summer temperatures, particularly June temperatures, since the 1970s (Fig. 4.10). Even though the growing season has been lengthened into the late summer, the climate-growth relationship shifted from July to June precipitation because the period of earlywood development is the most critical period for radial growth (Fritts, 1976; Vaganov et al., 1999). Significant increases in temperatures typically result in decreasing soil moisture availability to trees (Fritts, 1976). However, the strengthened positive relationship of COMP1 with June precipitation and early summer temperatures indicates that decreased soil moisture availability due to rapidly increasing temperatures have been counteracted by greater precipitation.

The earlier initiation of the growing season is also visible at the decadal scale (Fig. 4.12). Following 1977, as the growing season extended into June, the limiting factor for white spruce growth shifted from July to June precipitation. The high correlation values, especially those for June and June-July precipitation, support the notion that summer precipitation, and consequently soil moisture availability, is an important driver of the area's white spruce growth at the decadal scale. Additionally, the COMP1 chronology likely contains a decadal summer precipitation signal, a moisture stress signal, or both, beyond the period of gridded and instrumental climate data due to the high correlation values (Section 4.5.3). 


\subsection{Comparison with temperature reconstructions and other regional tree-ring chronologies}

Even though COMP1 growth has been more limited by precipitation than temperature since 1943, COMP1 exhibits similar low and medium-frequency trends to temperature sensitive tree-ring chronologies from the Northern Hemisphere and in the surrounding regions of northwestern North America (Fig. 5.1). Using a network of treering chronologies from across the Northern Hemisphere, D’Arrigo et al. (2006) identified relatively cool periods during the early 1700 s and from $\sim 1800$ to 1850 consistent with the COMP1 chronology. Also, D’Arrigo et al. (2006) and Szeicz and MacDonald (1995) describe increasing temperatures from 1750 to 1800 and after 1850 with the warmest period occurring in the late- $20^{\text {th }}$ century similar to radial growth trends recorded by the COMP1 chronology. There is a decoupling of the COMP1 chronology from these two temperature reconstructions between 1740 and 1780 when the COMP1 chronology exhibits increasing growth initiated twenty years after that shown in the two reconstructions. Furthermore, a temperature sensitive ring-width chronology developed by D'Arrigo et al. (2009) at latitudinal treeline from Coppermine River, NT exhibits similar trends where white spruce growing at Coppermine River experiences suppressed growth during the early $18^{\text {th }}$ and $19^{\text {th }}$ centuries and growth release from 1850 onward (Fig. 5.1c).

In contrast, Szeicz and MacDonald (1996) were unable to separate the combined effect of precipitation and temperature on white spruce growth at the Campbell Dolomite Upland, NT. They developed a qualitative assessment of past soil moisture stress in the area and found that the periods of $1700-1710$ and $1820-1855$ were periods of growth 

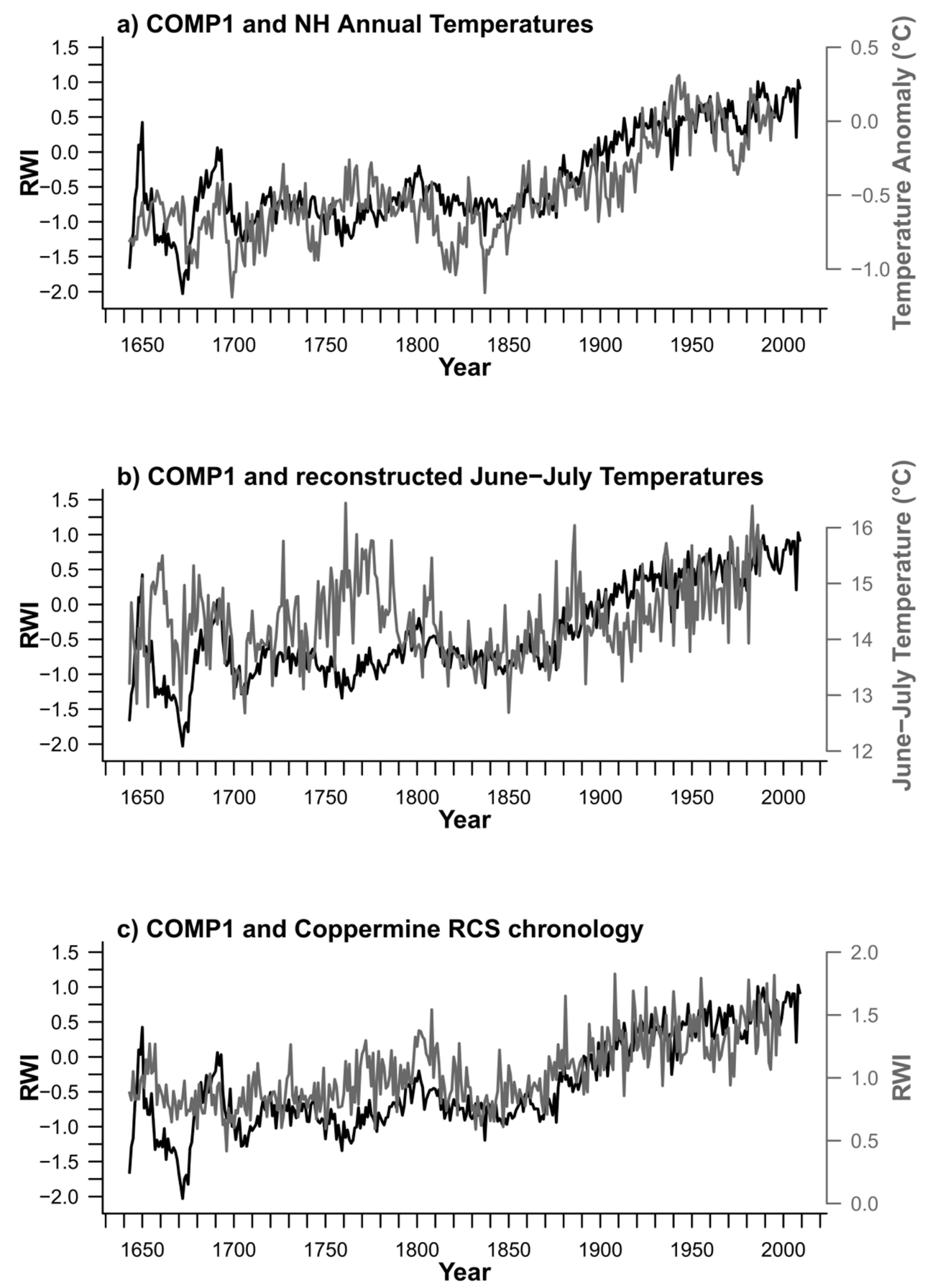

Figure 5.1 a) COMP1 and reconstructed Northern Hemisphere annual temperature anomalies from the 1961-1990 mean (1643-2000; $r=0.743, \mathrm{p} \leq 0.0001$; D'Arrigo et al., 2006); b) COMP1 and reconstructed June-July mean temperatures from northwestern Canada (1643-1990; $r=0.302, \mathrm{p} \leq 0.0001$; Szeicz and MacDonald, 1995); c) COMP1 and Coppermine River, NT tree-ring chronology $(1643-2000 ; r=0.685, \mathrm{p} \leq 0.0001$; D'Arrigo et al., 2009). The three chronologies were retrieved from http://www.ncdc.noaa.gov/data-access/paleoclimatology-data/datasets. 
suppression. COMP1 growth during these two periods is noticeably suppressed (Fig. 4.5). Additionally, the COMP1 chronology and the Schweingruber et al. (1993) Great Slave Lake region ring-width chronology exhibit similar medium-frequency changes. Schweingruber et al. (1993) found that tree growth in the area was suppressed by colder/drier conditions between 1810-1825, 1910-1920, and 1940-1950. Comparing the COMP1 chronology with a jack pine tree-ring precipitation reconstruction from the Yellowknife area reveals a good agreement between the chronologies at the medium scale. Pisaric et al. (2009) reconstructed relatively dry periods for $1698-1735,1776-$ $1796,1842-1865$, and $1879-1893$. The periods with above average reconstructed June precipitation include 1756-1775, 1822-1841, 1894-1926, and 1976-2005. These periods agree with periods of growth suppression and release in the composite chronologies, respectively.

Pointer year analysis revealed that the ten site chronologies demonstrated consistent network wide high-frequency variability (Fig. 4.3 and Table 4.3). Highfrequency variability in tree-rings is believed to represent growth responses to wide spread climatic events (Fritts, 1976; Schweingruber et al., 1990; Briffa et al., 1998b; Neuwirth et al., 2007; Elferts, 2007; Génova, 2012). White spruce in this study appears to be regulated by the combined effects of moisture and temperature stress; therefore, extreme negative pointer years should indicate regional to larger scale cold/dry conditions and/or extreme positive pointer years should indicate warm/wet conditions. However, the pointer years in this network only display moderate coherence with reconstructed June precipitation extremes from the Yellowknife area (Pisaric et al., 2009). Two narrow pointer years (1904 and 1942) and two wide pointer years (1948 and 
1981) match with the reconstructed June precipitation extremes (Pisaric et al., 2009). This indicates that white spruce growing in the area may not have been regulated by larger scale precipitation patterns before the $20^{\text {th }}$ century.

Negative pointer years sometimes reflect a substantial decrease in average temperatures and insolation due to major volcanic events (Briffa et al., 1998b). The narrowest year of growth of the network is 1837 and may reflect the extended impacts of the Coseguina eruption of 1835 (Self et al., 1989). The Coseguina eruption cooled Northern Hemisphere temperatures in 1836 and 1837 to $0.29{ }^{\circ} \mathrm{C}$ and $0.32{ }^{\circ} \mathrm{C}$ below the 1881-1960 base, respectively (Briffa et al., 1998b). While 1836 was not found to be a pointer year, the 1836 ring was the only year that consistently had poor latewood development and demonstrated significant frost damage. Major volcanic events cannot be attributed to the other narrow pointer years; however, volcanic eruptions have also been shown to reduce hemispheric temperatures on decadal and multi-decadal timescales (Briffa et al., 1998b). As a result, the 1815 Tambora, Indonesia and the 1912 Novarupta, Alaska eruptions may have played a role in the relatively suppressed growth of the late 1810 s and the 1910s.

\subsection{Divergence}

Divergence is defined as the negative response of traditionally, and theoretically, temperature-sensitive trees to rising temperatures in the $20^{\text {th }}$ century, particularly at high latitudes (Briffa et al., 1998a; D'Arrigo et al., 2008). Given this definition, the network of ten white spruce chronologies showed divergence at the group level much like Porter and Pisaric (2011) and Porter et al. (2013). Pointer year, correlation matrix, and principal component analysis revealed that the site chronologies are highly synchronous prior to 
the 1930s, whereupon they diverge in trend. Additionally, from the 1790s until the 1930s, COMP1 and COMP2 exhibit similar low, medium, and high frequency signals. After the 1930s, COMP1 continued to experience increasing growth trends; whereas, COMP2 begins to exhibit decreasing growth.

The divergence in trend was reflected in the climate-growth relationships of the COMP1 and COMP2 chronologies. Climate growth analysis revealed that the COMP1 chronology maintained a weak positive response to current-year early summer temperatures and a strong positive response to current-year total June-July precipitation after the early-1940s (Fig. 4.6). Conversely, the COMP2 chronology responded negatively to previous-year mean May-August temperatures (Fig. 4.7) and slightly negatively to current-year May precipitation. During the period of increasing $20^{\text {th }}$ century temperatures, soil evapotranspiration demands increased and likely resulted in greater moisture stress at diverging COMP2. Importantly, the divergence in the network is confined to low and medium frequency trends, as demonstrated by the results of pointer year analysis that revealed a consistent high-frequency signal across the tree-ring network before and after the 1930s (Fig. 4.3).

\subsubsection{Timing of Divergence}

The COMP2 chronology divergence in trend occurred during the 1930s (Fig. 4.5) and adds to the growing body of evidence that identifies divergence earlier than the more traditionally identified timing of divergence during the 1950s (e.g. Briffa et al., 1998a; Pisaric et al., 2007; Porter and Pisaric, 2011; Porter et al., 2013). In particular, two studies have observed the initiation of divergence in northwestern Canada during the 1930s. Pisaric et al. (2007) found that subpopulations of white spruce exhibited divergence in the 
1930s in the Mackenzie Delta. Additionally, Porter and Pisaric (2011) determined that divergence began in the 1930s in the northern Yukon, which is twenty years earlier than the timing of divergence they observed from 28 re-examined, independent white spruce chronologies from previously published sites across northwestern North America.

\subsubsection{Possible Causes}

The widespread nature of the divergence problem indicates that a large-scale, possibly global, cause likely accounts for a portion of the divergence exhibited in this study (Briffa et al., 1998a; Wilmking et al., 2005; Lloyd and Bunn, 2007; Porter and Pisaric, 2011). At the continental to global scale, the most widely proposed cause of divergence is temperature-induced drought stress (e.g. Jacoby and D'Arrigo, 1995; Barber et al., 2000; Lloyd and Fastie, 2002; D'Arrigo et al., 2009; McGuire et al., 2010), which may account for some of the divergence in this network. In their study white spruce growing in Alaska at altitudinal and latitudinal treeline, Lloyd and Fastie (2002) observed that growth declines were more common at warmer and drier sites than cooler and more humid sites. The authors suggest that rising temperatures resulted in greater moisture stress resulting in less tree growth. However, Alaska has experienced decreasing precipitation in a period of rising temperatures, while central NT has experienced greater precipitation since the early-mid $20^{\text {th }}$ century. Nonetheless, D'Arrigo et al. (2009) observed divergence at Thelon South, Nunavut where rising temperatures and greater precipitation occurred since the 1950s. D'Arrigo et al. (2009) suggest that while precipitation has increased in some regions of northern Canada, the increase has not offset higher evapotranspiration demands caused by rising temperatures. 
The link between soil moisture conditions and divergence is not straightforward. The results of this study possibly contradict the proposal by King (2009) that the effects of organic layer thickness on thicker depths of the surficial organic layers limit evapotranspiration rates of the active layer and keep temperatures cooler, resulting in more positive responses of white spruce radial growth to temperatures. Conversely, thinner organic layers resulted in warmer and drier active layers that resulted in negative temperature responses of white spruce (King, 2009). In this study, soil depths were not directly measured, but field observations noted that thinner soils were found at the COMP1 sites compared to COMP2 sites.

Other potential large scale factors that could lead to divergence include: exceeded temperature thresholds (Wilmking et al., 2004; D’Arrigo et al., 2008), non-linear growth responses to changes in snow cover (Vaganov et al., 1999), falling stratospheric ozone concentrations (Briffa et al., 2004), and 'global dimming' (D'Arrigo et al., 2008). It is possible that many of these proposed causes have affected white spruce growth in the study area either individually or concurrently.

\subsubsection{Interior Boreal vs. Treeline Forest Cover}

Current and previous-year temperatures positively affected productivity of white spruce at the colder, more open-canopy COMP1 sites (Tables 4.8 and 4.9). Conversely, the warmer, more closed-canopy COMP2 sites exhibited strong and significant negative correlations with current and previous season temperatures (Tables 4.8 and 4.9). These results correspond with recent dendroclimatological studies that have demonstrated decreasing growth trends at closed-canopy white spruce sites (e.g. Lloyd and Bunn, 2007; Williams et al., 2011). Williams et al. (2011) studied 59 white spruce site chronologies 
from Alaska and identified three key tendencies also found in this study's network: (i) growth is more sensitive to temperature during relatively cold growing seasons; (ii) cooler sites with lower growing season temperatures were more sensitive to temperature than warmer sites; and, (iii) warmer, closed-canopy sites are responding negatively to increasing temperatures beyond the optimal growing season temperature.

The network's divergence is consistent with satellite observations of 'greening' near and beyond the forest-tundra boundary in response to $20^{\text {th }}$ century warming, and the 'browning' of warmer, closed-canopied regions (e.g., Bunn and Goetz, 2006; Beck and Goetz, 2011; Beck et al., 2011; Berner et al., 2011; Xu et al., 2013). These satellitederived studies also note differing seasonal trends between treeline regions and closedcanopy vegetation similar to the differing responses of COMP1 and COMP2 (Bunn and Goetz, 2006). Treeline and tundra vegetation is responding favourably to increasing temperatures throughout the summer months (May-August); whereas, closed-canopy forested areas are showing net photosynthetic gains during the early summer (May-June) that are offset by net photosynthetic losses in the late summer (July-August) resulting in net browning (Bunn and Goetz, 2006).

The divergence exhibited by white spruce in this study may be exemplifying a poleward shift of the boreal forest treeline, which has been reported in the circumpolar north (Beck et al., 2011; Xu et al., 2013). Rapidly rising winter temperatures in recent decades has decreased temperature seasonality in northern environments. Given that the photosynthetic activity is tied to threshold temperatures, Xu et al. (2013) propose that, as temperature seasonality decreases, the timing of these thresholds has changed resulting in decreased growth at interior boreal forests sites. This may account for the decreasing 
trend of the COMP2 chronology. Whereas, temperatures at colder sites are no longer limiting white spruce growth due to more optimal climatic conditions (Beck et al., 2011; Xu et al., 2013), and may account for the improved summer temperature relationship of the COMP1 chronology since the 1970s.

\subsection{Potential for Reconstruction}

White spruce growth at the COMP1 sites was strongly influenced by summer precipitation over the period 1943-2009; however, the relationship has not been stable since 1943. During the 1970s, July to June precipitation combined with co-varying, unstable influences of summer temperatures. COMP2 sites exemplified synchronous growth trends to the COMP1 sites until the 1930s, when the two regional chronologies began to diverge from one another. The white spruce sampled in this study should be used with caution for climate reconstructions because reconstructions require a time stable relationship between radial growth and climate.

This network of chronologies provides an important glimpse into the climategrowth relationship over time and illustrates how diverging trends in the $20^{\text {th }}$ century are the result of differing responses to rapidly rising temperatures. In particular, the network indicates that a mid-1970s shift in radial growth response from July to June precipitation in conjunction with a phase shift of the PDO is likely due to the lengthening of the growing season. Identification of the time-transgression shift in the radial growth response supports the need to assess the time stability of climate-growth relationships before reconstructing climate variables. 


\section{Chapter Six}

\section{Conclusion}

\subsection{Summary}

White spruce tree-ring samples were collected at 10 sites along a latitudinal gradient northeast of Yellowknife, NT. The sites range from those characterized by closed-canopy boreal forests in the south to open-canopy forests at the northern limits of the transect. Standard dendrochronological methods were used to collect and prepare the samples, measure the ring-widths, and crossdate the ring-width series to develop standardized site chronologies. A signal-free RCS technique was used to remove age related radial growth trends and preserve low and medium frequency trends. Over 265 living and dead tree samples were measured to develop site chronologies ranging in length from 206 to 367 years. Extending to 1643, the regional chronology represents the oldest tree ring-width record in the area. The site chronologies were assessed using pointer year, correlation matrix, and principal component analysis to identify inter-site variability and to develop two composite chronologies. Climate-growth relationships were identified by correlation analyses with instrumental climate records from the Yellowknife climate station and regional gridded climate records. Split period and moving interval correlation analysis was performed to assess the temporal stability and identify shifts in the limiting factors for growth.

Significant climate-growth relationships were identified at the site level and composite chronology level. The two composite chronologies display opposing responses to summer precipitation and temperatures. COMP1 responded positively to current and previous-year summer precipitation and temperatures. COMP2 responded negatively to changes in current and previous-year May precipitation and summer temperatures. 
The climate-growth relationships were not time-stable. Split period and moving correlation analysis revealed that the COMP1 white spruce experienced a shift in limiting growth factors. White spruce was positively correlated with July precipitation for 19431976, but a shift to June precipitation occurred during the period 1977-2009. This shift coincides with the 1977 phase shift in the PDO from negative to positive indices. Forward evolutionary analysis indicated that the COMP1 chronology began to be significantly sensitive to June temperatures around $\sim 1972$, and sensitive to July temperatures around $\sim 1987$. The amplified warming and precipitation resulted in an extension of the growing season into the early summer changing the limiting factors responsible for white spruce growth during recent decades.

The divergence identified between the two composite chronologies is similar to that identified around the circumpolar north, and appears to be a $20^{\text {th }}$ century phenomenon. Pointer year, correlation matrix, and principal component analysis revealed that site chronologies were highly synchronous prior to the 1930s. After the 1930s, the COMP1 chronology continued to experience increasing growth trends. On the other hand, the COMP2 chronology diverged after the 1930s, somewhat earlier than the divergence point identified in most previous dendroclimatological studies (i.e. $\sim 1950 \mathrm{~s}$ ).

A singular cause of divergence in trend and climate-growth response was not identified in this study. As with most previous research, the possible causes of divergence appears to range from small and site-specific to large and global in scale. At the sitelevel, climate-growth relationships indicate that rising temperatures have outpaced increases in precipitation, which may have depleted available soil moisture for trees at some sites due to micro-topographic conditions. In recent decades, trees growing at 
COMP2 sites appear to have experienced greater moisture stress compared to nondiverging sites comprising the COMP1 regional chronology.

At the larger scale, the site-level divergence is possibly symptomatic of late $20^{\text {th }}$, early $21^{\text {st }}$ century landscape patterns of tree growth in northern environments. Several dendroclimatological studies have identified increasing growth trends at cooler opencanopy sites, but decreasing growth trends at warmer, closed-canopy sites (e.g. Lloyd and Bunn, 2007; Williams et al., 2011). Correspondingly, productivity of white spruce at colder, open-canopy sites closer to treeline (BLK1 and DRY1) exhibits strong and significant positive correlations with current and previous season temperatures. The COMP2 sites are the three southernmost sites and are typified by closed-canopy conditions. They exhibit strong and significant negative correlations with current and previous-year temperatures. These diverging trends appear to be connected to observed, satellite-derived trends of circumpolar vegetation productivity. Large portions of northern environments near and beyond the forest-tundra boundary have been greening in response to $20^{\text {th }}$ century warming, but warmer regions within forest interiors are browning (e.g. Bunn and Goetz, 2006; Beck and Goetz, 2011; Beck et al., 2011; Berner et al., 2011; Xu et al., 2013). Lastly, divergence in this network is likely indicative of the poleward shift of the boreal forest treeline in the circumpolar north (e.g. Beck et al., 2011; Xu et al., 2013).

\subsection{Recommendations for Future Research}

1) Additional chronologies should be collected along the latitudinal transect to increase the strength of the climate signal contained in the chronologies by removing potential site-specific influences. This study showed that white spruce trees situated at 
colder sites closer to treeline are more sensitive to temperature variability and do not display a $20^{\text {th }}$ century divergence in trend. White spruce chronologies from cooler, opencanopy sites are potentially well suited to use in dendroclimatic temperature reconstructions. Developing more white spruce chronologies south of the treeline would enable further insight into the issues of divergence and landscape-scale browning and greening. Further sampling along the network would allow statistical testing of the spatial and temporal coherence of white spruce growth with satellite-derived vegetation productivity data (i.e. NDVI) in recent decades.

2) Studying other tree proxies of the chronologies would provide more insight into climate-growth dynamics and possibly circumvent the observed divergence in trend noted in several chronologies in this study. Maximum density chronologies have been observed to be a more reliable proxy at sites where summer temperatures appear to negatively affect ring-widths (e.g. D'Arrigo et al., 2009; Andreu-Hayles et al., 2011; Anchukaitis et al., 2013). Moreover, other tree-ring proxies such as latewood and earlywood width, or stable isotopes could be used as proxies for climate variables to provide different insights. 


\section{References}

Aakala, T., \& Kuuluvainen, T. (2011). Summer droughts depress radial growth of Picea abies in pristine taiga of the Arkhangelsk province, northwestern Russia. Dendrochronologia, 29, 67-75. doi:10.1016/j.dendro.2010.07.001.

Anchukaitis, K. J., Evans, M. N., Kaplan, A., Vaganov, E. A., Hughes, M. K., GrissinoMayer, H. D., \& Cane, M. A. (2006). Forward modeling of regional scale treering patterns in the southeastern United States \& the recent influence of summer drought. Geophysical Research Letters, 33, L04705. doi: 10.1029/2005GL025050.

Anchukaitis, K. J., D’Arrigo, R. D., Andreu-Hayles, L., Frank, D., Verstege, A., Curtis, A., Buckley, B. M., Jacoby, G. C., \& Cook, E. R. (2013). Tree-ring reconstructed summer temperatures from northwestern North America during the last nine centuries. Journal of Climate, 26, 3001-3012. doi:10.1175/JCLI-D-11-00139.1.

Andreu-Hayles, L., D’Arrigo, R., Anchukaitis, K. J., Beck, P. S. A., Frank, D., \& Goetz, S. (2011). Varying boreal forest response to Arctic environmental change at the Firth River, Alaska. Environmental Research Letters, 6, 045503.

Barber, V., Juday, G., \& Finney, B. (2000). Reduced growth of Alaska white spruce in the twentieth century from temperature-induced drought stress. Nature, 405, 668672.

Barber, V., Juday, G., Finney, B., \& Wilmking, M. (2004). Reconstruction of summer temperatures in interior Alaska from tree-ring proxies: evidence for changing synoptic climate regimes. Climatic Change, 63, 91-120.

Beck, P. S. A., \& Goetz, S. J. (2011). Satellite observations of high northern latitude vegetation productivity changes between 1982 \& 2008: ecological variability \& regional differences. Environmental Research Letters, 6, 045501. doi: 10.1088/1748-9326/6/4/045501.

Beck, P. S. A, Juday, G. P., Alix, C., Barber, V. A, Winslow, S. E., Sousa, E. E. ... Heiser, P. (2011). Changes in forest productivity across Alaska consistent with biome shift. Ecology Letters, 14, 373-379. doi:10.1111/j.14610248.2011.01598.x.

Berner, J., Ha, S.-Y., Hacker, J. P., Fournier, A., \& Snyder, C. (2011). Model uncertainty in a mesoscale ensemble prediction system: stochastic versus multiphysics representations. Monthly Weather Review, 139, 1972-1995.

Biondi, F., \& Waikul, K. (2004). DENDROCLIM2002: A C++ program for statistical calibration of climate signals in tree-ring chronologies. Computers \& Geosciences, 30, 303-311.

Bradley, R. S. (1999). Chapter 5: Ice cores. In Paleoclimatology: Reconstructing Climates of the Quaternary $2^{\text {nd }}$ Edition (pp. 125-190). New York, NY: Academic Press.

Briffa, K. R., \& Jones, P. D. (1990). Basic chronology statistics \& assessment. In: E. R. Cook, \& L. A. E. Kairiukstis (Eds.), Methods of Dendrochronology: Applications 
in the Environmental Sciences (pp. 137-152). Dordrecht, Germany: Kluwer Academic Publishers.

Briffa, K., Schweingruber, F., Jones, P., \& Osborn, T., (1998a). Reduced sensitivity of recent tree growth to temperature at high northern latitudes. Nature, 391, 678682.

Briffa, K., Jones, P., Schweingruber, F., \& Osborn, T. (1998b). Influence of volcanic eruptions on Northern Hemisphere summer temperatures over the past 600 years. Nature, 393, 450-455.Briffa, K. (2000). Annual climate variability in the Holocene: intepreting the message of ancient trees. Quaternary Science Reviews, 19, 87-105.

Briffa, K., Osborn, T., Schweingruber, F., Harris, I., Jones, P., \& Shiyatov, S. (2002a). Tree-ring width and density data around the Northern Hemisphere: Part 1, local and regional climate signals. The Holocene, 12, 737-757.

Briffa, K., Osborn, T., Schweingruber, F., Harris, I., Jones, P. \& Shiyatov, S. (2002b). Tree-ring width and density data around the Northern Hemisphere: Part 2, spatiotemporal variability and associated climate patterns. The Holocene, 12, 759-789.

Briffa, K., Osborn, T., \& Schweingruber, F. (2004). Large-scale temperature inferences from tree-rings: a review. Global and Planetary Change, 40, 11-26.

Briffa, K., \& Melvin T. M. (2008) A closer look at Regional Curve Standardisation of tree-ring records: justification of the need, a warning of some pitfalls, and suggested improvements in its application. In: Hughes M.K., Diaz H.F., Swetnam T.W. (eds), Dendroclimatology: Progress and Prospects (pp. 113-145). Dordecht, Germany: Springer Verlag.

Brohan, P., Kennedy, J. J., Harris, I., Tett, S. F. B., \& Jones, P. D. (2006). Uncertainty estimates in regional and global observed temperature changes: a new dataset from 1850. Journal of Geophysical Research, 111, D12106. doi:10.1029/2005JD006548.

Bryson, R. A. (1966). Air masses, streamlines and the boreal forest. Geographical Bulletin, 8, 228-269.

Bunn, A. G., \& Goetz, S. J. (2006). Trends in satellite observed circumpolar photosynthetic activity from 1982-2003: The influence of seasonality, cover type and vegetation density. Earth Interactions, 10, 1-19.

Büntgen, U., Frank, D. C., Schmidhalter, M., Neuwirth, B., Seifert, M., \& Esper, J. (2005). Growth/climate response shift in a long subalpine spruce chronology. Trees, 20(1), 99-110. doi: 10.1007/s00468-005-0017-3.

Büntgen, U., Frank, D. C., Schmidhalter, M., Neuwirth, B., Seifert, M., \& Esper, J. (2006). Growth/climate response shift in a long subalpine spruce chronology. Trees Structure and Function, 20, 99-110.

Büntgen, U., Wilson, R., Wilmking, M., Niedzwiedz, T., \& Bräuning, A. (2008a). The “ Divergence Problem " in tree-ring research. TRACE, 1-9. 
Büntgen, U., Frank, D. C., Wilson, R., Carrer, M., Urbinati, C., \& Esper, J., (2008b). Testing for tree-ring divergence in the European Alps. Global Change Biology, $14,2443-2453$.

Büntgen, U., Frank, D., Trouet, V., \& Esper, J. (2009). Diverse climate sensitivity of Mediterranean tree-ring width and density. Trees, 24, 261-273. doi:10.1007/s00468-009-0396-y.

Burstyn, I. (2004). Principal component analysis is a powerful instrument in occupational hygiene inquiries. The Annals of Occupational Hygiene, 48, 655-661.

Burt, J. E., Barber, G. M., \& Rigby, D. L. (2009). Elementary Statistics for Geographers, Third Edition. New York, NY: The Guilford Press.

Canadian Forest Service, (1999). Distribution map of white spruce. by Natural Resources Canada. Retrieved from http://tidcf.nrcan.gc.ca/trees/. Accessed on 27/09/13.

Carrer, M., \& Urbinati, C. (2006). Long-term change in the sensitivity of tree-ring growth to climate forcing in Larix decidua. The New Phytologist, 170, 861-871. doi:10.1111/j.1469-8137.2006.01703.x.

Chavardès, R. D., Daniels, L. D., Waeber, P. O., Innes, J. L., \& Nitschke, C. R. (2013). Unstable climate-growth relations for white spruce in southwest Yukon, Canada. Climatic Change, 116, 593-611. doi:10.1007/s10584-012-0503-8.

Cohen, A.S. (2003). Paleolimnology: The History and Evolution of Lake Systems. Oxford, UK: Oxford University Press.

Cook, E. R. (1990). A conceptual linear aggregate model for tree rings. In E.R. Cook \& L.A. Kairiukstis (Eds.), Methods of Dendrochronology: Applications in the Environmental Sciences (pp. 98-102). Boston, Mass: Kluwer Academic Publishers.

Cook, E. R., Esper, J., \& D’Arrigo, R. (2004). Extra-tropical Northern Hemisphere land temperature variability over the past 1000 years. Quaternary Science Reviews, 23, 2063-2074.

Cook, E. R., Seager, R., Cane, M., \& Stahle, D. (2007). North American drought: Reconstructions, causes, and consequences. Earth-Science Reviews, 81, 93-134.

D’Arrigo, R. D., Jacoby, G. C., Free, M., \& Robock, A. (1999). Northern Hemisphere Temperature Variability for the Past Three Centuries: tree-ring and model estimates. Climatic Change, 42, 663-675.

D’Arrigo, R. D., Jacoby, G., Frank, D., Pederson, N., Cook, E., Buckley, B., Nachin, B., Mijiddorj, \& R., Dugarjav, C. (2001). 1738 years of Mongolian temperature variability inferred from a tree-ring width chronology of Siberian pine. Geophysical Research Letters, 28, 543-546. doi: 10.1029/2000GL011845.

D’Arrigo, R. D., Kaufmann, R. K., Davi, N., Jacoby, G. C., Laskowski, C., \& Myneni, R. B. (2004). Thresholds for warming-induced growth decline at elevational tree-line in the Yukon Territoy, Canada. Global Biogeochemical Cycles, 18, GB3021. 
D’Arrigo, R. D., Mashig, E., Frank, D., Wilson, R., \& Jacoby, G. (2005). Temperature variability over the past millennium inferred from northwestern Alaska tree rings. Climate Dynamics, 24, 227-236. doi: 10.1007/s00382-004-0502-1.

D’Arrigo, R. D., Wilson, R., Liepert, B., \& Cherubini, P. (2008). On the 'divergence problem' in northern forests: a review of the tree-ring evidence and possible causes. Global and Planetary Change, 60, 289-305.

D’Arrigo, R. D., Jacoby, G., Buckley, B., Sakulich, J., Frank, D. Wilson, R., Curtis, A., \& Anchukaitis, K. (2009). Tree growth and inferred temperature variability at the North American Arctic treeline. Global and Planetary Change, 65, 71-82.

Davi, N., Jacoby, G., \& Wiles, G. (2003). Boreal temperature variability inferred from maximum latewood density and tree-ring width data, Wrangell Mountain Region, Alaska. Quaternary Research, 60, 252-262.

Davi, N., Jacoby, G., Fang, K., Li, J., D’Arrigo, R., Baatarbileg, N., \& Robinson, D. (2010). Reconstructing drought variability for Mongolia based on a large-scale tree ring network: 1520-1993. Journal of Geophysical Research, 115(D22), D22103. doi:10.1029/2010JD013907.

Driscoll, W., Wiles, G., D’Arrigo, R., \& Wilmking, M., (2005). Divergent tree growth response to recent climatic warming, Lake Clark National Park and Preserve, Alaska. Geophysical Research Letters, 32, L20703. doi:10.1029/2005GL024258.

Ecosystem Classification Group. (2008). Ecological Regions of the Northwest Territories-Taiga Shield. Government of the Northwest Territories, Department of Environment and Natural Resources, Yellowknife, NWT, Canada.

Elliott, G. P. (2010). Influences of $20^{\text {th }}$-century warming at the upper tree-line contingent on local-scale interactions: evidence from a latitudinal gradient in the Rocky Mountains, USA. Global Ecology and Biogeography, 20, 46-57. doi: 10.1111/j.1466-8238.2010.00588.x.

Elferts, D. (2007). Scots pine pointer-years in northwestern Latvia and their relationship with climatic factors, Acta Universitatis Latviensis, 723, 163-170.

Environment Canada,(2012). Adjusted Historical Canadian Climate Data (AHCCD). Available at: http:// http://ec.gc.ca/dccha-ahccd. Accessed on: 04/07/2012.

Esper, J., Frank, D., Wilson, R. J. S., \& Briffa, K. (2005). Effect of scaling and regression on reconstructed temperature amplitude for the past millennium. Geophysical Research Letters, 32, doi:10.1029/2004GL021236.

Esper, J., Frank, D., \& Luterbacher, J. (2007). On selected issues and challenges in dendroclimatology. In F. Kienast, O. Wildi and S. Ghosh (Eds.), A Changing World. Challenges for Landscape Research (pp. 113-132). Berlin: Germany: Springer-Verlag.

Esper, J., \& Frank, D. (2009). Divergence pitfalls in tree-ring research. Climatic Change, 94(3-4), 261-266. doi: 10.1007/s10584-009-9594-2.

Felis, T., \& Pätzold, J. (2004). Corals as climate archive. In H. Fischer, T. Kumke, G. Lohmann, G. Flöser, H. Miller, H. v. Storch, J. F. W. Negendank (Eds.), The 
climate in historical times: Towards a synthesis of Holocene proxy data and climate models (pp. 91-108). Berlin: Germany: Springer-Verlag.

Flower, A. (2008). A dendroclimatic investigation in the northern Canadian Rocky Mountains, British Columbia (Master's Thesis). University of Victoria, Victoria, British Columbia.

Fritts, H. (1976). Tree-Rings and Climate. Caldwell: The Blackburn Press.

Gajewski, K., \& Atkinson, D. (2003). Climatic change in northern Canada. Journal of Environmental Reviews, 11, 69-102.

Génova, M. (2012). Extreme pointer years in tree-ring records of Central Spain as evidence of climatic events and the eruption of the Huaynaputina Volcano (Peru, 1600 AD). Climate of the Past, 8, 751-764. doi:10.5194/cp-8-751-2012.

Grissino-Mayer, H. (2001). Evaluating crossdating accuracy: a manual and tutorial for the computer program COFECHA. Tree-Ring Research, 57, 205-221.

Holmes, R. L. (1983). Computer assisted quality control in tree-ring dating and measurement. Tree-Ring Bulletin, 43, 69-78.

Holmes, R. L. (1986). Quality control of crossdating and measuring: a user's manual for program COFECHA. In R.L. Holmes, R.K. Adams, \& H.C. Fritts (Eds.), Treering chronologies of western North America: California, eastern Oregon, and northern Great Basin (pp. 41-49). Tuscon, Arizona: University of Arizona Press.

Hughes, M. (2002). Dendrochronology in climatology - the state of the art. Dendrochronologia, 20, 95-116. doi: 10.1078/1125-7865-00011.

Ibrahim, L., Cameron, A. D., \& Proe, M. F. (1997). Main effects of nitrogen supply and drought stress upon whole-plant carbon allocation in poplar. Canadian Journal of Forest Research, 27, 1413-1419.

Intergovernmental Panel on Climatic Change (IPCC). (2007). Climate Change 2007: the physical science basis. Summary for Policy Makers. IPCC: Geneva. Retrieved from http://ipcc-wg1.ucar.edu/.

International Tree Ring Databank. (2012). Tree Ring. Retrieved from http://www.ncdc.noaa.gov/paleo/treering.html. Accessed on: 04/01/2012.

Jackson, J. E. (1991). A User's Guide to Principal Components. Toronto, Canada: WileyInterscience Publication.

Jacoby, G. C. \& Ulan, L. D. (1982). Reconstruction of past ice conditions in a Hudson Bay estuary using tree-rings. Nature, 298, 637-639.

Jacoby, G. C., \& D'Arrigo, R. D. (1995). Tree-ring width and density evidence of climatic and potential forest change in Alaska. Global Biogeochemical Cycles, 9(2), 227. doi: 10.1029/95GB00321.

Jacoby, G. C., Lovelius, N. V., Shumilov, O. I., Raspopov, O. M., Karbainov, J. M., \& Frank, D. C. (2000). Long-term temperature trends and tree growth in the Taymir region of northern Siberia. Quaternary Research, 53, 312-318. doi:10.1006/qres.2000.2130. 
Joliffe, I. (1986). Principal Component Analysis. New York, NY: Springer-Verlag.

Jones, P. D., \& Mann, M. (2004). Climate Over Past Millennia, Reviews of Geophysics, 42, 1-42, RG2002. doi: 10.1029/2003RG000143.

Jones, P. D., Lister, D. H., Osborn, T. J., Harpham, G., Salmon, M., \& Morice, C. P. (2012), Hemispheric and large-scale land surface air temperature variations: An extensive revision and an update to 2010, Journal Geophysical Research, 117, D05127. doi:10.1029/2011JD017139.

Juday, G. P., \& Alix, C. (2012). Consistent negative temperature sensitivity and positive influence of precipitation on growth of floodplain Picea glauca in Interior Alaska, Canadian Journal of Forest Research, 573, 561-573. doi:10.1139/X2012-008.

King, G. M. (2009). Factors influencing the growth of white spruce (Picea glauca) in the Mackenzie Delta, NT. Unpublished M.Sc. thesis, Carleton University, Ottawa, Canada.

Kramer, P. J. \& Kozlowski, T. T. (1960). Physiology of Trees. New York, NY: McGrawHill Book Company.

Larsen, C. P. S. (1996). Fire and climate dynamics in the boreal forest of northern Alberta, Canada, from AD 1850 to 1989. The Holocene, 6, 449-456. doi: 10.1177/095968369600600407.

Larsen, C. P. S., \& MacDonald, G. M. (1998). An 840-Year Record of Fire and Vegetation in a Boreal White Spruce Forest. Ecology, 79, 106-118.

Little, E. L. Jr. (1971). Atlas of United States Trees, Volume 1, Conifers And Important Hardwoods. Washington, DC: U.S. Department of Agriculture Miscellaneous Publication.

Lloyd, A. H., \& Fastie, C. (2002). Spatial and temporal variability in the growth and climate response of treeline trees in Alaska. Climatic Change, 58, 481-509.

Lloyd, A. H., \& Bunn, A. G. (2007). Responses of the circumpolar boreal forest to $20^{\text {th }}$ century climate variability. Environmental Research Letters, 2, 045013. doi:10.1088/1748-9326/2/4/045013.

Lloyd, A. H., Bunn, A. G., \& Berner, L. (2011). A latitudinal gradient in tree growth response to climate warming in the Siberian taiga. Global Change Biology, 17, 1935-1945. doi: 10.1111/j.1365-2486.2010.02360.x.

Loehle, C. (2007). A mathematical analysis of the divergence problem in dendroclimatology. Climatic Change, 94, 233-245.

Luckman, B., \& Wilson, R. (2005). Summer temperatures in the Canadian Rockies during the last millenium: a revised record. Climate Dynamics, 24, 131-141.

Luckman, B. H. (2007). 'Dendroclimatology'. In S.A. Elias (Ed.) Encyclopedia of Quaternary Science (pp. 465-475). New York, NY: Elsevier Scientific.

MacDonald, G., \& Gajewski, K. (1992). The northern treeline of Canada. In D. G. Janelle, Geographical Snapshots of North America (pp. 34-37). New York, NY: The Guilford Press. 
Mäkinen, H., \& Vanninen, P. (1999). Effect of sample selection on the environmental signal derived from tree-ring series. Forest Ecology and Management, 113, 8389. doi: 10.1016/S0378-1127(98)00416-2.

Mann, M. (2002). Little Ice Age. In M. MacCraccken, and J. Perry, Encyclopedia of Global Environmental Change (pp. 504-509). Chicester: John Wiley \& Sons, Ltd.

Mann, M. (2004). On smoothing potentially non-stationary climate time series. Geophysical Research Letters, 31, L07214. doi:10.1029/2004GL019569.

McGuire, A. D., Ruess, R. W., Clein, J. S., Lloyd, A. H., Yarie, J., \& Juday, G. P. (2010). Vulnerability of white spruce tree growth in interior Alaska in response to climate variability: dendrochronological, demographic, and experimental perspectives. Canadian Journal of Forest Research, 40, 1197-1209. doi:10.1139/X09-206.

Meko, D. (2006). Tree-ring inferences on water-level fluctuations of Lake Athabasca. Canadian Water Resources Journal, 31, 229-248.

Melvin, T. M. (2004). Historical growth rates and changing climatic sensitivity of boreal conifers, (Doctoral dissertation). University of East Anglia.

Melvin, T. M., \& Briffa, K. R. (2008). A "Signal-Free" approach to dendroclimatic standardisation. Dendrochronologia, 26, 71-86.

Mérian, P., Pierrat, J.-C., \& Lebourgeois, F. (2013). Effect of sampling effort on the regional chronology statistics and climate-growth relationships estimation. Dendrochronologia, 31, 58-67. doi:10.1016/j.dendro.2012.07.001.

Myneni, R. B., Keeling, C. D., Tucker, C. J., Asrar, G., \& Nemanin, R. R., (1997). Increased plant growth in the northern high latitudes from 1981 to 1991. Nature. 386, 698-702.

Neuwirth, B., Schweingruber, F. H., \& Winiger, M. (2007). Spatial patterns of central European pointer years from 1901 to 1971. Dendrochronologia, 24, 79-89. doi:10.1016/j.dendro.2006.05.004.

Ohse, B., Jansen, F., \& Wilmking, M. (2012). Do limiting factors at Alaskan treelines shift with climatic regimes?. Environmental Research Letters, 7, 015505. doi:10.1088/1748-9326/7/1/015505.

Overpeck, J. (1997). Arctic environmental change of the last four centuries. Science, 278, 1251-1256. doi: 10.1126/science.278.5341.1251.

Palmer, W. C. (1965). Meteorological Drought. Research Paper No.45, Washington, D.C: Department. of Commerce.

Payette, S., Filion, L., Delwaide, A., \& Begin, C. (1989). Reconstruction of tree-line vegetation response to long-term climate change. Nature, 341, 429-432.

Payette, S., \& Lavoie, C. (1994). The arctic tree-line as a record of past and recent climatic changes. Environmental Reviews, 2, 78-90.

Pisaric, M. F., Carey, S., Kokelj, S. V., \& Youngblut, D. (2007). Anomalous $20^{\text {th }}$ century tree growth, Mackenzie Delta, Northwest Territories, Canada. Geophysical Research Letters, 34, L05714. doi: 10.1029/2006GL029139. 
Pisaric, M. F., St-Onge, S. M., \& Kokelj, S. V. (2009). Tree-ring reconstruction of earlygrowing season precipitation from Yellowknife, Northwest Territories, Canada. Arctic, Antarctic, and Alpine Research, 41, 486-496.

Porter, T. J., \& Pisaric, M. F. (2011). Temperature-growth divergence in white spruce forests of Old Crow Flats, Yukon Territory, and adjacent regions of northwestern North America. Global Change Biology, 17, 3418-3430. doi:10.1111/j.13652486.2011.02507.x.

Porter, T. J., Pisaric, M.F., Kokelj, S. V., \& deMontigny, P. (2013). A ring-width-based reconstruction of June-July minimum temperatures since AD 1245 from white spruce stands in the Mackenzie Delta region, northwestern Canada. Quaternary Research, 80, 167-179. http://dx.doi.org/10.1016/j.yqres.2013.05.004.

Prensky, S. (1992) Temperature measurements in boreholes: an overview of engineering and scientific applications. The Log Analyst. 33, 313-333

Rossi, S., Deslauriers, A., Anfodillo, T., \& Carraro, V. (2007). Evidence of threshold temperatures for xylogenesis in conifers at high altitudes. Oecologia, 152, 1-12. doi:10.1007/s00442-006-0625-7

Schweingruber, F. H., Eckstein, D., Serre-Bachet, F., \& Braker, O. U. (1990). Identification, presentation and interpretation of event years and pointer years in dendrochronology. Dendrochronologia, 8, 9-38.

Schweingruber, F. H. (1993). Trees and Wood in Dendrochronology. Springer Series in Wood Science, Berlin, Germany: Springer-Verlag.

Schweingruber, F. H., Briffa, K., \& Nogler, P. (1993). A tree-ring densitometric transect from Alaska to Labrador. International Journal of Biometeorology, 37, 151-169.

Scott, P. A., Hansell, R. I. C., \& Fayle, D. C. F. (1987). Establishment of white spruce populations and responses to climatic change at the treeline, Churchill, Manitoba, Canada. Arctic and Alpine Research, 19, 45-51.

Self, S., Rampino, M., \& Carr, M. (1989). A reappraisal of the 1835 eruption of Cosigina and its atmospheric impact. The Bulletin of Volcanology, 52, 57-65.

Speer, J. H. (2010). Fundementals of Tree-Ring Research. Tuscon, AZ: The University of Arizona Press.

Stanhill, G., \& Cohen, S. (2001). Global dimming: a review of the evidence for a widespread and significant reduction in global radiation with discussion of its probable causes and possible agricultural consequences. Agricultural and Forest Meteorology, 107, 255-278.

Stockton, C., \& Fritts, H. (1973). Long-term reconstructions of water level changes for Lake Athabasca by analysis of tree-rings. Water Resources Bulletin, 9, 10061027.

Strackee, J., \& Jansma, E. (1992). The statistical properties of 'mean sensitivity' - a reappraisal. Dendrochronologia, 10, 121-135. 
Szeicz, J. M., \& MacDonald, G. M. (1994). Age-dependent tree-ring growth responses of subarctic white spruce to climate. Canadian Journal of Forest Research, 24, 120 132.

Szeicz, J. M., \& MacDonald, G. M. (1995). dendroclimatic reconstruction of summer temperatures in northwestern canada since a.d. 1638 based on age-dependent modeling. Quaternary Research, 44, 257-266.

Szeicz, J. M. (1996). White spruce light rings in northwestern canada. Arctic and Alpine Research, 28, 184-189.

Szeicz, J. M., \& MacDonald, G. M. (1996). A 930-year ring-width chronology from moisture-sensitive white spruce (Picea glauca Moench) in northwestern Canada. The Holocene, 6, 345-351.

Tardif, J., Conciatori, F., \& Leavitt, S. (2008). Tree-rings, $\delta 13 \mathrm{C}$ and climate in Picea glauca growing near Churchill, subarctic Manitoba, Canada. Chemical Geology, 252, 88-101. doi: 10.1016/j.chemgeo.2008.01.015.

Tomkins, J. D., Lamoureux, S., \& Sauchyn, D. (2008). Reconstruction of climate and glacial history based on a comparison of varve and tree-ring records from Mirror Lake, Northwest Territories, Canada. Quarternary Science Reviews, 27, 14261441.

Vaganov, E. A., Hughes, M. K., Kirdyanov, A. V., Schweingruber, F. H., \& Silkin, P. P. (1999). Influence of snowfall and melt timing on tree growth in subarctic Eurasia. Nature, 400, 149-151.

Velmex Inc. (1992). The Velmex “TA” System for Research and Non-contact Measurement Analysis, Bloomfield, NY: Velmex Inc.

Vincent, L. A., (1998). A technique for the identification of inhomogeneities in Canadian temperature series. Journal of Climate, 11, 1094-1104.

Vincent, L. A., Wang, X. L., Milewska, E. J., Wan, H., Yang, F., \& Swail, V. (2012). A second generation of homogenized Canadian monthly surface air temperature for climate trend analysis. Journal of Geophysical Research, 117, D18110, doi:10.1029/2012JD017859.

VoorTech Consulting. (2007). MeasureJ2X. Holderness, New Hampshire.

Wigley, T. M. L., Briffa, K., \& Jones, P. D. (1984). On the average value of correlated time series, with applications in dendroclimatology and hydrometeorology. Journal of Applied Meteorology, 23, 201-213.

Williams, A. P., Xu, C., \& McDowell, N. G. (2011). Who is the new sheriff in town regulating boreal forest growth? Environmental Research Letters, 6, 041004. doi:10.1088/1748-9326/6/4/041004.

Wilmking, M., Juday, G., Barber, V., \& Zald, H., (2004). Recent climate warming forces contrasting growth responses of white spruce at treeline in Alaska through temperature thresholds. Global Change Biology, 10, 1724-1736. 
Wilmking, M., D’Arrigo, R. D., Jacoby, G., \& Juday, G. (2005). Increased temperature sensitivity and divergent growth responses in circumpolar boreal forests.

Geophysical Research Letters, 32, L15715. doi:10.1029/2005GLO23331.

Wilson, R. (1999). Dendroclimatic Reconstruction of Summer Temperatures from Upper Tree-Line Sites in Interior British Columbia. (Master's thesis). University of Western Ontario, London, Ontario.

Wilson, R., \& Luckman, B. (2003). Dendroclimatic reconstruction of maximum summer temperatures from upper treeline sites in interior British Columbia, Canada. The Holocene, 13, 851-861.

Wilson, R., D’Arrigo. R. D., Buckley, B., Büntgen, U., Esper, J., Frank, D., \& Youngblut, D. (2007). A matter of divergence - tracking recent warming at hemispheric scales using tree-ring data. Journal of Geophysical Research, A 112, doi:10.1029/2006JD008318.

Wright, H.E. (1967). The use of surface samples in Quaternary pollen analysis. Review of Palaeobotany and Palynology, 2, 321-330.

Wright, J. D. (2000). Global climate change in marine stable isotope records. In J. S. Noller, J. M. Sowers, \& W. R. Lettis (Eds.). Quaternary Geochronology: Methods and Applications, AGU Ref. Shelf, vol. 4 (pp. 427-433). Washington, DC: American Geophysical Union, doi:10.1029/RF004p0427.

Xu, L., Myneni, R. B., Chapin III, F. S., Callaghan, T. V., Pinzon, J. E., Tucker, C. J., \& Stroeve, J.C. (2013). Temperature and vegetation seasonality diminishment over northern lands. Nature Climate Change. 3, 581-586. doi: 10.1038/nclimate1836.

Yamaguchi, D. (1991). A simple method for cross-dating increment cores from living trees. Canadian Journal of Forest Research, 21, 414-416.

Youngblut, D., \& Luckman, B. (2008). Maximum June-July temperatures in the southwest Yukon over the last 300 years reconstructed from tree-rings.

Dendrochronologia, 25, 153-166.

Youngblut, D. K., \& Luckman, B. H. (2012). Evaluating the temperature sensitivity of radial growth patterns from whitebark pine in the western Canadian Cordillera. Dendrochronologia, 31, 16-28. doi:10.1016/j.dendro.2012.04.001.

Zhang, Y., \& Wilmking, M. (2010). Divergent growth responses and increasing temperature limitation of Qinghai spruce growth along an elevation gradient at the northeast Tibet Plateau. Forest Ecology and Management, 260, 1076-1082. 